\title{
Guía de práctica clínica para la valoración del riesgo cardiaco preoperatorio y el manejo cardiaco perioperatorio en la cirugía no cardiaca \\ Versión corregida 03/03/2010
}

Grupo de Trabajo de la Sociedad Europea de Cardiología (ESC) para la valoración del riesgo cardiaco preoperatorio y el manejo cardiaco perioperatorio en la cirugía no cardiaca; avalada por la Sociedad Europea de Anestesiología (ESA)

Autores/miembros del Grupo de Trabajo: Don Poldermans (Coordinador) (Países Bajos)*, Jeroen J. Bax (Países Bajos), Eric Boersma (Países Bajos), Stefan De Hert (Países Bajos), Erik Eeckhout (Suiza), Gerry Fowkes (Reino Unido), Bulent Gorenek (Turquía), Michael G. Hennerici (Alemania), Bernard lung (Francia), Malte Kelm (Alemania), Keld Per Kjeldsen (Dinamarca), Steen Dalby Kristensen (Dinamarca), José López-Sendón (España), Paolo Pelosi (Italia), François Philippe (Francia), Luc Pierard (Bélgica), Piotr Ponikowski (Polonia), Jean-Paul Schmid (Suiza), Olav F.M. Sellevold (Noruega), Rosa Sicari (Italia), Greet Van den Berghe (Bélgica) y Frank Vermassen (Bélgica)

Otros colaboradores: Sanne E. Hoeks (Países Bajos) e llse Vanhorebeek (Bélgica)

Comité de la ESC para la elaboración de Guías de Práctica Clínica (CPG): Alec Vahanian (Coordinador) (Francia), Angelo Auricchio (Suiza), Jeroen J. Bax (Países Bajos), Claudio Ceconi (Italia), Veronica Dean (Francia), Gerasimos Filippatos (Grecia), Christian Funck-Brentano (Francia), Richard Hobbs (Reino Unido), Peter Kearney (Irlanda), Theresa McDonagh (Reino Unido), Keith McGregor (Francia), Bogdan A. Popescu (Rumanía), Zeljko Reiner (Croacia), Udo Sechtem (Alemania), Per Anton Sirnes (Noruega), Michal Tendera (Polonia), Panos Vardas (Grecia) y Petr Widimsky (República Checa)

Revisores del documento: Raffaele De Caterina (Coordinador de revisión) (Italia), Stefan Agewall (Noruega), Nawwar Al Attar (Francia), Felicita Andreotti (Italia), Stefan D. Anker (Alemania), Gonzalo Barón-Esquivias (España), Guy Berkenboom (Bélgica), Laurent Chapoutot (Francia), Renata Cifkova (República Checa), Pompilio Faggiano (Italia), Simon Gibbs (Reino Unido), Henrik Steen Hansen (Dinamarca), Laurence Iserin (Francia), Carsten W. Israel (Alemania), Ran Kornowski (Israel), Nekane Murga Eizagaechevarría (España), Mauro Pepi (Italia), Massimo Piepoli (Italia), Hans Joachim Priebe (Alemania), Martin Scherer (Alemania), Janina Stepinska (Polonia), David Taggart (Reino Unido) y Marco Tubaro (Italia)

Los formularios de autorización de todos los autores y revisores se encuentran en la página web de la ESC www.escardio.org

${ }^{*}$ Correspondencia: Dr. D. Poldermans.

Department of Surgery. Erasmus Medical Center.

Gravendijkwal, 230. 3015 CE Rotterdam. Países Bajos.

Correo electrónico: d.poldermans@erasmusmc.nl

El contenido de las Guías de Práctica Clínica de la Sociedad Europea de Cardiología (ESC) ha sido publicado para uso exclusivamente personal y educacional. No está autorizado su uso comercial. No se autoriza la traducción o reproducción en ningún formato de las Guías de la ESC ni de ninguna de sus partes sin un permiso escrito de la ESC. El permiso puede obtenerse enviando una solicitud por escrito a Oxford University Press, la empresa editorial del European Heart Journal y representante autorizada de la ESC para gestionar estos permisos.

Responsabilidad: Las Guías de Práctica Clínica recogen la opinión de la ESC y se han elaborado tras una consideración minuciosa de las evidencias disponibles en el momento en que fueron escritas. Se anima a los profesionales de la sanidad a que las tengan en plena consideración cuando ejerzan su juicio clínico. No obstante, las Guías de Práctica Clínica no deben invalidar la responsabilidad individual de los profesionales de la salud a la hora de tomar decisiones adecuadas a las circunstancias individuales de cada paciente, consultando con el propio paciente y, cuando sea necesario y pertinente, con su tutor o representante legal. También es responsabilidad del profesional de la salud verificar las normas y los reglamentos que se aplican a los fármacos o dispositivos en el momento de la prescripción.

CThe European Society of Cardiology 2009. Reservados todos los derechos. Para la solicitud de permisos, dirijase por correo electrónico a: journals. permissions@oxfordjournals.org

Los comentarios-anotaciones (*) incluidos en esta traducción de la Guía han sido realizados por el Dr. José López-Sendón (Madrid, España). 


\section{ÍNDICE DE CONTENIDOS}

Acrónimos y abreviaturas .....................................2

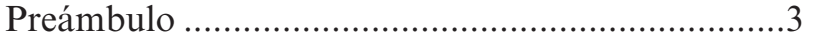

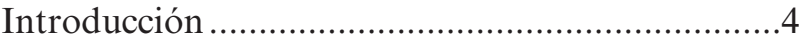

Magnitud del problema ...................................... 4

Impacto del envejecimiento de la población.........5

Propósito ....................................................... 6

Evaluación preoperatoria .....................................6

Riesgo quirúrgico de eventos cardiacos ..............6

Capacidad funcional ....................................... 8

Índices de riesgo.............................................

Biomarcadores...............................................10

Pruebas no invasivas........................................11

Angiografía..................................................15

Estrategias para la reducción del riesgo ................15

Estrategia farmacológica ................................15

Revascularización ............................................26

Enfermedades específicas.....................................29

Insuficiencia cardiaca crónica ............................30

Hipertensión arterial.........................................31

Valvulopatía …................................................ 31

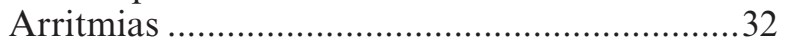

Enfermedad renal ...............................................34

Enfermedad cerebrovascular ...............................35

Enfermedad pulmonar...................................... 37

Monitorización perioperatoria ............................39

Electrocardiografía ............................................39

Ecocardiografía transesofágica ........................40

Cateterización de corazón derecho ....................41

Alteraciones del metabolismo de la glucosa ......41

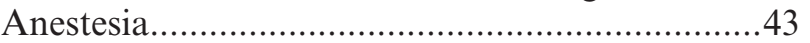

Manejo intraoperatorio de la anestesia ..............44

Técnicas neuraxiales .........................................44

Manejo del dolor postoperatorio .......................44

Armar las piezas del rompecabezas......................45

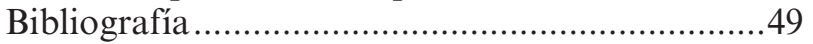

\footnotetext{
ABREVIATURAS

AAA: aneurisma aórtico abdominal.

ACC: American College of Cardiology.

AHA: American Heart Association.

BNP: péptido natriurético cerebral.

BRA: bloqueador de los receptores de la angiotensina.

CABG: cirugía de bypass aortocoronario.

CASS: Coronary Artery Surgery Study (estudio sobre cirugía coronaria).

CI: cardiopatía isquémica.

COX-2: ciclooxigenasa 2.

cTnI: troponina I cardiaca.

cTnT: troponina $\mathrm{T}$ cardiaca.

DE: desviación estándar.
}

DECREASE: Dutch Echocardiographic Cardiac Risk Evaluating Applying Stress Echo (estudio holandés sobre evaluación ecocardiográfica de riesgo cardiaco mediante ecocardiografía de estrés).

DIPOM: DIabetes PostOperative Mortality and Morbidity (estudio sobre morbimortalidad postoperatoria de la diabetes).

EA: estenosis aórtica.

ECA: enzima de conversión de angiotensina.

ECG: electrocardiograma.

ECV: enfermedad cardiovascular.

EED: ecocardiografía de estrés con dobutamina.

EM: estenosis mitral.

EPOC: enfermedad pulmonar obstructiva crónica.

ESC: Sociedad Europea de Cardiología.

ETE: ecocardiografía transesofágica.

FA: fibrilación auricular.

FRISC: Fast Revascularization in InStability in Coronary disease (estudio sobre revascularización precoz en la enfermedad coronaria inestable).

HAP: hipertensión arterial pulmonar.

HBPM: heparina de bajo peso molecular.

HNF: heparina no fraccionada.

HR: hazard ratio.

IC: intervalo de confianza.

ICP: intervención coronaria percutánea.

IM: infarto de miocardio.

IAMCEST: infarto de miocardio con elevación del segmento $\mathrm{ST}$.

INR: razón internacional normalizada.

IRM: técnicas de imagen por resonancia magnética.

LVP: latido ventricular prematuro.

MaVS: Metoprolol after Surgery (estudio sobre el uso postoperatorio de metoprolol).

MET: equivalente metabólico.

NICE-SUGAR: Normoglycaemia in Intensive Care Evaluation and Survival Using Glucose Algorithm Regulation (estudio sobre normoglucemia en cuidados intensivos y supervivencia mediante el uso de un algoritmo de regulación de la glucosa).

NT-proBNP: fracción aminoterminal del propéptido natriurético tipo $\mathrm{B}$.

NYHA: New York Heart Association.

OPUS: Orbofiban in Patients with Unstable coronary Syndromes (estudio sobre el uso de orbofiban en pacientes con síndromes coronarios inestables).

OR: odds ratio.

$\mathrm{PaCO}_{2}$ : volumen espirado mixto alveolar y de gas de espacio muerto.

PCR: proteína $\mathrm{C}$ reactiva.

PDA: asistente digital personal. 
PECP: prueba de esfuerzo cardiopulmonar.

PETCO $_{2}$ : volumen de $\mathrm{CO}_{2}$ al final de la espiración (end-tidal).

POISE: PeriOperative ISchaemic Evaluation trial (estudio sobre la evaluación de la isquemia perioperatoria).

QUO-VADIS: QUinapril On Vascular $A C E$ and Determinants of ISchemia (Estudio QUinapril On Vascular ACE and Determinants of ISchemia).

RA: regurgitación aórtica.

RCP: revascularización coronaria profiláctica.

$\mathrm{RM}$ : regurgitación mitral.

ROC: curva receiver operating characteristic.

$R P$ : razón de probabilidad.

SCA: síndrome coronario agudo.

SLF: stent liberador de fármacos o farmacoactivo.

SPECT: tomografía computarizada por emisión monofotónica.

SQTL: síndrome de QT largo.

SYNTAX: SYnergy between percutaneous coronary intervention with TAXus and cardiac surgery.

TACTICS: Treat angina with Aggrastat and determine Cost of Therapy with an Invasive or Conservative Strategy.

TC: tomografía computarizada.

TIA: ataque isquémico transitorio.

TIMI: trombolisis en el infarto de miocardio.

TSV: taquicardia supraventricular.

TV: taquicardia ventricular.

TVMS: taquicardia ventricular monomórfica sostenida.

TVPS: taquicardia ventricular polimórfica sostenida.

UCI: unidad de cuidados intensivos.

$\mathrm{VCO}_{2}$ : producción de dióxido de carbono.

VE: ventilación por minuto.

$\mathrm{VEF}_{1}$ : volumen espiratorio forzado el primer segundo.

VI: ventricular izquierdo.

VKA: antagonista de la vitamina $\mathrm{K}$.

$\mathrm{VO}_{2}$ : consumo de oxígeno.

\section{PREÁMBULO}

Las Guías de Práctica Clínica y los Documentos de Consenso de Expertos tienen como objetivo presentar todas las evidencias relevantes sobre un tema particular para ayudar a los médicos a seleccionar la mejor estrategia posible de tratamiento para un paciente en particular, que sufre una determinada enfermedad, no sólo teniendo en cuenta el resultado final, sino también sopesando los riesgos y los be- neficios de un procedimiento diagnóstico o terapéutico concretos. Las guías de práctica clínica no sustituyen a los libros de texto. Las implicaciones legales de las guías médicas se han presentado más arriba $^{1}$.

En los últimos años, la Sociedad Europea de Cardiología (ESC) y otras organizaciones y sociedades relacionadas han elaborado un gran número de Guías de Práctica Clínica y Documentos de Consenso de Expertos. Debido al impacto de las guías en la práctica clínica, se han establecido criterios de calidad para la elaboración de estas guías de forma que todas las decisiones se presenten de forma clara y transparente al usuario. Las recomendaciones de la ESC para la elaboración y edición de Guías de Práctica Clínica y Documentos de Consenso de Expertos se pueden encontrar en la sección de guías de la página web de la ESC (www. escardio.org).

De forma resumida, se designa a una serie de expertos sobre el tema para que realicen una revisión exhaustiva de la evidencia publicada sobre el manejo y/o la prevención de una determinada enfermedad. Se realiza una evaluación crítica de los procedimientos diagnósticos y terapéuticos, incluida la valoración de la razón riesgo/beneficio. Cuando hay datos disponibles, se incluyen también estimaciones de los resultados de salud esperados para poblaciones más grandes. Se valora el nivel de evidencia y la fuerza de la recomendación de una opción terapéutica particular de acuerdo con escalas predefinidas, tal como se indica en las tablas 1 y 2 .

Los expertos de los Comités de Redacción deben declarar por escrito cualquier relación que se pueda considerar conflicto de intereses real o potencial. Estas declaraciones escritas se conservan en los archivos de la Casa Europea del Corazón, la sede central de la ESC. Si durante el periodo de redacción se produce una modificación en las relaciones que se pueda considerar conflicto de intereses, debe ser notificada a la ESC. El informe del Grupo de Trabajo se financia en su totalidad por la ESC y se desarrolla sin ninguna participación de la industria.

El Comité para la Guías de Práctica Clínica (CPG) de la ESC supervisa y coordina la preparación de nuevas Guías de Práctica Clínica y Documentos de Consenso de Expertos elaborados por los Grupos de Trabajo, grupos de expertos o paneles de consenso. El Comité es responsable también de la aprobación de estas Guías de Práctica Clínica y Documentos de Consenso de Expertos o de sus comunicados. Una vez que se ha finalizado el documento y ha sido aprobado por todos los expertos que forman parte del Grupo de Trabajo, se envía a especialistas externos para su revisión. El CPG revisa el documento, le da su aprobación final y después se publica. 
TABLA 1. Grados de recomendación

\begin{tabular}{|c|c|}
\hline Grados de Recomendación & Definición \\
\hline Clase I & $\begin{array}{l}\text { Evidencia y/0 acuerdo general de que un determinado procedimiento diagnóstico/tratamiento es beneficioso, } \\
\text { útil y efectivo }\end{array}$ \\
\hline Clase II & Evidencia conflictiva y/o divergencia de opinión acerca de la utilidad/eficacia del tratamiento \\
\hline Clase Ila & El peso de la evidencia/opinión está a favor de la utilidad/eficacia \\
\hline Clase Illb & La utilidad/eficacia está menos establecida por la evidencia/opinión \\
\hline Clase III & Evidencia 0 acuerdo general de que el tratamiento no es útil/efectivo y en algunos casos puede ser perjudicial \\
\hline
\end{tabular}

\section{TABLA 2. Niveles de evidencia}

Nivel de evidencia A Datos procedentes de múltiples ensayos clínicos con distribución aleatoria o metaanálisis

Nivel de evidencia B Datos procedentes de un único ensayo clínico con distribución aleatoria o de grandes estudios sin distribución aleatoria

Nivel de evidencia C Consenso de opinión de expertos y/o pequeños estudios, práctica habitual

Después de su publicación, es primordial que se produzca una difusión del mensaje. Para ello, resulta de ayuda la publicación de versiones de bolsillo o versiones que puedan ser descargadas a PDA. Sin embargo, los sondeos han demostrado que los usuarios a los que van dirigidas estas guías a menudo no conocen su existencia o simplemente no las ponen en práctica. Por lo tanto, son necesarios los programas de implementación para las nuevas guías, que forman parte importante de la diseminación del conocimiento. La ESC organiza reuniones que se dirigen a sus sociedades nacionales y a los líderes de opinión en Europa. También pueden llevarse a cabo reuniones para la implementación nacional de estas recomendaciones, una vez que las guías han sido respaldadas por las sociedades miembro de la ESC y traducidas al idioma nacional. Los programas de implementación son necesarios, porque se ha demostrado que los resultados clínicos se ven influidos favorablemente por la aplicación de las recomendaciones clínicas ${ }^{2}$.

En conjunto, la función de las Guías de Práctica Clínica o los Documentos de Consenso de Expertos incluye no solamente la integración de la investigación más reciente, sino también la creación de instrumentos educacionales y programas de implementación para las recomendaciones. El círculo entre la investigación clínica, la redacción de las guías y su implementación en la práctica clínica sólo puede completarse si se organizan sondeos y registros para verificar que la práctica clínica actual se hace de acuerdo con lo que se recomienda en las guías. Este tipo de sondeos y registros también posibilita la evaluación del impacto que tiene la implementación estricta de sus recomendaciones en el resultado clínico de los pacientes. Las guías de práctica clínica y las recomendaciones deben asistir a los profesionales de la salud en la toma de decisiones clínicas en su ejercicio diario. No obstante, el juicio último sobre el cuidado de un paciente concreto debe ser hecho por el médico responsable (*).

\section{INTRODUCCIÓN}

\section{Magnitud del problema}

Esta guía trata sobre el manejo cardiológico de pacientes que van a ser sometidos a cirugía no cardiaca y en los que la enfermedad cardiaca es una fuente potencial de complicaciones intraoperatorias. El riesgo de complicaciones perioperatorias depende del estado previo del paciente, la presencia de comorbilidades y la magnitud y la duración del procedimiento quirúrgico ${ }^{3}$. Más concretamente, las

\footnotetext{
(*) Estas guías sobre valoración del riesgo y tratamiento de pacientes que van a ser sometidos a cirugía no cardiaca constituyen la primera recomendación general sobre cómo realizar lo que en España llamamos un «estudio preoperatorio».

La importancia de estas guías es extraordinaria por tres motivos:

1) La valoración preoperatoria en nuestro país no sigue, en el momento actual, ningún estándar basado en evidencia clínica. 2) La identificación de pacientes de mayor riesgo, o lo contrario, permite seleccionar fácilmente los pacientes que necesitan pruebas diagnósticas adicionales (actualmente se indican más cuando no están indicadas, y viceversa); con esto se evitan listas de espera e incertidumbres. 3) El riesgo se puede reducir con intervenciones farmacológicas, otra vez sólo en pacientes de alto riesgo, que habitualmente no se utilizan; esto incluye estatinas y betabloqueantes con dosis bien ajustada antes de la cirugía para evitar hipotensión.

Por otra parte, la aplicación de las guías será difícil por otros tres motivos principales: 1) Las guías son complejas debido a la gran cantidad de variables y subgrupos existentes en la práctica clínica; se necesitará realizar formación continuada en una población muy amplia de médicos de varias especialidades. 2) No existe la adecuada colaboración entre cardiólogos, anestesistas y cirujanos no cardiacos, necesaria para la correcta aplicación de las guías. 3) A diferencia de lo que sucede con otras guías, y a excepción de la SEC al traducirlas y publicarlas, nadie ha mostrado (industria farmacéutica, colegios de médicos, sociedades científicas locales, autoridades sanitarias), todavía, interés por su difusión. Sin embargo, la difusión y, sobre todo, la aplicación de estas guías, con todas las modificaciones y simplificación necesarias a nivel local y práctico, contribuirán, sin ninguna duda, a una mejor valoración de los pacientes y a la prevención de las complicaciones cardiovasculares asociadas a la cirugía no cardiaca.
} 
complicaciones cardiacas pueden aparecer en pacientes con cardiopatía isquémica documentada o asintomática, con disfunción ventricular izquierda o valvulopatía, sometidos a un procedimiento quirúrgico que causa un estrés hemodinámico y cardiaco prolongado. En la isquemia miocárdica perioperatoria, se conocen dos mecanismos importantes: a) un desajuste crónico entre el aporte y la demanda del flujo sanguíneo en respuesta a las necesidades metabólicas, similar desde el punto de vista clínico al efecto de las estenosis que limitan el flujo coronario que se observa en la cardiopatía isquémica estable, y $b$ ) la rotura de la placa coronaria debido a procesos inflamatorios vasculares que se presentan como síndrome coronario agudo (SCA). Por ello, aunque la disfunción del ventrículo izquierdo (VI) también puede darse en poblaciones más jóvenes por distintas causas, la morbimortalidad cardiaca perioperatoria es, predominantemente, un problema en la población adulta sometida a cirugía mayor no cardiaca.

En Europa la magnitud del problema puede comprenderse mejor por: a) la cohorte de pacientes adultos sometidos a cirugía no cardiaca, y $b$ ) el riesgo medio de complicaciones cardiacas de esta cohorte. Desafortunadamente, no disponemos del número y el tipo de operaciones por año ni de los resultados clínicos de toda Europa. A escala nacional, en algunos países se dispone de información, pero son muy variadas las definiciones, la cantidad y la calidad de los datos. En los Países Bajos, con una población de 16 millones de habitantes, durante el periodo 1991-2005 se realizó una media anual de 250.000 procedimientos de cirugía mayor en pacientes mayores de 20 años, lo cual resulta en una tasa anual del $1,5 \%{ }^{4}$. Si aplicamos esta tasa a Europa, con una población total de 490 millones de habitantes, este dato podría traducirse en unos 7 millones de procedimientos de cirugía mayor por año en pacientes con riesgo cardiaco.

Con base en los escasos ensayos clínicos realizados a gran escala y algunos registros de pacientes sometidos a cirugía no cardiaca, pueden derivarse datos sobre los resultados cardiacos. Lee et $\mathrm{al}^{5}$ estudiaron a 4.315 pacientes sometidos a cirugía no cardiaca mayor electiva en un hospital universitario terciario entre 1989 y 1994. En ese estudio, 92 pacientes $(2,1 \%)$ presentaron complicaciones cardiacas graves, entre ellas muerte cardiaca e infarto de miocardio (IM). En una cohorte de 108.593 pacientes consecutivos sometidos a cirugía entre 1991 y 2000 en un hospital universitario de los Países Bajos, la mortalidad perioperatoria afectó a 1.877 pacientes $(1,7 \%)$; entre ellos se identificaron 543 casos de muerte por causas cardiovasculares $(0,5 \%)^{6}$. Los estudios DECREASE I, II y IV (Dutch Echocardiographic Cardiac Risk Evaluating Applying Stress Echo) incluyeron entre
1996 y 2008 a 3.893 pacientes quirúrgicos con riesgo intermedio o alto, de los que $136(3,5 \%)$ sufrieron muerte cardiaca perioperatoria o $\mathrm{IM}^{7-9}$. El estudio POISE (Perioperative Ischaemic Evaluation), realizado en 2002-2007 con un total de 8.351 pacientes sometidos a cirugía no cardiaca, ofrece la evidencia final en cuanto al resultado clínico ${ }^{10}$. Sufrieron muerte perioperatoria 226 pacientes $(2,7 \%)$, de los que en $133(1,6 \%)$ fue de causa cardiovascular, mientras que 367 pacientes $(4,4 \%)$ sufrieron un IM no fatal. Las diferencias observadas entre los distintos estudios pueden explicarse fundamentalmente por la selección de pacientes y la definición del objetivo relativo al IM (la cirugía mayor no cardiaca se asocia a una incidencia de muerte cardiaca de un $0,5-1,5 \%$ y de complicaciones cardiacas graves de un 2-3,5\%). Estos datos, aplicados a la población de los Estados miembro de la Unión Europea, se traducen en 150.000-250.000 complicaciones cardiacas con riesgo de muerte anuales asociadas a procedimientos de cirugía no cardiaca.

\section{Impacto del envejecimiento de la población}

En los próximos 20 años, la aceleración del envejecimiento de la población tendrá un impacto importante en el manejo perioperatorio del paciente. Se estima que los pacientes de edad avanzada requieren cirugía 4 veces más frecuentemente que el resto de la población ${ }^{11}$. Aunque no se dispone de datos exactos sobre el número de pacientes sometidos a cirugía en Europa, se estima que el número aumentará en un $25 \%$ en 2020 y que, para el mismo periodo, la población de edad avanzada aumentará en más del 50\%. El número total de procedimientos quirúrgicos aumentará a un ritmo mayor debido a la mayor frecuencia de las intervenciones quirúrgicas en la población mayor ${ }^{12}$. Los resultados del US National Hospital Discharge Survey muestran que, de forma general, el número de procedimientos quirúrgicos aumentará en prácticamente todos los grupos de edad y que el mayor aumento ocurrirá en los grupos de adultos y ancianos (tabla 3 ).

Los datos demográficos de los pacientes sometidos a cirugía muestran una tendencia hacia un mayor número de pacientes de edad avanzada y a la presencia de comorbilidades ${ }^{13}$. Aunque la mortalidad por enfermedades cardiacas está disminuyendo en la población general, la prevalencia de cardiopatía isquémica, insuficiencia cardiaca y factores de riesgo cardiovascular, especialmente la diabetes mellitus, está en aumento. De las abundantes comorbilidades del paciente mayor que requiere cirugía, las enfermedades cardiovasculares (ECV) tienen la mayor prevalencia. A partir de datos de atención primaria, en el grupo de edad de 75-84 años, el 19\% de los varones y el 12\% de las mujeres 
TABLA 3. Cambios en el número de altas de procedimientos quirúrgicos por edad entre 19941995 y 2004-2005, datos publicados en US National Hospital Discharge Survey (2005, hospitales no federales de corta estancia) ${ }^{15}$

\begin{tabular}{lccr}
\hline Edad (años) & \multicolumn{2}{c}{ Procedimientos (millares) } & Cambio, \% \\
\hline & $\mathbf{1 9 9 4 - 1 9 9 5}$ & $\mathbf{2 0 0 4 - 2 0 0 5}$ & \\
\hline $18-44$ & 7.311 & 7.326 & $+2,1$ \\
$45-64$ & 4.111 & 5.210 & $+26,7$ \\
$65-74$ & 3.069 & 3.036 & $-1,1$ \\
$\geq 75$ & 3.479 & 4.317 & $+24,1$ \\
$\geq 18$ & 17.969 & 19.889 & $+10,7$ \\
\hline
\end{tabular}

presentan cierto grado de $\mathrm{ECV}^{14}$. Sin embargo, la edad por sí sola aparentemente sólo motiva un ligero aumento en el riesgo de complicaciones; el mayor riesgo se asocia a la urgencia del procedimiento y el concurso de enfermedad cardiaca, pulmonar o renal significativa. El número de individuos afectados será probablemente más elevado en países con un mortalidad por ECV más alta, especialmente en Europa central y del este. Estas entidades deberán tener, por lo tanto, un mayor impacto en la evaluación del riesgo del paciente, en lugar de la edad por sí sola.

\section{Propósito}

La ESC, hasta la fecha, no había elaborado una guía oficial sobre la evaluación del riesgo preoperatorio y el manejo cardiaco perioperatorio. El objetivo de esta guía es implementar una estrategia estandarizada y basada en la evidencia para el manejo cardiaco perioperatorio. Para ello, esta guía propone una evaluación práctica y gradual, que integre los factores clínicos de riesgo, los resultados de las pruebas y el estrés asociado al procedimiento quirúrgico que se va a realizar. Esta estrategia permite realizar una evaluación individualizada del riesgo cardiaco, instaurar las medidas terapéuticas necesarias (tratamiento farmacológico, intervenciones coronarias) y seleccionar las técnicas quirúrgica y anestésica más adecuadas para optimizar el estado perioperatorio del paciente. Los datos derivados de ensayos clínicos aleatorizados, considerados la evidencia idónea para la elaboración de guías de práctica clínica, son escasos en el contexto quirúrgico respecto al no quirúrgico. Por ello, cuando no se dispone de ensayos clínicos sobre el manejo cardiaco específico antes de la cirugía, las recomendaciones se basan en datos derivados de ensayos clínicos no quirúrgicos y se aplican distintos grados de evidencia. Se pone un énfasis especial en el uso profiláctico de la revascularización coronaria, ya que raramente se indica a efectos de asegurar la supervivencia del paciente a la cirugía. La valoración preoperatoria requiere una estrategia multidisciplinaria integrada en la que participen especialistas en anestesia, cardiología, medicina interna, neumología, geriatría y cirugía. Normalmente, los responsables de este proceso son los anestesistas, por su experiencia y su conocimiento de las demandas específicas del procedimiento quirúrgico propuesto.

Las guías de práctica clínica tienen el potencial de mejorar los resultados postoperatorios. Sin embargo, como muestra un estudio observacional realizado en los Países Bajos, en el que se incluyó a 711 pacientes quirúrgicos, la adhesión a las guías de práctica clínica es baja ${ }^{16-18}$. En dicho estudio, 185 pacientes del total de 711 (26\%) cumplían los criterios de la ACC/AHA para la evaluación preoperatoria cardiaca no invasiva, pero sólo 38 (21\%) fueron evaluados ${ }^{16}$. El tratamiento farmacológico recomendado por las guías para el periodo perioperatorio, a base de una combinación de aspirina y estatinas en todos los pacientes y bloqueadores beta en pacientes con cardiopatía isquémica, se cumplió sólo en el $41 \%$ de los $\operatorname{casos}^{18}$. Sin embargo, la administración de tratamiento médico basado en la evidencia durante el periodo perioperatorio se asoció a una reducción de la mortalidad a los 3 años tras el ajuste de las características clínicas (hazard ratio $[\mathrm{HR}]=0,65$; intervalo de confianza [IC] del 95\%, $0,45-0,94)$. Estos datos indican que hay una clara oportunidad para mejorar la calidad de la atención médica en este grupo de pacientes de alto riesgo. Además de promover una mejor atención médica perioperatoria, las guías de práctica clínica deben ofrecer recomendaciones para el manejo a largo plazo, ya que es de esperar que el paciente viva lo suficiente para disfrutar de los beneficios de la cirugía. Tras el desarrollo y la introducción de las guías sobre manejo cardiaco perioperatorio, se debe evaluar su efecto en los resultados. La evaluación objetiva de los cambios observados en los resultados es fundamental para futuras guías de práctica clínica sobre este tema.

\section{EVALUACIÓN PREOPERATORIA}

\section{Riesgo quirúrgico de eventos cardiacos}

Las complicaciones cardiacas tras la cirugía no cardiaca dependen no sólo de factores de riesgo específicos, sino también del tipo de cirugía y las condiciones en que se realice ${ }^{19}$. Los factores quirúrgicos que influyen en el riesgo cardiaco están relacionados con la urgencia, la magnitud, el tipo y la duración del procedimiento, además de los cambios en la temperatura corporal, la pérdida de sangre y las alteraciones de los fluidos ${ }^{12}$. 
Poldermans D et al. Guías de práctica clínica para la valoración del riesgo cardiaco preoperatorio y el manejo cardiaco perioperatorio en la cirugía no cardiaca

TABLA 4. Estimación del riesgo quirúrgico* (modificado de Boersma et $\mathbf{a l}^{6}$ )

\begin{tabular}{|c|c|c|}
\hline Bajo riesgo, $<1 \%$ & Riesgo intermedio, 1-5\% & Alto riesgo, $>5 \%$ \\
\hline Mamas & Abdominal & Cirugía vascular mayor y aórtica \\
\hline Dental & Carótidas & Cirugía vascular periférica \\
\hline Endocrina & Angioplastia arterial periférica & \\
\hline Ocular & Reparación endovascular de aneurisma & \\
\hline Ginecológica & Cirugía de cabeza y cuello & \\
\hline Reconstructiva & Neurológica/ortopédica mayor (cirugía de cadera y columna) & \\
\hline Ortopédica menor (cirugía de rodilla) & Cirugía renal, pulmonar/trasplante de hígado & \\
\hline Urológica menor & Urológica mayor & \\
\hline
\end{tabular}

*Riesgo de infarto de miocardio y muerte cardiaca a los 30 días de la cirugía.

Cualquier intervención quirúrgica produce estrés. Esta respuesta se inicia por el daño tisular, está mediada por factores neuroendocrinos y puede inducir taquicardia e hipertensión. Al estrés quirúrgico hay que añadir las alteraciones de los fluidos durante el periodo perioperatorio. El estrés aumenta la demanda de oxígeno del miocardio. La cirugía también causa alteraciones del equilibrio de factores protrombóticos y fibrinolíticos, y puede favorecerse la hipercoagulación y la aparición de trombosis coronaria (elevación de fibrinógenos y otros factores de coagulación, aumento de la activación y agregación plaquetarias y reducción de la fibrinolisis). El grado de dichas alteraciones es proporcional a la magnitud y la duración de la intervención. Todos estos factores pueden causar isquemia miocárdica e insuficiencia cardiaca. En los pacientes con alto riesgo debe prestarse atención a estos factores y, cuando esté indicado, deberá adaptarse el plan quirúrgico.

$\mathrm{Si}$ bien los factores de riesgo específico del paciente son más importantes que los específicos de la cirugía para la predicción de los riesgos cardiacos en la cirugía no cardiaca, no podemos ignorar la importancia del tipo de cirugía a la hora de evaluar a un paciente concreto que va a ser sometido a una intervención ${ }^{6,20}$. Respecto al riesgo cardiaco, las intervenciones quirúrgicas pueden clasificarse en intervenciones de bajo riesgo, riesgo intermedio y riesgo alto, con tasas estimadas de eventos cardiacos (muerte cardiaca e IM) a los 30 días $<1,1-5$ y $>5 \%$, respectivamente (tabla 4 ). Pese a tratarse de una clasificación muy amplia, esta estratificación de riesgo es un instrumento útil para establecer la necesidad de una valoración cardiaca, el tratamiento farmacológico y el cálculo de riesgo de eventos cardiacos.

En el grupo con alto riesgo se incluye la cirugía vascular mayor. En la categoría de riesgo intermedio, éste depende de la magnitud, la duración, la localización, la pérdida de sangre y la alteración de fluidos relacionados con el procedimiento específico. En el grupo con riesgo bajo, el riesgo cardiaco es insignificante, excepto en presencia de otros factores de alto riesgo específicos del paciente.
La necesidad y la utilidad de la evaluación cardiaca preoperatoria dependen también de la urgencia de la cirugía. En caso de cirugía urgente, como la realizada por rotura de aneurisma aórtico abdominal (AAA), traumatismo mayor o perforación visceral, la evaluación cardiaca no cambiará el curso y el resultado de la intervención, pero puede influir en el manejo del postoperatorio inmediato. En caso de entidades quirúrgicas urgentes sin tratar, como el bypass por isquemia aguda de las extremidades inferiores o el tratamiento por obstrucción intestinal, la morbimortalidad de la entidad subyacente sin tratar supera el riesgo cardiaco potencial asociado a la intervención. En estos casos, la evaluación cardiaca puede influir en las medidas que se deben adoptar en el periodo perioperatorio para reducir dicho riesgo, pero no influyen en la decisión de realizar la intervención. En algunos casos, el riesgo cardiaco puede influir en el tipo de intervención y orientar la elección hacia un tipo de intervención menos invasiva, como la angioplastia arterial periférica en lugar de bypass infrainguinal o la reconstrucción extraanatómica en lugar de un procedimiento aórtico, incluso cuando estos tratamientos ofrezcan resultados menos favorables a largo plazo. Por último, en algunas circunstancias, la evaluación cardiaca, por su capacidad de predicción de complicaciones cardiacas y de estimación de la supervivencia a largo plazo, debe ser tomada en consideración a la hora de decidirse por realizar la intervención o no. Esto sucede en algunas intervenciones profilácticas, como el tratamiento de pequeños AAA o de la estenosis carotídea asintomática, en los que las expectativas de vida del paciente y el riesgo de la operación son factores importantes para la evaluación del beneficio potencial de la intervención quirúrgica.

Las intervenciones vasculares tienen un interés especial, no sólo porque presentan el mayor riesgo de complicaciones cardiacas debido a la alta probabilidad de que el proceso aterosclerótico afecte también a las coronarias, sino también porque numerosos estudios muestran que puede modificarse el riesgo aplicando las medidas perioperatorias ade- 
TABLA 5. Índice Lee y modelo Erasmus: factores clínicos de riesgo utilizados para la estratificación del riesgo cardiaco preoperatorio ${ }^{5,6}$

\begin{tabular}{lll}
\hline Características clínicas & Índice Lee & Modelo Erasmus \\
\hline Cardiopatía isquémica (angina de pecho y/o IM) & $\mathrm{x}$ & $\mathrm{x}$ \\
Riesgo quirúrgico & Cirugía de alto riesgo & Cirugía de riesgo alto, intermedio-alto, intermedio-bajo, bajo \\
Insuficiencia cardiaca & $\mathrm{x}$ & $\mathrm{x}$ \\
Ictus/AIT & $\mathrm{X}$ & $\mathrm{x}$ \\
Diabetes mellitus que requiere tratamiento con insulina & $\mathrm{x}$ & $\mathrm{x}$ \\
Disfunción renal/hemodiálisis & $\mathrm{x}$ & $\mathrm{x}$ \\
Edad & & $\mathrm{x}$ \\
\hline
\end{tabular}

AIT: accidente isquémico transitorio; IM: infarto de miocardio.

cuadas para estos pacientes. Los procedimientos abiertos de aorta y los procedimientos infrainguinales siempre deben ser considerados de alto riesgo ${ }^{6}$. Aunque se trate de una intervención de menor magnitud, la revascularización infrainguinal conlleva un riesgo cardiaco similar o incluso mayor que los procedimientos aórticos. Esto puede explicarse por la mayor incidencia de diabetes mellitus, disfunción renal y cardiopatía isquémica, además de la edad avanzada, en este grupo de pacientes. Ésta es también la razón por la que el riesgo asociado a la angioplastia arterial periférica, procedimiento mínimamente invasivo, no es insignificante. En varios estudios aleatorizados, y también en estudios poblacionales, se ha demostrado que el riesgo cardiaco tras la reparación endovascular de aneurisma de aorta es sustancialmente inferior comparado con la reparación abierta ${ }^{21}$. Esta diferencia puede explicarse por el menor daño tisular, porque es innecesario el pinzamiento aórtico y por la ausencia de obstrucción intestinal. Sin embargo, la técnica quirúrgica utilizada no parece influir en la supervivencia a largo plazo, pero sí la enfermedad cardiaca subyacente ${ }^{22}$. Aunque la endarterectomía carotídea se considera un procedimiento de riesgo intermedio, el riesgo cardiaco y la supervivencia a largo plazo deben ser tomados en consideración en el proceso de toma de decisiones, pues pueden determinar la elección entre endarterectomía o la implantación de stents.

Los procedimientos laparoscópicos tienen la ventaja de causar menos daño tisular y parálisis intestinal que la cirugía abierta, lo que resulta en menos dolor en la zona de incisión y menos alteraciones de los fluidos relacionadas con la parálisis intestinal ${ }^{23}$. Por otra parte, el neumoperitoneo utilizado en estos procedimientos produce elevación de la presión intraabdominal y reducción del retorno venoso, lo cual resulta en reducción del gasto cardiaco y aumento de la resistencia sistémica vascular. Por lo tanto, en pacientes con insuficiencia cardiaca, la laparoscopia no reduce el riesgo cardiaco respecto a la cirugía abierta, y ambas deben ser evaluadas de la misma forma. Esto afecta especialmente a los pacientes que van a ser operados de obesidad mórbida ${ }^{24,25}$.

\section{Recomendación/declaración sobre la estimación del riesgo quirúrgico}

\begin{tabular}{lcc}
\hline Recomendación/declaración & Clase $^{\mathbf{a}}$ & Nivel $^{\mathbf{b}}$ \\
\hline Los procedimientos laparoscópicos producen un & $\mathrm{A}$ & $\mathrm{A}$ \\
estrés cardiaco similar a la cirugía abierta, & & \\
por lo tanto debe evaluarse al paciente antes & & \\
del procedimiento & \\
\hline
\end{tabular}

aClase de recomendación.

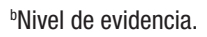

\section{Capacidad funcional}

Se considera fundamental en la evaluación del riesgo cardiaco preoperatorio determinar la capacidad funcional. La capacidad funcional se mide en equivalentes metabólicos (MET); 1 MET equivale a la tasa metabólica basal. La prueba de esfuerzo proporciona una evaluación objetiva de la capacidad funcional; en caso de no realizarse dicha prueba, la capacidad funcional puede estimarse mediante la capacidad de realizar las actividades diarias normales. Dado que 1 MET representa la demanda metabólica en reposo, subir dos tramos de escalera requiere 4 MET y el ejercicio intenso, como nadar, > 10 MET (fig. 1).

La incapacidad para subir dos tramos de escalera o correr una distancia corta $(<4$ MET) indica una capacidad funcional baja y se asocia a un aumento de la incidencia postoperatoria de eventos cardiacos. Tras la cirugía torácica, una capacidad funcional baja se ha relacionado con aumento de la mortalidad (riesgo relativo $[\mathrm{RR}]=18,7$; IC del 95\%, 5,9-59). Por el contrario, una capacidad funcional baja no se asocia a un aumento de la mortalidad tras otras operaciones no cardiacas $(\mathrm{RR}=0,47$; IC del $95 \%, 0,09-2,5)^{28}$. Esto podría reflejar la importancia de la función pulmonar, muy relacionada con la capacidad funcional, como poderoso predictor de la supervivencia tras la cirugía torácica. Estos hallazgos se confirmaron en un estudio con 5.939 pacientes programados para cirugía no cardiaca, en los que la importancia pronóstica de la capacidad funcional preoperatoria se midió en 
Fig. 1. Estimación de la energía necesaria para distintas actividades. Basado en Hlatky et $\mathrm{al}^{26}$ y Fletcher et $\mathrm{al}^{27}$.

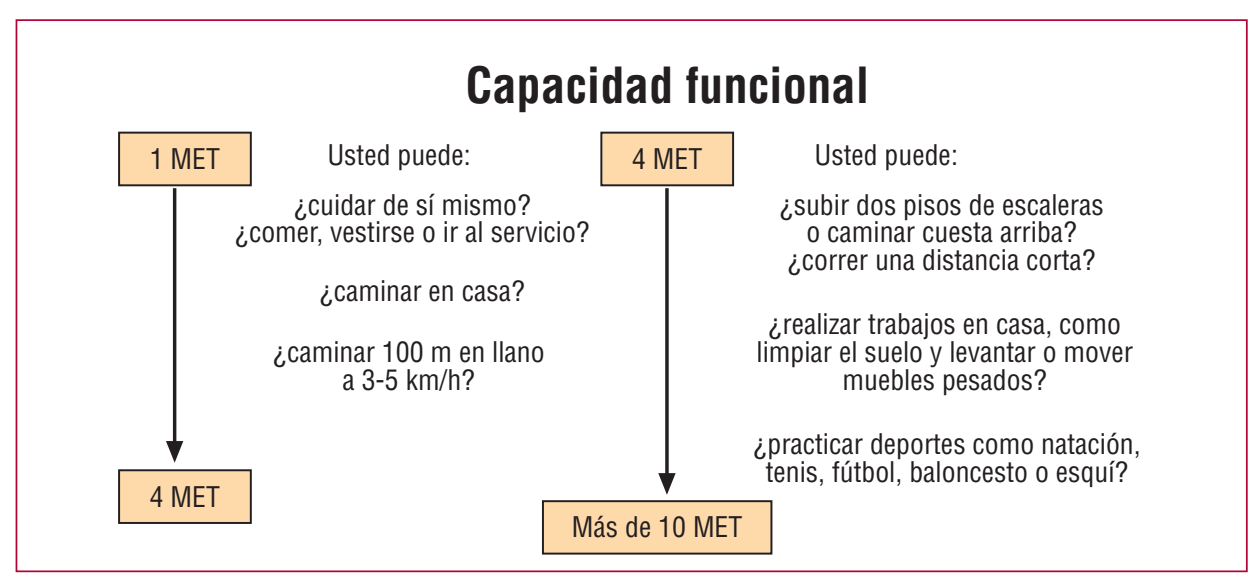

$\mathrm{MET}^{29}$. Mediante la curva ROC (receiver operating characteristic), la asociación de la capacidad funcional con los eventos cardiacos postoperatorios o muerte mostró un área bajo la curva ROC de tan sólo 0,664 , comparado con 0,814 para la edad. Considerando la asociación relativamente débil de la capacidad funcional y los eventos cardiacos postoperatorios, ¿qué importancia debemos asignar a la determinación de la capacidad funcional en la evaluación preoperatoria de riesgo en la cirugía no cardiaca? Cuando la capacidad funcional es buena, el pronóstico es excelente, incluso en presencia de cardiopatía isquémica estable u otros factores de riesgo ${ }^{30}$. En este caso, el manejo perioperatorio no suele modificarse por los resultados de pruebas cardiacas adicionales y, por lo general, puede procederse con la intervención quirúrgica programada. La capacidad para subir dos tramos de escaleras o correr una distancia corta indican una buena capacidad funcional. Cuando la capacidad funcional es baja o desconocida, la presencia y el número de factores de riesgo respecto al riesgo de la cirugía determinan la estratificación del riesgo preoperatorio y el manejo perioperatorio.

\section{Índices de riesgo}

Una estrategia efectiva para la reducción del riesgo de complicaciones cardiacas perioperatorias debe incluir la evaluación cardiaca preoperatoria a partir de la historia clínica, por dos razones fundamentales. La primera es que los pacientes en los que, tras una evaluación cardiaca minuciosa, se prevé un riesgo cardiaco bajo pueden ser operados con garantías y sin mayor retraso. En estos casos, es poco probable que las estrategias de reducción de riesgo puedan reducir más el riesgo perioperatorio. En segundo lugar, la reducción del riesgo mediante tratamiento farmacológico es más coste-efectivo en pacientes en que se sospecha un mayor riesgo cardiaco. Las técnicas de imagen no invasivas permiten la identificación de los pacientes con mayor riesgo.
Sin embargo, estas técnicas deben reservarse para los pacientes en los que los resultados de las pruebas puedan influir en la modificación del manejo. Es obvio que la intensidad de la evaluación cardiaca depende del estado clínico del paciente y de la urgencia de las circunstancias que requieren la cirugía. Cuando hace falta una cirugía de urgencia, la evaluación cardiaca debe limitarse necesariamente. Sin embargo, en la mayoría de los casos puede aplicarse una estrategia más amplia y sistemática para la evaluación del riesgo cardiaco, que incluya inicialmente las características clínicas del paciente y el tipo de cirugía y, cuando esté indicado, un electrocardiograma en reposo (ECG), pruebas de laboratorio y pruebas no invasivas (eco de estrés).

En los últimos 30 años se han desarrollado distintos índices de riesgo basados en análisis multivariables de datos observacionales que representan la relación entre las características clínicas y la morbimortalidad cardiaca perioperatoria. Los índices desarrollados por Goldman (1977), Detsky (1986) y Lee (1999) son muy conocidos ${ }^{5,31,32}$. El índice Lee, que de hecho es una modificación del índice Goldman original, es considerado por muchos médicos e investigadores el mejor de los índices disponibles para la predicción del riesgo cardiaco en la cirugía no cardiaca. Fue desarrollado en un estudio prospectivo en el que se recogieron datos de 2.893 pacientes sin seleccionar (y validado en otros 1.422 pacientes) que fueron sometidos a un amplio espectro de procedimientos quirúrgicos, con un seguimiento sistemático durante la fase postoperatoria de los resultados cardiacos clínicamente relevantes. El índice Lee está formado por cinco determinantes clínicos independientes de eventos cardiacos perioperatorios graves: historia de cardiopatía isquémica, historia de enfermedad cerebrovascular, insuficiencia cardiaca, diabetes mellitus insulinodependiente y función renal afectada. La cirugía de alto riesgo es el sexto factor que se incluye en este índice. Cada uno de los factores aporta la misma contribución al índice (1 punto cada uno) y la incidencia de complica- 
ciones cardiacas graves estimadas es del 0,4 , el 0,9 , el 7 y el $11 \%$ en pacientes con índices de $0,1,2$ y $\geq 3$ puntos, respectivamente. El área bajo la curva ROC del grupo de datos utilizados para la validación se sitúa en 0,81 , lo cual indica que este índice tiene una buena capacidad para discriminar a los pacientes con y sin riesgo de eventos cardiacos graves.

No obstante, los pacientes estudiados por Lee et al no pueden ser considerados una cohorte media, no seleccionada, de cirugía no cardiaca. Los pacientes sometidos a cirugía torácica $(12 \%)$, cirugía vascular $(21 \%)$ o cirugía ortopédica $(35 \%)$ están representados en exceso. Además, a pesar del considerable tamaño de la muestra, el estudio no tenía suficiente poder estadístico para revelar una amplia gama de determinantes de eventos cardiacos, ya que sólo se observaron 56 eventos en la cohorte de derivación. Varios estudios de validación externos indican que el índice Lee probablemente sea subóptimo para la identificación de pacientes con múltiples factores de riesgo ${ }^{6}$. De hecho, el tipo de cirugía estaba clasificada solamente en dos subtipos: el primero, los procedimientos de alto riesgo, entre los que se incluían la cirugía intraperitoneal, la intratorácica y la vascular suprainguinal, y el segundo, el resto de los procedimientos no laparoscópicos, entre los que se incluía principalmente la cirugía ortopédica y la abdominal y otros procedimientos vasculares. Se dispone de evidencia de que una clasificación más detallada, como la utilizada en el modelo Erasmus, ofrece una mejor discriminación del riesgo ${ }^{6}$. En este modelo, la utilización de una clasificación detallada del tipo de cirugía y de la edad aumentó el valor pronóstico para los eventos cardiacos perioperatorios (el área bajo la curva ROC para la predicción de la mortalidad cardiovascular aumentó de 0,63 a 0,85).

\section{Recomendación/declaración sobre la estratificación del riesgo cardiaco}

\begin{tabular}{lcc}
\hline Recomendación/declaración & Clase $^{\mathbf{a}}$ & Nivel $^{\mathbf{b}}$ \\
\hline $\begin{array}{l}\text { Se recomienda la utilización de índices de riesgo } \\
\text { clínico para la estratificación del riesgo }\end{array}$ & I & B \\
postoperatorio & & \\
$\begin{array}{l}\text { Se recomienda la utilización del índice Lee aplicando } \\
\text { sus seis variables para el riesgo cardiaco } \\
\text { perioperatorio }\end{array}$ & I & A
\end{tabular}

aClase de recomendación.

${ }^{b}$ Nivel de evidencia.

\section{Biomarcadores}

Un marcador biológico, o biomarcador, es una característica que se puede medir y evaluar objetivamente y es un indicador de las alteraciones en los procesos o respuestas biológicas y patogénicas a in- tervenciones terapéuticas. En el contexto perioperatorio los biomarcadores pueden dividirse en marcadores de isquemia y daño miocárdico, de inflamación y de disfunción del VI.

Las troponinas cardiacas T e I (cTnT y cTnI) son los marcadores utilizados para el diagnóstico del IM, ya que tienen sensibilidad y especificidad tisular superiores a los de otros biomarcadores ${ }^{33,34}$. La información pronóstica es independiente y complementaria de otros importantes indicadores cardiacos de riesgo, como la elevación del ST y la función del VI. La relevancia pronóstica de la elevación de las troponinas, aunque sea leve, se ha demostrado en numerosos estudios clínicos y poblacionales (TACTICS-TIMI 18, FRISC II, OPUSTIMI) ${ }^{35,36}$, tanto en grupos con alto riesgo como en poblaciones en riesgo intermedio. La determinación de cTnI y la de cTnT ofrecen el mismo valor para la evaluación del riesgo en los SCA, en presencia o en ausencia de insuficiencia renal ${ }^{33}$. El pronóstico de muerte por todas las causas en pacientes con enfermedad renal terminal y pequeñas elevaciones de la cTnT es 2-5 veces peor que en los pacientes con valores no detectables. Con base en la evidencia disponible, se cree que incluso pequeñas elevaciones de la cTnT en el periodo perioperatorio se reflejan en daño miocárdico clínicamente relevante, con peores pronóstico y resultados cardiacos ${ }^{37}$. El desarrollo de nuevos biomarcadores, como las troponinas de alta sensibilidad, mejorará la evaluación del daño miocárdico. Es preciso señalar que la elevación de las troponinas puede observarse en muchas otras entidades. El diagnóstico de infarto de miocardio sin elevación del ST (IAMSEST) no debe realizarse únicamente con base en la determinación de biomarcadores.

En el periodo preoperatorio, los marcadores inflamatorios pueden identificar a los pacientes con mayor riesgo de placa coronaria inestable. La proteína $\mathrm{C}$ reactiva (PCR) es un reactante de fase aguda que se produce en el hígado. La PCR también se expresa en las células de músculo liso presentes en las arterias con enfermedad aterosclerótica y está implicada en muchos aspectos de la aterogénesis y de la vulnerabilidad de la placa, como adhesión molecular, inducción de óxido nítrico y función complementaria afectada, y en la inhibición de la fibrinolisis intrínseca ${ }^{38}$. Sin embargo, no se dispone de datos sobre el uso de la PCR como marcador para el inicio de estrategias de reducción del riesgo en el contexto quirúrgico.

El péptido natriurético cerebral (BNP) y la fracción aminoterminal de su propéptido (NT-proBNP) se producen en los miocitos cardiacos en respuesta a un aumento del estrés de la pared miocárdica. Esto puede ocurrir en cualquier fase de la insuficiencia cardiaca, independientemente de la pre- 
sencia o ausencia de isquemia miocárdica. Los valores plasmáticos de BNP y NT-proBNP se han convertido en importantes indicadores pronósticos en pacientes con insuficiencia cardiaca, SCA y cardiopatía isquémica estable en contextos clínicos no quirúrgicos ${ }^{39-41}$. Las cifras de BNP y NT-proBNP preoperatorias ofrecen un valor pronóstico adicional para la mortalidad a largo plazo y eventos cardiacos tras cirugía mayor no cardiaca ${ }^{42-46}$.

Los datos de estudios prospectivos y aleatorizados sobre el uso de biomarcadores en la fase preoperatoria son escasos. Con base en los datos disponibles, no puede recomendarse el uso sistemático de biomarcadores séricos como índice de daño celular en pacientes programados para cirugía no cardiaca.

\section{Recomendación/declaración sobre biomarcadores}

\begin{tabular}{|c|c|c|}
\hline Recomendación/declaración & Clase $^{a}$ & Nivel $^{b}$ \\
\hline $\begin{array}{l}\text { Se considerará la determinación del NT-proBNP } \\
\text { y el BNP para obtener información pronóstica } \\
\text { independiente sobre el riesgo perioperatorio } \\
\text { y tardío de eventos cardiacos de pacientes } \\
\text { en alto riesgo }\end{array}$ & Ila & $B$ \\
\hline $\begin{array}{l}\text { No se recomienda el muestreo sistemático } \\
\text { de biomarcadores para la prevención } \\
\text { de eventos cardiacos }\end{array}$ & III & $C$ \\
\hline
\end{tabular}

\section{Pruebas no invasivas}

Las pruebas no invasivas preoperatorias proporcionan información sobre tres marcadores de riesgo cardiaco: disfunción del VI, isquemia miocárdica y alteraciones en las válvulas cardiacas, considerados todos ellos determinantes de un pronóstico adverso. La función del VI se evalúa en reposo mediante diferentes técnicas de imagen. Para la detección de isquemia miocárdica pueden utilizarse el ECG de esfuerzo u otras técnicas de imagen no invasivas. En líneas generales, el algoritmo diagnóstico para la estratificación del riesgo de isquemia miocárdica y función del VI debe ser similar al propuesto en un contexto no quirúrgico para los pacientes con cardiopatía isquémica conocida o sospechada ${ }^{47}$. Las pruebas no invasivas no deben considerarse sólo en el caso de revascularización coronaria, sino también para aconsejar al paciente, modificar el manejo perioperatorio en cuanto a tipo de cirugía y elección de la anestesia y tener el pronóstico a largo plazo. La ecocardiografía es la técnica de elección para la evaluación de valvulopatías (véase en «Enfermedades específicas» el apartado sobre valvulopatías).

\section{Pruebas no invasivas para la enfermedad cardiaca}

\section{Electrocardiografía}

Normalmente, se realiza un ECG de 12 derivaciones como parte de la evaluación del riesgo cardiovascular preoperatorio en pacientes que van a ser sometidos a cirugía no cardiaca. En pacientes con cardiopatía isquémica, el ECG preoperatorio ofrece importante información pronóstica y permite predecir la evolución a largo plazo, independientemente de los hallazgos clínicos y de la isquemia perioperatoria ${ }^{48}$. Sin embargo, en un paciente con isquemia o infarto, el ECG puede ser normal o inespecífico. El uso sistemático del ECG antes de cualquier tipo de cirugía es objeto de debate. En un estudio retrospectivo en el que se incluyó a un total de 23.036 pacientes y 28.457 procedimientos quirúrgicos, se observó que los pacientes con un ECG anormal tuvieron mayor incidencia de muerte cardiovascular que los pacientes con un ECG normal (el 1,8 frente al 0,3\%). En los pacientes sometidos a cirugía de bajo riesgo o de riesgo bajo-intermedio, la diferencia absoluta en la incidencia de muerte cardiovascular entre los pacientes con/sin anomalías en el ECG fue tan sólo del 0,5\% $\%^{49}$.

\section{Recomendaciones sobre el electrocardiograma}

\begin{tabular}{|c|c|c|}
\hline Recomendación & Clase $^{a}$ & Nivel $^{b}$ \\
\hline $\begin{array}{l}\text { Se recomienda la realización de ECG preoperatorio } \\
\text { a pacientes con uno o más factores de riesgo } \\
\text { que están programados para cirugía de riesgo } \\
\text { intermedio o alto }\end{array}$ & I & B \\
\hline $\begin{array}{l}\text { Se considerará la realización de ECG preoperatorio } \\
\text { en pacientes con uno o más factores de riesgo } \\
\text { que están programados para cirugía de bajo riesgo }\end{array}$ & Ila & $B$ \\
\hline $\begin{array}{l}\text { Se considerará la realización de ECG preoperatorio } \\
\text { en pacientes sin factores de riesgo que están } \\
\text { programados para cirugía de riesgo intermedio }\end{array}$ & Ilb & $B$ \\
\hline $\begin{array}{l}\text { No se recomienda la realización de ECG preoperatorio } \\
\text { en pacientes sin factores de riesgo que están } \\
\text { programados para cirugía de bajo riesgo }\end{array}$ & III & $B$ \\
\hline
\end{tabular}

ECG: electrocardiograma.

${ }^{a}$ Clase de recomendación

bNivel de evidencia

\section{Evaluación de la función ventricular}

Antes de la cirugía no cardiaca, la función del VI en reposo puede evaluarse mediante ventriculografía con radionúclidos, tomografía computarizada por emisión monofotónica (SPECT), ecocardiografía, resonancia magnética (RM) o tomografía computarizada (TC) multicorte, con similar grado 
de precisión ${ }^{50}$. No se recomienda la ecocardiografía sistemática para la evaluación preoperatoria de la función del VI, pero puede realizarse en pacientes asintomáticos programados para cirugía de alto riesgo. Un metaanálisis de los datos disponibles demuestra que una fracción de eyección del VI $<35 \%$ tiene una sensibilidad del $50 \%$ y una especificidad del $91 \%$ para la predicción del IM no fatal y la muerte cardiaca perioperatorios ${ }^{51}$. El limitado valor predictivo de la evaluación de la función del VI para los resultados perioperatorios puede deberse al fracaso en la detección de una cardiopatía isquémica subyacente grave. Las recomendaciones para la evaluación preoperatoria de los pacientes con soplos (asintomáticos) aparecen en el apartado sobre valvulopatías.

\section{Recomendaciones sobre ecocardiografía en reposo}

\begin{tabular}{lcc}
\hline Recomendación & Clase $^{\mathrm{a}}$ & Nivel $^{\mathrm{b}}$ \\
\hline $\begin{array}{l}\text { Se considerará la realización de ecocardiografía en } \\
\text { reposo para la evaluación de la función del ventrículo }\end{array}$ & Ila & C \\
izquierdo en pacientes programados para cirugía & & \\
de alto riesgo & & \\
No se recomienda la realización de ecocardiografía \\
$\begin{array}{l}\text { en reposo para la evaluación de la función del } \\
\text { ventrículo izquierdo en pacientes asintomáticos }\end{array}$
\end{tabular}

aClase de recomendación.

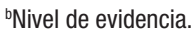

\section{Pruebas no invasivas para la detección de cardiopatía isquémica}

La prueba de esfuerzo en cinta continua o la ergometría con bicicleta son los métodos de elección para la detección de la isquemia. La prueba de esfuerzo permite determinar la capacidad funcional, la presión arterial y la respuesta de la frecuencia cardiaca, y permite detectar la isquemia miocárdica por las alteraciones del segmento ST. La precisión de la prueba de esfuerzo varía sensiblemente entre distintos ensayos clínicos. Un metaanálisis de los estudios publicados en pacientes de cirugía vascular en los que se realizó una prueba de esfuerzo en cinta continua muestra una sensibilidad y una especificidad relativamente bajas (74\% [IC del 95\%, $60 \%-88 \%$ ] y $69 \%$ [IC del 95\%, 60\%-78\%] respectivamente), comparables a las observadas en la práctica clínica diaria $^{51}$. El valor predictivo positivo fue bajo $(10 \%)$, mientras que el valor predictivo negativo fue muy alto $(98 \%)$. Sin embargo, la estratificación del riesgo mediante esta prueba no es adecuada para los pacientes con una capacidad de ejercicio limitada, ya que dichos pacientes no pueden alcanzar el umbral de isquemia. Además, las alteraciones del segmento ST, especialmente en las derivaciones precordiales V5 y V6 en reposo, dificultan el análisis del segmento ST. Un gradiente de severidad en los resultados de la prueba se asocia a los resultados perioperatorios: la aparición de una respuesta isquémica miocárdica con una carga de trabajo baja se asocia a un aumento significativo del riesgo perioperatorio y eventos cardiacos a largo plazo. Por otra parte, la aparición de isquemia miocárdica con cargas altas de trabajo se asocia a un riesgo significativamente menos ele$\operatorname{vado}^{30}$. Las pruebas de estrés farmacológicas con técnicas de imagen por perfusión nuclear o ecocardiografía son más adecuadas en pacientes con una capacidad de ejercicio limitada.

El papel de las técnicas de imagen por perfusión miocárdica en la estratificación preoperatoria del riesgo está bien establecido. En pacientes con una capacidad de ejercicio limitada, el estrés farmacológico (dipiridamol, adenosina o dobutamina) es una buena alternativa. Las imágenes reflejan la distribución de la sangre en el miocardio en el momento de la inyección. Las pruebas se realizan, tanto en reposo como con estrés, para determinar la presencia de defectos reversibles, que reflejan el miocardio isquémico amenazado, o defectos fijos, que reflejan cicatrices o tejido inviable.

En un metaanálisis de varios estudios realizados en pacientes de cirugía vascular, se estudió el valor pronóstico del grado de afección de miocardio isquémico determinado por perfusión miocárdica con dipiridamol y análisis semicuantitativo ${ }^{52}$. Los objetivos del estudio eran la muerte cardiaca y el IM perioperatorios. Los autores incluyeron nueve estudios con un total de 1.179 pacientes de cirugía vascular, con una tasa del 7\% de eventos a los 30 días. En ese análisis, la isquemia reversible en menos del $20 \%$ del miocardio del VI no modificó la probabilidad de eventos cardiacos perioperatorios respecto a la ausencia de isquemia. Los pacientes con defectos reversibles más extensos presentaron más riesgo: reversibilidad del 20-29\% (razón de probabilidades $[\mathrm{RP}]=1,6[\mathrm{IC}$ del 95\%, 1-2,6]); reversibilidad del 30-39\% (RP = 2,9 [IC del 95\%, 1,6-5,1]); reversibilidad del 40-49\% $(\mathrm{RP}=2,9$ [IC del 95\%, $1,4-6,2])$, y reversibilidad $\geq 50 \%(\mathrm{RP}=11$ [IC del $95 \%, 5,8-20])$.

En un segundo metaanálisis en el que se evaluó el valor pronóstico de seis pruebas diagnósticas, las técnicas de perfusión miocárdica mostraron una sensibilidad del 83\% (IC del 95\%, 77-92\%) y una especificidad mucho más baja del $47 \%$ (IC del 95\%, $41-57 \%)^{51-53}$. Los valores predictivos positivos y negativos fueron del 11 y el $97 \%$, respectivamente.

En un tercer metaanálisis se analizaron los resultados de diez estudios en los que se evaluaba el papel de las pruebas de perfusión miocárdica con talio 201-dipiridamol en candidatos a cirugía vascular durante un periodo de 9 años (1985-1994) ${ }^{53}$. Las tasas de muerte cardiaca o IM a los 30 días fueron del $1 \%$ en pacientes con pruebas normales, 
del 7\% en pacientes con defectos fijos y del $9 \%$ en pacientes con defectos reversibles en las imágenes con talio 201. Por otra parte, tres de los estudios, en los cuales se utilizaron escalas de análisis semicuantitativo, demostraron una mayor incidencia de eventos cardiacos en pacientes con dos o más defectos reversibles.

En términos generales, el valor predictivo positivo de los defectos reversibles en cuanto a la muerte o el IM perioperatorios ha disminuido en los últimos años. Esto probablemente se deba a los cambios introducidos en el manejo perioperatorio y en los procedimientos quirúrgicos, que resultan en una reducción de la tasa de eventos cardiacos en los pacientes con isquemia miocárdica detectada en las pruebas de estrés preoperatorias. Sin embargo, y debido a la alta sensibilidad de las técnicas de imagen nuclear para la detección de isquemia miocárdica, los pacientes con un escáner normal tienen un pronóstico excelente. Las pruebas de estrés con dobutamina mediante perfusión miocárdica tienen un buen perfil de seguridad. En una serie de 1.076 pacientes consecutivos se observó un 3,4\% de hipotensión (definida como una disminución de la presión sistólica $\geq 40 \mathrm{mmHg}$ ) y un $3,8 \%$ de arritmias graves. Todas las arritmias se resolvieron espontáneamente o tras la administración de metoprolol ${ }^{54}$.

La ecocardiografía de estrés mediante ejercicio o fármacos (dobutamina, dipiridamol) se ha utilizado ampliamente en la evaluación del riesgo cardiaco preoperatorio. Esta prueba ofrece información sobre la función del VI en reposo, sobre anomalías valvulares y sobre la presencia y el grado de isquemia inducible por estrés ${ }^{55}$. En un estudio con 530 pacientes se evaluó el valor de la ecocardiografía de estrés con dobutamina (EED) en la evaluación preoperatoria del riesgo cardiaco antes de la cirugía no vascular ${ }^{56}$. Los predictores multivariables de eventos postoperatorios en pacientes con isquemia fueron una historia previa de insuficiencia cardiaca (odds ratio [OR] $=4,7$; IC del 95\%, 1,6-14) y un umbral de isquemia $<60 \%$ de la frecuencia cardiaca máxima estimada por edad (OR = 7; IC del 95\%, 2,8-17,6). La EED permitió la identificación de un $60 \%$ de pacientes con bajo riesgo (ausencia de isquemia), un $32 \%$ con riesgo intermedio (umbral de isquemia $\geq 60 \%$ ) y un $8 \%$ con alto riesgo (umbral de isquemia $<60 \%$ ); las tasas de eventos postoperatorios fueron 0 , el 9 y el $43 \%$, respectivamente. En un reciente metaanálisis se demostró que la sensibilidad y la especificidad de la EED para la muerte cardiaca y el IM perioperatorios son altas (el 85 y el 70\%, respectivamente) ${ }^{51}$. La EED puede realizarse de forma segura en pacientes con una tolerancia razonable -incidencia de arritmias cardiacas e hipotensión (definida como una disminución de la presión sistólica $\geq 40 \mathrm{mmHg}$ - . La EED presenta algunas limitaciones, pues no debe reali- zarse en pacientes con arritmias graves, hipertensión significativa, aneurisma aórtico con presencia de trombos grandes o hipotensión.

En general, la ecocardiografía de estrés tiene un valor predictivo negativo alto $(90-100 \%)$. Una prueba negativa se asocia a una incidencia muy baja de eventos cardiacos e indica la seguridad del procedimiento quirúrgico. Sin embargo, el valor predictivo positivo es relativamente bajo $(25-45 \%)$, lo cual significa que la probabilidad de que ocurra un evento cardiaco postoperatorio es baja, aunque se detecten anomalías en la movilidad de la pared durante la ecocardiografía de estrés.

En un metaanálisis de 15 estudios que comparaban la gammagrafía cardiaca con talio 201-dipiridamol y la ecocardiografía con dobutamina en la estratificación del riesgo antes de cirugía vascular, se demostró un valor pronóstico similar de las anomalías detectadas con dichas pruebas de estrés respecto a la incidencia de eventos isquémicos perioperatorios, si bien la precisión variaba en función de la prevalencia de cardiopatía isquémica ${ }^{53}$. En pacientes con una incidencia baja de cardiopatía isquémica, la precisión diagnóstica es menor que en pacientes con una alta incidencia de esta entidad.

La RM también puede utilizarse para la detección de la isquemia; permite valorar tanto la perfusión como la movilidad parietal, ya sea durante el estrés o en reposo ${ }^{57}$. La presencia de isquemia, más que la cardiopatía isquémica per se, se asocia a eventos cardiacos adversos postoperatorios. Por lo tanto, las pruebas funcionales son preferibles a las que proporcionan información anatómica sobre la existencia de estenosis. La movilidad parietal permite valorar la presencia de isquemia con altas sensibilidad $(83 \%$; IC del $95 \%, 79 \%-88 \%)$ y especificidad (86\%; IC del 95\%, 81\%-91\%) (14 estudios, 754 pacientes). Si además de las anomalías de movilidad se evalúa la perfusión (24 estudios, 1.516 pacientes), la sensibilidad en la detección de la isquemia aumenta al 91\% (IC del 95\%, 88\%-94\%), pero la especificidad disminuye al 81\% (IC del 95\%, 77\%-85\%). La RM de estrés con dobutamina se utilizó en un estudio que incluía a 102 pacientes programados para cirugía mayor no cardiaca ${ }^{58}$. La aparición de anomalías en la movilidad parietal se utilizó como marcador de isquemia. Según el análisis multivariable, la isquemia miocárdica fue el predictor más poderoso de eventos cardiacos perioperatorios (muerte, IM e insuficiencia cardiaca). La RM permitió la realización de angiografía no invasiva y el metaanálisis de datos existentes, tomando la cardiopatía isquémica detectada por angiografía coronaria como referencia. El análisis por vasos (16 estudios, 2.041 vasos) demostró sensibilidad y especificidad del 75\% (IC del 95\%, 68\%-80\%) y el $85 \%$ (IC del 95\%, 78\%-90\%), respectivamente, y el 
análisis por pacientes (13 estudios, 607 pacientes), sensibilidad y especificidad del $88 \%$ (IC del 95\%, $82 \%-92 \%$ ) y el $56 \%$ (IC del $95 \%, 53 \%-68 \%$ ), respectivamente $^{59}$. Hasta la fecha no se dispone de datos para la estratificación del riesgo preoperatorio.

La TC se puede utilizar para la detección de calcio en las coronarias, lo que refleja aterosclerosis coronaria. Además, la TC por haz de electrones y la TC multicorte permiten la angiografía no invasiva. Un metaanálisis de datos disponibles, en el que se tomaba como referencia la cardiopatía isquémica detectada por angiografía coronaria, demostró una sensibilidad del $82 \%$ (IC del $95 \%, 80 \%-85 \%$ ) y una especificidad del 91\% (IC del 95\%, 90\%-92\%) con base en el análisis de los vasos (8 estudios, 2.726 vasos), y basándose en el de los pacientes (21 estudios, 1.570 pacientes), una sensibilidad del $96 \%$ (IC del 95\%, 94\%-98\%) y una especificidad del 74\% (IC del $95 \%, 65 \%-84 \%)^{60}$. No se dispone de datos sobre la estratificación preoperatoria del riesgo y es preciso hacer una advertencia sobre los riesgos de la radiación $^{61}$. En pacientes programados para cirugía valvular, la angiografía por TC puede utilizarse para descartar una cardiopatía isquémica concomitante, con lo que se evita una angiografía coronaria invasiva $^{62}$. Este planteamiento puede ser útil para la estratificación preoperatoria del riesgo; sin embargo, no se dispone de datos al respecto.

¿Cómo podemos utilizar estos datos en un algoritmo práctico? Las pruebas diagnósticas sólo deben realizarse si los resultados pueden cambiar el manejo perioperatorio. Los pacientes con alto grado de isquemia inducida por estrés constituyen una población con alto riesgo en la que el tratamiento farmacológico convencional suele ser insuficiente para la prevención de eventos cardiacos perioperatorios $^{63}$. Se debe considerar las pruebas preoperatorias para los pacientes que van a ser sometidos a cirugía de alto riesgo y presentan menos de tres factores clínicos de riesgo. Sin embargo, en estos pacientes, el efecto beneficioso del tratamiento cardioprotector suele ser suficiente, lo que hace innecesario realizar pruebas de estrés. Los resultados de un estudio multicéntrico y aleatorizado (DECREASE-II) mostraron que la tasa de eventos cardiacos perioperatorios de los pacientes de cirugía vascular tratados con bloqueadores beta se había reducido tanto que los resultados de las pruebas y la posterior modificación del manejo perioperatorio estaban de más ${ }^{8}$. No se observaron diferencias en muerte cardiaca e IM a los 30 días entre los 770 pacientes a los que no se realizaron las pruebas de estrés y el grupo asignado a la prueba (el 1,8 frente al $2,3 \%$; OR $=0,78$; IC del 95\%, 0,28-2,1). Un dato que tener en cuenta es que, debido a las pruebas preoperatorias, la cirugía se retrasó más de 3 semanas. Para los pacientes con riesgo intermedio las recomendaciones son similares, aunque no se dispone de datos de estudios aleatorizados. Con base en la baja tasa de eventos en pacientes programados para cirugía de bajo riesgo, es poco probable que los resultados de las pruebas de los pacientes estables puedan alterar el manejo perioperatorio.

\section{Recomendaciones sobre las pruebas de estrés antes de la cirugía}

\begin{tabular}{|c|c|c|}
\hline Recomendación & Clase $^{a}$ & Nivel $^{b}$ \\
\hline $\begin{array}{l}\text { Se recomienda la realización de pruebas de estrés } \\
\text { en pacientes con tres o más factores clínicos } \\
\text { de riesgo }{ }^{\complement} \text { que están programados para cirugía } \\
\text { de alto riesgo }\end{array}$ & I & C \\
\hline $\begin{array}{l}\text { Puede considerarse la realización de pruebas de estrés } \\
\text { en pacientes con } 2 \text { o menos factores clínicos } \\
\text { de riesgo que están programados para cirugía } \\
\text { de alto riesgo }\end{array}$ & Ilb & B \\
\hline $\begin{array}{l}\text { Puede considerarse la realización de pruebas de estrés } \\
\text { en la cirugía de riesgo intermedio }\end{array}$ & Illb & C \\
\hline $\begin{array}{l}\text { No se recomienda la realización de pruebas de estrés } \\
\text { en la cirugía de bajo riesgo }\end{array}$ & III & C \\
\hline
\end{tabular}

\section{Evaluación integrada de la función cardiopulmonar}

La prueba de esfuerzo cardiopulmonar (PECP) permite una evaluación general de la respuesta integrada de los aparatos respiratorio, cardiovascular y locomotor. La PECP es una ergometría que se realiza en bicicleta o cinta continua en la que se miden los gases inspirados y espirados mediante una mascarilla o gafas nasales. Esta prueba proporciona información sobre la toma de oxígeno y su utilización ${ }^{64}$. Los datos de esta prueba que se utilizan normalmente son el consumo de oxígeno durante el ejercicio pico (pico $\mathrm{VO}_{2}$ ) y el umbral anaeróbico $\left(\mathrm{VO}_{2} \mathrm{AT}\right)$, definido como el punto en que la demanda metabólica excede el suministro de oxígeno y comienza el metabolismo anaeróbico. Los umbrales utilizados para la clasificación de los pacientes con bajo riesgo suelen ser un pico $\mathrm{VO}_{2}>15$ $\mathrm{ml} / \mathrm{kg} / \mathrm{min}$ y un $\mathrm{VO}_{2} \mathrm{AT}>11 \mathrm{ml} / \mathrm{kg} / \mathrm{min}$. Estos umbrales equivalen aproximadamente a $4 \mathrm{MET}^{65}$. Antes de la resección pulmonar, la PECP puede ayudar a estratificar el riesgo quirúrgico y optimizar los cuidados perioperatorios. En una cohorte de 204 pacientes consecutivos sometidos a lobectomía pulmonar o neumonectomía, un pico $\mathrm{VO}_{2}$ $<20 \mathrm{ml} / \mathrm{kg} / \mathrm{min}$ fue predictor de complicaciones pulmonares, complicaciones cardiológicas y muerte; un pico $\mathrm{VO}_{2}<12 \mathrm{ml} / \mathrm{kg} / \mathrm{min}$ se asoció a una tasa de mortalidad 13 veces superior ${ }^{66}$. En un estudio con 187 pacientes de edad avanzada se determinó el 
$\mathrm{VO}_{2} \mathrm{AT}$ antes de la cirugía abdominal mayor ${ }^{67}$. La mortalidad total fue del 5,9\%; los pacientes con un $\mathrm{VO}, \mathrm{AT}<11 \mathrm{ml} / \mathrm{kg} / \mathrm{min}(\mathrm{n}=55)$ tuvieron una mortalidad del $18 \%$, mientras que los pacientes con un $\mathrm{VO}_{2} \mathrm{AT}>11 \mathrm{ml} / \mathrm{kg} / \mathrm{min}(\mathrm{n}=132)$ tuvieron una mortalidad del $0,8 \%$ (HR = 24; IC del 95\%, 3,1-183). Entre los pacientes que presentaron signos de isquemia durante la prueba, la mortalidad fue del $42 \%$ en los que tenían un $\mathrm{VO}_{2} \mathrm{AT}<11 \mathrm{ml} / \mathrm{kg} /$ min y sólo del $4 \%$ en los que tenían un $\mathrm{VO}_{2} \mathrm{AT}>11$ $\mathrm{ml} / \mathrm{kg} / \mathrm{min}(\mathrm{p}<0,001)$. La PECP también ofrece información precisa sobre el pronóstico de los pacientes con insuficiencia cardiaca: una relación excesivamente elevada entre la ventilación por minuto (VE) y la producción de dióxido de carbono $\left(\mathrm{VCO}_{2}\right)$, expresada como el gradiente $\mathrm{VE} / \mathrm{VCO}_{2}$ determinado entre el momento de la carga de trabajo y el final del periodo de taponamiento isocápnico, identificado por el aumento del gradiente $\mathrm{VE} / \mathrm{VCO}_{2}$ y la reducción del volumen de $\mathrm{CO}_{2}$ al final de la espiración $\left(\mathrm{PETCO}_{2}\right)$ (o el volumen alveolar y de gas de espacio muerto, $\mathrm{PaCO}_{2}$ ), se asocia con un mal resultado, ya que se trata de un patrón de oscilación de la ventilación durante el ejercicio, definido como fluctuaciones cíclicas en la VE en reposo que persisten durante el ejercicio ${ }^{68}$. Podrían darse discrepancias entre la PECP y las pruebas funcionales determinadas por MET, las cuales impiden el uso generalizado de la PECP. La presencia de factores externos a las funciones cardiaca y respiratoria, tales como la función del músculo esquelético y el entrenamiento físico, puede conducir a subestimar la actividad metabólica aeróbica. La última consideración se refiere a la disponibilidad de esta técnica ya que, por el momento, la PECP no se encuentra disponible en todos los centros. El papel de la PECP en la evaluación del riesgo preoperatorio no está claramente establecido y no debe considerarse como sustituta de las pruebas de estrés en la práctica clínica.

\section{Angiografía}

La angiografía coronaria es un procedimiento diagnóstico ampliamente utilizado, pero rara vez está indicada para la valoración del riesgo en el contexto de la cirugía no cardiaca. No se dispone de suficiente información derivada de estudios aleatorizados sobre su utilidad en la evaluación de los pacientes candidatos a cirugía no cardiaca. Por otra parte, la realización de una angiografía coronaria podría retrasar de forma impredecible e innecesaria una intervención quirúrgica ya planificada. Sin embargo, un número significativo de pacientes en los que está indicado un procedimiento quirúrgico no cardiaco puede tener cardiopatía isquémica. En los pacientes con cardiopatía isquémica conocida, las

\section{Recomendaciones sobre la angiografía coronaria preoperatoria}

\begin{tabular}{|c|c|c|}
\hline Recomendación & Clase $^{a}$ & Nivel $^{\mathrm{b}}$ \\
\hline $\begin{array}{l}\text { Se recomienda la realización de angiografía } \\
\text { coronaria preoperatoria en pacientes con IAMCEST }\end{array}$ & I & A \\
\hline $\begin{array}{l}\text { Se recomienda la realización de angiografía } \\
\text { coronaria preoperatoria en pacientes con IAMSEST } \\
\text { y angina inestable }\end{array}$ & I & A \\
\hline $\begin{array}{l}\text { Se recomienda la realización de angiografía coronaria } \\
\text { preoperatoria en pacientes con angina resistente } \\
\text { al tratamiento farmacológico adecuado }\end{array}$ & I & A \\
\hline $\begin{array}{l}\text { Puede considerarse la realización de angiografía } \\
\text { coronaria preoperatoria en pacientes estables } \\
\text { que están programados para cirugía de alto riesgo }\end{array}$ & llb & B \\
\hline $\begin{array}{l}\text { Puede considerarse la realización de angiografía } \\
\text { coronaria preoperatoria en pacientes estables } \\
\text { que están programados para cirugía } \\
\text { de riesgo intermedio }\end{array}$ & llb & C \\
\hline $\begin{array}{l}\text { No se recomienda la angiografía coronaria } \\
\text { preoperatoria en pacientes estables que están } \\
\text { programados para cirugía de bajo riesgo }\end{array}$ & III & C \\
\hline
\end{tabular}

IAMCEST: infarto agudo de miocardio con elevación del segmento ST; IAMSEST: infarto agudo de miocardio sin elevación del segmento ST.

aClase de recomendación.

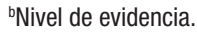

indicaciones de angiografía coronaria y revascularización son similares a las indicaciones en el contexto no quirúrgico ${ }^{47,69-71}$. Se recomienda el control de la isquemia, bien mediante tratamiento farmacológico, bien por una intervención, siempre que la cirugía pueda aplazarse.

\section{ESTRATEGIAS DE REDUCCIÓN DEL RIESGO}

\section{Estrategia farmacológica}

El IM que se presenta durante la cirugía o en el periodo postoperatorio inmediato suele precederse de isquemia miocárdica prolongada o recurrente. El estrés de la cirugía y la anestesia pueden causar la isquemia, debido a la falta de equilibrio entre la demanda miocárdica y el aporte de oxígeno. Aparte de las estrategias de reducción del riesgo adaptadas a un paciente y al tipo de cirugía, la evaluación preoperatoria del riesgo brinda la oportunidad de revisar y optimizar el control de todos los factores de riesgo cardiovascular.

\section{Bloqueadores beta}

Durante el periodo perioperatorio se produce un aumento de la liberación de catecolaminas que con- 
TABLA 6. Resumen de los ensayos clínicos aleatorizados y controlados para evaluar el efecto del uso preoperatorio de bloqueadores beta en la mortalidad y el infarto de miocardio no fatal postoperatorios

\begin{tabular}{|c|c|c|c|c|c|c|c|c|c|c|c|}
\hline \multirow[t]{2}{*}{ Estudio } & \multirow{2}{*}{ N } & \multirow{2}{*}{$\begin{array}{c}\text { Cirugía } \\
\text { vascular } \\
\quad \%\end{array}$} & \multicolumn{4}{|c|}{$\begin{array}{l}\text { Bloqueador } \\
\text { beta }\end{array}$} & \multirow{2}{*}{$\begin{array}{c}\text { Selección } \\
\text { de pacientes } \\
\text { según riesgo } \\
\text { cardiaco }\end{array}$} & \multicolumn{2}{|c|}{$\begin{array}{c}\text { Mortalidad a los } 30 \text { días, } \\
\text { n/N (\%) }\end{array}$} & \multicolumn{2}{|c|}{$\begin{array}{l}\text { Tasa de IM no fatal a los } 30 \text { días, } \\
\text { n/N (\%) }\end{array}$} \\
\hline & & & Tipo & $\begin{array}{c}\text { Inicio } \\
\text { (antes de } \\
\text { la cirugía) }\end{array}$ & $\begin{array}{c}\text { Duración } \\
\text { (días tras } \\
\text { cirugía) }\end{array}$ & $\begin{array}{c}\text { Ajuste } \\
\text { de dosis }\end{array}$ & & $\begin{array}{l}\text { Bloqueador } \\
\text { beta }\end{array}$ & Control & $\begin{array}{l}\text { Bloqueador } \\
\text { beta }\end{array}$ & Control \\
\hline Mangano et al ${ }^{76}$ & 200 & 40 & Atenolol & $30 \mathrm{~min}$ & 7 & No & $\begin{array}{l}\mathrm{Cl} 0 \geq 2 \\
\text { factores } \\
\text { de riesgo }\end{array}$ & $5 / 99(5,1)^{\mathrm{a}}$ & $12 / 101(11,9)^{\mathrm{a}}$ & - & - \\
\hline DECREASE ${ }^{9}$ & 112 & 100 & Bisoprolol & 7 días & 30 & Sí & EED positiva & $2 / 59(3,4)$ & 9/53 (17) & $0 / 59$ & 9/53 (17) \\
\hline $\mathrm{POBBLE}^{74}$ & 103 & 100 & $\begin{array}{l}\text { Tartrato de } \\
\text { metoprolol }\end{array}$ & $<24 \mathrm{~h}$ & 7 & No & No & $3 / 55(5,4)$ & $1 / 48(2,1)$ & $3 / 55(5,5)$ & $5 / 48(10,4)$ \\
\hline MaVS $^{77}$ & 496 & 100 & $\begin{array}{c}\text { Succinato de } \\
\text { metoprolol }\end{array}$ & $2 \mathrm{~h}$ & 5 & No & No & $0 / 246$ & $4 / 250(1,6)$ & $19 / 246(7,7)$ & $21 / 250(8,4)$ \\
\hline DIPOM $^{75}$ & 921 & 7 & $\begin{array}{c}\text { Succinato } \\
\text { de metoprolol }\end{array}$ & $12 \mathrm{~h}$ & 8 & No & $\begin{array}{l}\text { Diabetes } \\
\text { mellitus }\end{array}$ & $74 / 462(16)$ & $72 / 459(15,7)$ & $3 / 462(0,6)$ & $4 / 459(0,9)$ \\
\hline $\mathrm{BBSA}^{78}$ & 219 & 5 & Bisoprolol & $>3 \mathrm{~h}$ & 10 & Sí & $\begin{array}{l}\mathrm{Cl} 0 \geq 2 \\
\text { factores } \\
\text { de riesgo }\end{array}$ & $1 / 110(0,9)$ & $0 / 109$ & $0 / 110$ & $0 / 109$ \\
\hline POISE ${ }^{10}$ & 8.351 & 41 & $\begin{array}{c}\text { Succinato } \\
\text { de metoprolol }\end{array}$ & ol $2-4 \mathrm{~h}$ & 30 & v & $\begin{array}{c}\mathrm{Cl} 0 \\
\text { aterosclerosis } \\
0 \text { cirugía } \\
\text { vascular mayor } \\
0 \geq 3 \text { factores } \\
\text { de riesgo }\end{array}$ & $129 / 4.174(3,1)$ & $97 / 4.177(2,3)$ & $152 / 4.174(3,6)$ & $215 / 4.177(5,1)$ \\
\hline
\end{tabular}

Cl: cardiopatía isquémica; EED: ecocardiografía de estrés con dobutamina.

${ }^{\mathrm{a} A}$ los 6 meses.

lleva un aumento de la frecuencia cardiaca y de la contractilidad miocárdica y, por consiguiente, aumenta el consumo miocárdico de oxígeno. El objetivo fundamental del tratamiento perioperatorio con bloqueadores beta es la reducción del consumo miocárdico de oxígeno mediante la reducción de la frecuencia cardiaca, lo cual resulta en una prolongación del llenado diastólico y en una menor contractilidad miocárdica ${ }^{72}$. Otros factores cardioprotectores que ofrece son la redistribución del flujo coronario al subendocardio, la estabilización de la placa y un aumento del umbral de la fibrilación ventricular $^{72}$. En varios estudios aleatorizados se ha demostrado que el uso de bloqueadores beta y otros fármacos reductores de la frecuencia cardiaca puede reducir la isquemia miocárdica perioperatoria, determinada por la monitorización continua del segmento $\mathrm{ST}^{73}$. Sin embargo, sólo puede establecerse el beneficio clínico de este tratamiento mediante ensayos clínicos que analicen la incidencia de eventos cardiovasculares. Hasta la fecha se han publicado siete estudios en los que se evaluó el efecto de la administración perioperatoria de bloqueadores beta

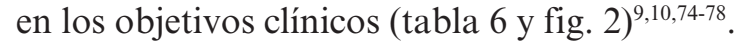

Tres estudios se centraron en una población con alto riesgo de complicaciones perioperatorias asociadas al tipo de cirugía, la presencia de cardiopatía isquémica $\mathrm{u}$ otros factores de riesgo de complicaciones cardiacas perioperatorias ${ }^{9,76,78}$. En otros tres estudios, la presencia de factores clínicos de riesgo no era un requisito, excepto la diabetes mellitus en uno de ellos ${ }^{74,75,77}$. En el estudio POISE se incluyó a pacientes con un amplio espectro de riesgo de complicaciones cardiacas perioperatorias ${ }^{10}$.

En el primer estudio se incluyó de forma aleatorizada a 200 pacientes con al menos dos factores de riesgo de cardiopatía isquémica o con cardiopatía isquémica conocida, programados para procedimientos quirúrgicos no cardiacos con anestesia general, entre los que se incluía un $40 \%$ de intervenciones quirúrgicas vasculares mayores ${ }^{76}$. El uso de atenolol se asoció a una reducción significativa de 


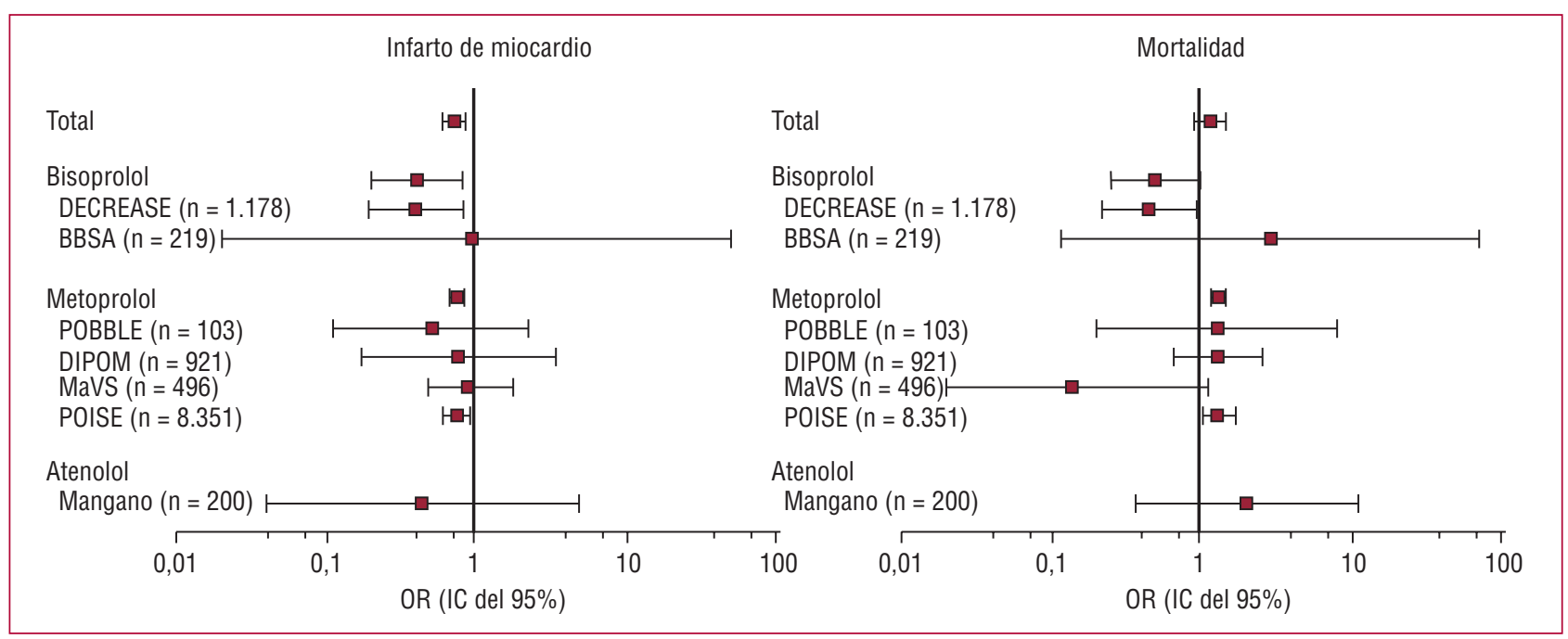

Fig. 2. Efecto de los bloqueadores beta en las tasas de infarto de miocardio no fatal y mortalidad por todas las causas a los 30 días según siete ensayos clínicos aleatorizados. Nota: en el estudio de Mangano et al la mortalidad se evaluó a los 6 meses. IC: intervalo de confianza. OR: odds ratio.

la mortalidad total y a un aumento de la supervivencia libre de eventos a los 6 meses; este beneficio se mantuvo durante 2 años. El estudio DECREASE (Dutch Echographic Cardiac Risk Evaluating Applying Stress Echo) incluyó a 112 pacientes, seleccionados entre 1.453 pacientes de cirugía vascular, en los que se combinaban al menos un factor clínico de riesgo y EED positiva, y excluyó a los pacientes con un alto grado de afección de la movilidad de la pared ${ }^{9}$. Los pacientes fueron asignados de forma aleatoria a cuidados convencionales o tratamiento con bisoprolol, instaurado 1 semana antes de la cirugía y con ajuste de la dosis según la frecuencia cardiaca. Los resultados mostraron una reducción del $89 \%$ de la mortalidad cardiaca y/o IM en el grupo asignado a bisoprolol (el 3,4 frente al $34 \% ; \mathrm{p}<0,001)$. El tratamiento se mantuvo durante 3 años.

El estudio POBBLE (PeriOperative BetaBlockadE Trial) incluyó a 103 pacientes con bajo riesgo sometidos a cirugía vascular infrarrenal electiva, que fueron asignados de forma aleatoria a tartrato de metoprolol o placebo ${ }^{74}$. No se observaron diferencias en la incidencia de muerte, IM o accidente cerebrovascular entre los dos grupos (el 13 y el $15 \%$, respectivamente; $\mathrm{p}=0,78$ ). Todos los pacientes presentaban bajo riesgo cardiaco, ya que quedaron excluidos los pacientes con historia de IM en los últimos 2 años. En el estudio MaVS (Metoprolol after Vascular Surgery Trial), 497 pacientes programados para cirugía vascular abdominal o infrainguinal fueron asignados a tratamiento con succinato de metoprolol o placebo ${ }^{77}$. No se observaron diferencias en el objetivo compuesto de muerte, IM, insuficiencia cardiaca, arritmias o accidente cerebrovascular a los 30 días entre los dos grupos (el 10,2 y el 12\%, respectivamente; $\mathrm{p}=0,57$ ).
El índice Lee fue $\leq 2$ en el $90 \%$ de los pacientes $y \leq 1$ en el $60 \%$.

En el estudio DIPOM (Diabetes Postoperative Mortality and Morbidity Trial) se seleccionó a 921 pacientes con diabetes mellitus, edad $>39$ años y duración de la cirugía $>1$ h (el 39\% de cirugía de bajo riesgo $)^{75}$. Los pacientes fueron asignados de forma aleatoria a tratamiento con succinato de metoprolol o placebo. No se observaron diferencias en el objetivo compuesto de muerte, IM, angina inestable o insuficiencia cardiaca a los 30 días entre ambos grupos (el 6 y el 5\%, respectivamente; $\mathrm{p}=0,66)$. Sin embargo, sólo el $54 \%$ de los pacientes sometidos a cirugía de riesgo intermedio o alto tenía una historia de cardiopatía isquémica u otro factor de riesgo cardiaco adicional.

En el estudio POISE, 8.351 pacientes fueron asignados de forma aleatoria a tratamiento con succinato de metoprolol o placebo ${ }^{10}$. Los criterios de inclusión fueron la edad $\geq 45$ años, tener enfermedad cardiovascular conocida, tener al menos tres de siete factores clínicos de riesgo o estar programado para cirugía vascular mayor. El tratamiento consistía en $100 \mathrm{mg}$ de succinato de metoprolol 2-4 h antes del procedimiento y $100 \mathrm{mg}$ durante las primeras $6 \mathrm{~h}$ tras la cirugía; la administración se interrumpía en caso de un descenso de la presión sistólica a menos de $100 \mathrm{mmHg}$. El tratamiento de mantenimiento se iniciaba $12 \mathrm{~h}$ más tarde, llegando a una dosis de $400 \mathrm{mg}$ de succinato de metoprolol en las primeras $24 \mathrm{~h}$, al menos en algunos pacientes. La reducción del objetivo compuesto de muerte, IM o parada cardiaca no fatal a los 30 días fue del 17\% (el 5,8 frente al 6,9\%; $p=0,04$ ). Sin embargo, la reducción del $30 \%$ en el IM no fatal (el 3,6 frente al $5,1 \% ; \mathrm{p}<0,001)$ fue superada por un aumento del $33 \%$ en la mortalidad total (el 3,1 frente al 2,3\%; 
TABLA 7. Metaanálisis sobre el efecto perioperatorio de los bloqueadores beta en la cirugía no cardiaca; mortalidad por todas las causas y mortalidad cardiovascular ${ }^{95}$

\begin{tabular}{|c|c|c|c|c|c|c|c|c|c|c|}
\hline & \multicolumn{5}{|c|}{ Mortalidad por todas las causas } & \multicolumn{5}{|c|}{ Mortalidad cardiovascular } \\
\hline & $\mathbf{n}$ & $\begin{array}{c}\text { Muertes, } \\
\text { n (\%) }\end{array}$ & $\begin{array}{c}\text { OR } \\
\text { (IC del 95\%) }\end{array}$ & $\begin{array}{l}\text { Homogeneidad } \\
\text { de OR, } p\end{array}$ & $\begin{array}{l}\text { Beneficio } \\
\text { por } 1.000 \text {, } \\
\text { media } \pm \text { DE }\end{array}$ & $\mathbf{n}$ & $\begin{array}{l}\text { Muertes, } \\
\text { n (\%) }\end{array}$ & $\begin{array}{c}\text { OR } \\
\text { (IC del 95\%) }\end{array}$ & $\begin{array}{l}\text { Homogeneidad } \\
\text { de OR, p }\end{array}$ & $\begin{array}{l}\text { Beneficio } \\
\text { por 1.000, } \\
\text { media } \pm \text { DE }\end{array}$ \\
\hline \multicolumn{11}{|l|}{ POISE } \\
\hline Bloqueador beta & 4.174 & $129(3,1)$ & $1,34(1,03-1,75)$ & 0,027 & $-7,7 \pm 3,6$ & 4.174 & $75(1,8)$ & $1,30(0,92-1,84)$ & 0,086 & $-4,1 \pm 2,7$ \\
\hline Control & 4.177 & $97(2,3)$ & & & & 4.177 & $58(1,4)$ & & & \\
\hline \multicolumn{11}{|l|}{ Otros estudios } \\
\hline Bloqueador beta & 1.896 & $36(1,9)$ & $0,74(0,47-1,17)$ & & $6,4 \pm 5$ & 1.866 & $18(1)$ & $0,70(0,37-1,31)$ & & $4,1 \pm 3,7$ \\
\hline Control & 1.615 & $41(2,5)$ & & & & 1.598 & $22(1,4)$ & & & \\
\hline \multicolumn{11}{|c|}{ Ictus documentados en estudios distintos del POISE } \\
\hline Bloqueador beta & 1.536 & $31(2)$ & $1,01(0,60-1,69)$ & 0,017 & $-0,1 \pm 5,2$ & 1.536 & $16(1)$ & $1,08(0,52-2,25)$ & 0,021 & $-0,8 \pm 3,7$ \\
\hline Control & 1.346 & $27(2)$ & & & & 1.346 & $13(1)$ & & & \\
\hline \multicolumn{11}{|c|}{ Ictus no documentados en estudios distintos del POISE } \\
\hline Bloqueador beta & 360 & $5(1,4)$ & $0,26(0,09-0,72)$ & & $38,2 \pm 14,9$ & 330 & $2(0,6)$ & $0,16(0,04-0,77)$ & & $29,7 \pm 12,4$ \\
\hline Control & 269 & $14(5,2)$ & & & & 252 & $9(3,6)$ & & & \\
\hline
\end{tabular}

DE: desviación estándar; IC: intervalo de confianza; OR: odds ratio.

$\mathrm{p}=0,03)$ y por la duplicación de la tasa de accidentes cerebrovasculares (el 1 frente al $0,5 \%$; $p=0,005)$. La hipotensión fue más frecuente en los pacientes tratados con metoprolol (el 15 frente al $9,7 \% ; \mathrm{p}<0,0001)$. El análisis posterior mostró que la hipotensión presentó el mayor riesgo de muerte y accidente cerebrovascular atribuible a la población.

En siete metaanálisis se analizaron 5, 11, 6, 15, 8, 22 y 33 ensayos clínicos publicados sobre el uso perioperatorio de bloqueadores beta, con un total de $586,866,632,1.077,2.437,2.057$ y 12.306 pacientes, respectivamente ${ }^{79-85}$. En cinco metaanálisis se observó una reducción significativa de isquemia miocárdica e IM perioperatorios en los pacientes tratados con bloqueadores beta ${ }^{79-83}$. Otros metaanálisis coincidieron también en la reducción de la isquemia miocárdica y el IM perioperatorios, además de observarse una reducción en la mortalidad cardiaca en pacientes tratados con bloqueadores beta ${ }^{84,85}$. La reducción del riesgo fue más marcada en los pacientes con alto riesgo. El metaanálisis más reciente concluyó que el uso de bloqueadores beta resultó en 16 IM no fatales menos cada 1.000 pacientes tratados, a costa de 3 accidentes cerebrovasculares no fatales discapacitantes y 3 complicaciones fatales (posiblemente) cardiacas o no cardiacas ${ }^{83}$.

Sin embargo, hay que mencionar que el estudio POISE, recientemente publicado, es el más representado en todos los metaanálisis. De hecho, aproximadamente el $80 \%$ de las muertes, IM y accidentes cerebrovasculares del último metaanálisis citado derivan del estudio POISE, cifra que asciende al $84 \%$ en los estudios denominados de bajo riesgo.
Por ello es necesario un análisis más detallado en el que se comparen los resultados del estudio POISE y de los demás estudios (tabla 7). En primer lugar, en el estudio POISE, la mortalidad por todas las causas aumentó en un $34 \%$ en los pacientes tratados con bloqueadores beta, mientras que en el resto de los estudios se observó una tendencia a la reducción de la mortalidad cardiovascular y por todas las causas en los pacientes tratados con bloqueadores beta, aunque dicha reducción no fue estadísticamente significativa. La discrepancia en el efecto del tratamiento parece estar relacionada con la alta mortalidad de los pacientes tratados con bloqueadores beta del estudio POISE (el 3,1 frente al 1,9\% en el resto de los estudios), y no por la diferencia en los resultados de los grupos de control (el 2,3 frente al 2,5\%). Por lo tanto, sería necesario comprender la causa y el momento de las muertes ocurridas en el estudio POISE. La muerte perioperatoria de los pacientes del estudio POISE asignados a tratamiento con succinato de metoprolol estuvieron asociadas a hipotensión, bradicardia y accidentes cerebrovasculares perioperatorios. Una historia de enfermedad cerebrovascular se asoció a un aumento de riesgo de accidente cerebrovascular. La hipotensión puede relacionarse con el uso de dosis altas de metoprolol sin ajuste de la dosis. Se considera que $200 \mathrm{mg}$ de metoprolol tienen, aproximadamente, el mismo efecto bloqueador que $100 \mathrm{mg}$ de atenolol y $10 \mathrm{mg}$ de bisoprolol.

Las discrepancias en el efecto protector de los bloqueadores beta pueden explicarse por las diferencias en las características de los pacientes, el tipo 
de cirugía y la modalidad de tratamiento (instauración, duración, ajuste de la dosis y tipo de fármaco). Además, estos hallazgos reflejan también la dificultad de incluir datos de estudios que no fueron diseñados para evaluar el riesgo cardiaco perioperatorio o estudios en los que se utilizaba una única dosis de bloqueador beta antes de la anestesia, sin continuidad tras la cirugía ${ }^{84}$. Un metaanálisis reciente indica que la mayoría de las diferencias entre los distintos estudios sobre el efecto cardioprotector de los bloqueadores beta puede atribuirse a la variabilidad de la respuesta de la frecuencia cardiaca ${ }^{86}$. Más concretamente, la reducción del IM postoperatorio fue muy significativa en los estudios con estrecho control de la frecuencia cardiaca.

$\mathrm{Si}$ bien los datos de estudios observacionales deben interpretarse con precaución, éstos nos proporcionan elementos adicionales para una mejor comprensión de la interacción entre la estratificación del riesgo y el tratamiento perioperatorio con bloqueadores beta.

En un estudio prospectivo sobre una cohorte de 1.351 pacientes sometidos a cirugía vascular, 360 pacientes $(27 \%)$ recibieron tratamiento con bloqueadores beta ${ }^{63}$. Del total de la población del estudio, el $83 \%$ presentaba menos de tres factores clínicos de riesgo. Estos pacientes tuvieron un menor riesgo de muerte e IM al recibir tratamiento con bloqueadores beta $(0,8 \%)$, frente a los pacientes $\sin$ tratar $(2,3 \%)$. En el $17 \%$ de los pacientes con tres o más factores de riesgo, el riesgo de muerte o IM se redujo con el uso de bloqueadores beta del 5,8 al $2 \%$ en ausencia de isquemia inducida y del 33 al $2,8 \%$ en presencia de isquemia limitada inducida por estrés (1-4 segmentos miocárdicos). Los pacientes con isquemia extensa inducida por estrés ( $\geq 5 / 16$ segmentos miocárdicos) presentaron un riesgo particularmente elevado de muerte o IM, independientemente del tratamiento utilizado (el 33\% con bloqueadores beta y el $36 \%$ sin tratamiento). En un estudio retrospectivo se analizó una cohorte muy extensa extraída de una base de datos sobre la calidad de la atención médica en la que se incluyó a 663.635 pacientes que fueron sometidos a cirugía no cardiaca (el 30\% de cirugía de alto riesgo) ${ }^{87}$. La diferencia en la mortalidad intrahospitalaria entre 119.632 pacientes tratados con bloqueadores beta y 216.220 pacientes con características comparables que no recibieron dicho tratamiento no fue significativa (el 2,3 frente al 2,4\%, respectivamente; $\mathrm{p}=0,68)$. Sin embargo, hubo diferencias importantes según el perfil de riesgo. El uso de bloqueadores beta se asoció a una reducción significativa de la mortalidad cuando el índice Lee fue $\geq 3$. No se observaron diferencias significativas para los índices Lee 1 o 2. La mortalidad aumentó en el grupo con riesgo más bajo (índice Lee $=0$ ).
Los estudios aleatorizados con pacientes de alto riesgo, las cohortes de estudios y los metaanálisis proporcionan evidencia convincente sobre la reducción de la mortalidad cardiaca y el IM mediante la administración de bloqueadores beta en pacientes con factores clínicos de riesgo que van a ser sometidos a cirugía de alto riesgo (fundamentalmente vascular). En estos pacientes, el tratamiento perioperatorio con bloqueadores beta es coste-efectivo. Sin embargo, los pacientes con isquemia extensa documentada por pruebas de estrés tienen un riesgo particularmente alto de complicaciones cardiacas perioperatorias a pesar del tratamiento con bloqueadores beta.

Por otra parte, los estudios aleatorizados que incluyen a pacientes con bajo riesgo y las cohortes de estudios indican que el tratamiento perioperatorio con bloqueadores beta no disminuye el riesgo de complicaciones cardiacas en los pacientes sin factores clínicos de riesgo. Los resultados de un estudio retrospectivo ${ }^{87}$ y del estudio POISE ${ }^{10}$ indican la posibilidad de efectos perjudiciales en cuanto a la mortalidad. La bradicardia y la hipotensión pueden perjudicar a los pacientes con aterosclerosis y favorecer un accidente cerebrovascular.

No se justifica la exposición de los pacientes con bajo riesgo a los efectos secundarios potenciales si no hay beneficios probados. Esta cuestión sigue siendo motivo de debate en cuanto a los pacientes en riesgo intermedio, es decir, pacientes con uno o dos factores clínicos de riesgo. Los resultados del estudio DECREASE IV indican que se debe utilizar bloqueadores beta en pacientes programados para cirugía de riesgo intermedio ${ }^{88}$. En este estudio, los pacientes asignados a tratamiento con bisoprolol $(\mathrm{n}=533)$ tuvieron una menor incidencia del objetivo primario relativo a la eficacia que los pacientes del grupo de control (el 2,1 frente al 6\% de eventos; $\mathrm{HR}=0,34$; IC del 95\%, 0,17-0,67). En estudios observacionales se ha mostrado un aumento de la mortalidad tras la suspensión del tratamiento con bloqueadores beta en el periodo preoperatorio ${ }^{89,90}$. El tratamiento con bloqueadores beta debe continuarse si está indicado por la presencia de cardiopatía isquémica o arritmias. Si el tratamiento con bloqueadores beta está indicado por hipertensión, debido a la falta de evidencia del efecto cardioprotector de otros fármacos antihipertensivos, no se recomienda un cambio de tratamiento. No debe suspenderse el tratamiento con bloqueadores beta en los pacientes tratados por insuficiencia cardiaca estable secundaria a disfunción sistólica del VI. En caso de insuficiencia cardiaca descompensada, podría ser necesario reducir o suspender temporalmente el tratamiento con bloqueadores beta ${ }^{91}$. Al objeto de optimizar el tratamiento farmacológico y estabilizar el estado del paciente, siempre que sea 


\section{Recomendaciones sobre el uso de bloqueadores beta $^{\mathrm{a}}$}

\begin{tabular}{|c|c|c|}
\hline Recomendación & Clase $^{b}$ & Nivel $^{c}$ \\
\hline $\begin{array}{l}\text { Se recomienda el uso de bloqueadores beta en } \\
\text { pacientes con cardiopatía isquémica conocida } \\
0 \text { isquemia miocárdica documentada en pruebas } \\
\text { de estrés preoperatorias }^{\mathrm{a}}\end{array}$ & I & B \\
\hline $\begin{array}{l}\text { Se recomienda el uso de bloqueadores beta en } \\
\text { pacientes programados para cirugía de alto riesgo }{ }^{\mathrm{a}}\end{array}$ & I & B \\
\hline $\begin{array}{l}\text { Se recomienda continuar el tratamiento con } \\
\text { bloqueadores beta en pacientes previamente } \\
\text { tratados con ellos por cardiopatía isquémica, } \\
\text { arritmias o hipertensión }\end{array}$ & I & C \\
\hline $\begin{array}{l}\text { Puede considerarse el uso de bloqueadores beta } \\
\text { en pacientes programados para cirugía } \\
\text { de riesgo intermedio }{ }^{\mathrm{a}}\end{array}$ & Ila & B \\
\hline $\begin{array}{l}\text { Debe considerarse la continuación del tratamiento } \\
\text { con bloqueadores beta en pacientes tratados } \\
\text { previamente con ellos por insuficiencia cardiaca } \\
\text { crónica con disfunción sistólica }\end{array}$ & Ilb & C \\
\hline $\begin{array}{l}\text { Puede considerarse el uso de bloqueadores beta } \\
\text { en pacientes con uno o más factores de riesgo } \\
\text { que están programados para cirugía de bajo riesgo }\end{array}$ & Ilb & B \\
\hline $\begin{array}{l}\text { No se recomienda la administración perioperatoria } \\
\text { de altas dosis de bloqueadores beta sin ajuste } \\
\text { previo de la dosis }\end{array}$ & III & $A$ \\
\hline $\begin{array}{l}\text { No se recomienda el uso de bloqueadores beta } \\
\text { en pacientes sin factores de riesgo que están } \\
\text { programados para cirugía de bajo riesgo }\end{array}$ & III & B \\
\hline
\end{tabular}

${ }^{a} E$ I tratamiento debe iniciarse preferiblemente entre 30 días y 1 semana antes de la cirugía. Objetivos: frecuencia cardiaca, 60-70 lat/min; presión sistólica $>100 \mathrm{mmHg}$.

${ }^{\mathrm{b}}$ Clase de recomendación.

'Nivel de evidencia.

posible, deberá aplazarse la cirugía no cardiaca. Se deberá tener en cuenta las contraindicaciones del tratamiento con bloqueadores beta (asma, afección grave de la conducción, bradicardia e hipotensión sintomáticas). Los bloqueadores beta no están contraindicados en la claudicación intermitente; como se ha demostrado en estudios aleatorizados, el empeoramiento de los síntomas no es más frecuente ${ }^{92}$. En cuanto a los pacientes con enfermedad pulmonar obstructiva crónica (EPOC) programados para cirugía vascular, en un reciente estudio se demostró que el uso de bloqueadores beta cardioselectivos se asociaba a una reducción de la mortalidad $^{93}$. Si no hay contraindicaciones, la dosis de bloqueadores beta se aumentará hasta alcanzarse una frecuencia cardiaca de 60-70 lat $/ \mathrm{min}$. Es acon- sejable el uso de un bloqueador beta-1 selectivo sin actividad simpaticomimética intrínseca.

La iniciación del tratamiento y la elección de la dosis óptima están muy relacionadas. Se ha observado que en los pacientes con una frecuencia cardiaca más baja, la isquemia miocárdica mejora, se reduce la liberación de troponinas y mejoran los resultados a largo plazo ${ }^{94}$. Sin embargo, debe evitarse el desarrollo de bradicardia e hipotensión. Por ello el tratamiento no debe comenzar a dosis excesivamente altas. La dosis de bloqueadores beta debe aumentar gradualmente, lo cual implica que el tratamiento debe iniciarse idealmente entre 30 días y 1 semana, como mínimo, antes de la cirugía. Se recomienda instaurar el tratamiento con una dosis diaria de $2,5 \mathrm{mg}$ de bisoprolol o $50 \mathrm{mg}$ de succinato de metoprolol y ajustar la dosis antes de la cirugía hasta alcanzar una frecuencia cardiaca en reposo de 60-70 lat/min y una presión sistólica $>100 \mathrm{mmHg}$. La frecuencia cardiaca debe mantenerse en esos límites durante todo el periodo perioperatorio, con administración intravenosa cuando no sea posible la administración oral. La aparición de taquicardia postoperatoria puede estar más relacionada con el tratamiento de la enfermedad subyacente (hipovolemia, dolor, pérdida de sangre o infección) que con el aumento de la dosis de bloqueadores beta.

Los datos derivados de estudios aleatorizados no permiten establecer la duración óptima del tratamiento perioperatorio con bloqueadores beta. Sin embargo, la posibilidad de presentación de eventos cardiacos tardíos puede justificar la continuación del tratamiento durante varios meses. En pacientes con una prueba de estrés positiva antes de la cirugía, el tratamiento debe mantenerse indefinidamente. Las nuevas estrategias de cardioprotección recomiendan el uso de bloqueadores beta-1 selectivos sin actividad simpaticomimética intrínseca y con una vida media larga (como bisoprolol).

\section{Estatinas}

Por su efecto hipolipemiante, el tratamiento con estatinas (inhibidores de la HMGCoA reductasa) es de uso generalizado en pacientes con riesgo de cardiopatía isquémica. Los pacientes con aterosclerosis no coronaria (carotídea, periférica, aórtica, renal) deben recibir tratamiento con estatinas como prevención secundaria, independientemente de la cirugía ${ }^{96}$. Las estatinas también favorecen la estabilización de la placa coronaria, al reducir la oxidación lipídica, la inflamación, la metaloproteinasa de la matriz y la muerte celular, y aumentan la inhibición tisular de la metaloproteinasa y del colágeno. El llamado efecto «no lipídico» o pleotrópico puede prevenir la rotura de la placa y el consecuente IM en el periodo perioperatorio ${ }^{97}$. 
En importantes estudios clínicos y observacionales se ha demostrado el efecto beneficioso de la administración perioperatoria de estatinas ${ }^{98,99}$. En el primer estudio aleatorizado, controlado y prospectivo, 100 pacientes programados para cirugía vascular fueron asignados a tratamiento con $20 \mathrm{mg}$ diarios de atorvastatina durante 45 días o placebo, independientemente de la concentración de colesterol sérico ${ }^{100}$. La cirugía vascular tuvo lugar, como promedio, a los 31 días y el seguimiento se prolongó durante 6 meses. En esos 6 meses, la atorvastatina redujo significativamente la incidencia de eventos cardiacos (el 8 frente al 26\%; p =0,03). Los resultados de un metaanálisis que incluía a 223.010 pacientes de 12 estudios retrospectivos y 3 estudios prospectivos mostraron que las estatinas reducen significativamente la mortalidad, un $44 \%$ en pacientes de cirugía no cardiaca y un $59 \%$ en pacientes de cirugía vascular ${ }^{98}$. El estudio aleatorizado y controlado más reciente es el DECREASE III. Un total de 497 pacientes fueron asignados a fluvastatina de liberación lenta $(80 \mathrm{mg} /$ día $)$ o placebo, iniciándose el tratamiento 37 días antes de la intervención. La incidencia de isquemia miocárdica en los pacientes tratados con fluvastatina fue del $10,8 \%$, frente al $19 \%$ del grupo placebo $(\mathrm{OR}=0,55$; IC del $95 \%$, 0,34-0,88). La incidencia de muerte cardiaca o IM en los dos grupos de estudio fue del 4,8 y el $10,2 \%$, respectivamente $(\mathrm{OR}=0,47$; IC del 95\%, 0,24$0,94)^{101}$.

Una cuestión preocupante del uso perioperatorio de estatinas es el riesgo de miopatía y rabdomiolisis inducidas por las estatinas. En el periodo perioperatorio, los factores que aumentan este riesgo son numerosos, entre ellos, una función renal afectada tras la cirugía mayor y el uso de múltiples fármacos durante la anestesia. Además, la administración de analgésicos y el dolor postoperatorio pueden enmascarar los signos de miopatía. Si no se detecta la miopatía inducida y se continúa el tratamiento con estatinas, hay riesgo de rabdomiolisis e insuficiencia renal aguda. En relación con este tema, no se dispone de datos de estudios clínicos, a excepción de algunos casos publicados. En un estudio retrospectivo con 981 pacientes consecutivos de cirugía vascular, no se observó ningún caso de rabdomiolisis ni un aumento significativo de las cifras de creatincinasa o de la incidencia de miopatía en los pacientes tratados con estatinas ${ }^{102}$.

Recientemente se ha señalado que la interrupción del tratamiento con estatinas puede producir un efecto rebote y ser desventajosa ${ }^{99,103}$. Una limitación potencial del tratamiento perioperatorio con estatinas es la falta de una formulación intravenosa.

Por ello se recomienda el uso de estatinas de vida media larga o de liberación lenta, como rosuvastatina, atorvastatina y fluvastatina de liberación lenta, que permiten prolongar el efecto del fármaco durante el periodo inmediatamente posterior a la cirugía, cuando la administración oral no es posible.

\section{Recomendaciones sobre el uso de estatinas}

\begin{tabular}{lcc}
\hline Recomendación & Clase $^{\mathbf{a}}$ & Nivel $^{\mathbf{b}}$ \\
\hline $\begin{array}{l}\text { Se recomienda que el tratamiento con estatinas } \\
\text { se inicie preferiblemente } 1 \text { mes o al menos }\end{array}$ & I & B \\
1 semana antes de la cirugía & & \\
$\begin{array}{l}\text { Se recomienda mantener el tratamiento con estatinas } \\
\text { durante el periodo perioperatorio }\end{array}$ & । & C \\
\hline
\end{tabular}

aClase de recomendación.

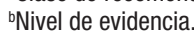

\section{Nitratos}

El efecto de la nitroglicerina en la reversión de la isquemia miocárdica es bien conocido. Un pequeño estudio con grupo control demostró una reducción de la isquemia miocárdica perioperatoria en pacientes con angina estable a los que se administró nitroglicerina intravenosa durante la cirugía no cardiaca $^{104}$. Sin embargo, no se observó ningún efecto en la incidencia de IM o muerte cardiaca. Estos hallazgos se confirmaron en otro estudio similar en el que tampoco se observaron cambios en la incidencia de isquemia miocárdica, IM o muerte cardiaca $^{105}$. Por otra parte, el uso perioperatorio de nitroglicerina podría suponer un riesgo hemodinámico significativo para los pacientes. La reducción de la precarga puede desembocar en taquicardia e hipotensión.

\section{Recomendaciones sobre el uso de nitratos}

\begin{tabular}{lcc}
\hline Recomendación & Clase $^{\mathrm{a}}$ & Nivel $^{\mathrm{b}}$ \\
\hline $\begin{array}{l}\text { Puede considerarse la administración perioperatoria } \\
\text { de nitroglicerina para la prevención de eventos }\end{array}$ & $\mathrm{llb}$ & $\mathrm{B}$ \\
isquémicos adversos & & \\
\hline
\end{tabular}

${ }^{a}$ Clase de recomendación.

bNivel de evidencia.

\section{Inhibidores de la enzima de conversión de angiotensina}

Independientemente de su efecto reductor de la presión sanguínea, los inhibidores de la enzima de conversión de angiotensina (IECA) preservan la función orgánica. Este efecto mejora la función endotelial y las propiedades antiinflamatorias e interfiere directamente en el proceso de la aterogénesis ${ }^{106}$. El efecto inhibidor de los IECA previene eventos asociados a la isquemia miocárdica y a la función del VI. Por lo tanto, parece razonable se- 
ñalar que el tratamiento perioperatorio con IECA puede tener efectos beneficiosos en la evolución postoperatoria.

El estudio QUO VADIS comparó el efecto del quinaprilo (IECA) con placebo en pacientes programados para cirugía cardiaca. El tratamiento con quinaprilo se inició 4 semanas antes de la cirugía electiva y se mantuvo durante 1 año ${ }^{107}$. El estudio demostró una reducción significativa de los eventos cardiovasculares postoperatorios en el grupo de pacientes tratados con quinaprilo ( $\mathrm{HR}=0,23$; IC del $95 \%, 0,06-0,87)$. Sin embargo, el efecto beneficioso observado en el estudio QUO VADIS podría ser resultado del tratamiento postoperatorio. En una revisión recientemente publicada se aportan datos conflictivos sobre el uso de IECA tras la cirugía cardiaca $^{108}$.

Por otra parte, el uso perioperatorio de IECA comporta un riesgo de hipotensión grave durante la anestesia, especialmente si se han administrado bloqueadores beta. La hipotensión es menos frecuente cuando se interrumpe la administración de IECA 1 día antes de la cirugía. Aunque este tema sigue siendo motivo de debate, se considerará suspender los IECA $24 \mathrm{~h}$ antes de la cirugía si el tratamiento fue indicado para la hipertensión y reiniciar el tratamiento cuando se estabilice el volumen. El riesgo de hipotensión es similar con el uso de bloqueadores de los receptores de la angiotensina (BRA) que con los IECA, y la respuesta a los vasopresores puede quedar afectada. En pacientes con disfunción sistólica del VI y un estado clínico estable, parece razonable continuar el tratamiento con IECA durante el periodo perioperatorio bajo estrecha vigi-

\section{Recomendaciones sobre el uso de inhibidores de la enzima de conversión de angiotensina}

\begin{tabular}{|c|c|c|}
\hline Recomendación & Clase $^{\mathrm{a}}$ & Nivel $^{b}$ \\
\hline $\begin{array}{l}\text { Se recomienda la continuación del tratamiento } \\
\text { con IECA durante la cirugía no cardiaca en pacientes } \\
\text { estables con disfunción sistólica del VI }\end{array}$ & I & C \\
\hline $\begin{array}{l}\text { Se recomienda el uso de IECA en pacientes estables } \\
\text { con disfunción sistólica del VI que están programados } \\
\text { para cirugía de alto riesgo }\end{array}$ & I & C \\
\hline $\begin{array}{l}\text { Debe considerarse el uso de IECA en pacientes estables } \\
\text { con disfunción sistólica del VI que están programados } \\
\text { para cirugía de riesgo intermedio-bajo }\end{array}$ & Ila & C \\
\hline $\begin{array}{l}\text { Debe considerarse la suspensión temporal del tratamient } \\
\text { con IECA antes de la cirugía no cardiaca en pacientes } \\
\text { hipertensos }\end{array}$ & & C \\
\hline
\end{tabular}

lancia. Cuando se descubre una disfunción del VI durante la evaluación preoperatoria en pacientes sin tratar, se recomienda el aplazamiento de la intervención, siempre que sea posible, para iniciarse el tratamiento con IECA y bloqueadores beta, como se recomienda en las guías de práctica clínica de la ESC sobre insuficiencia cardiaca ${ }^{91}$.

\section{Bloqueadores de los canales de calcio}

Por su efecto en el balance entre aporte y demanda miocárdica de oxígeno, los bloqueadores de los canales de calcio parecen adecuados, teóricamente, para una estrategia de reducción del riesgo. Es preciso distinguir entre las dihidropiridinas, que no actúan directamente en la frecuencia cardiaca, y el diltiazem o el verapamilo, que son reductores de la frecuencia cardiaca.

La importancia de los estudios aleatorizados sobre el efecto perioperatorio de los bloqueadores de los canales de calcio está limitada por su pequeño tamaño y por carecer de una estratificación del riesgo y de una evaluación sistemática de la muerte cardiaca y el infarto de miocardio. En un metaanálisis se analizaron los datos de 11 estudios aleatorizados con un total de 1.007 pacientes. Todos los pacientes sometidos a cirugía no cardiaca recibían tratamiento con bloqueadores de los canales de calcio (diltiazem en siete estudios, verapamilo en dos y nifedipino en uno; otro estudio tenía tres brazos: diltiazem, nifedipino y grupo control) ${ }^{109}$. El análisis conjunto de los datos de los pacientes tratados con bloqueadores de los canales de calcio mostró una reducción del número de episodios de isquemia miocárdica y taquicardia supraventricular. Sin embargo, la reducción de la mortalidad y el IM sólo era estadísticamente significativa en el

\section{Recomendaciones sobre el uso de bloqueadores de los canales de calcio}

\begin{tabular}{lcc}
\hline Recomendación & Clase $^{\mathbf{a}}$ & Nivel $^{\text {b }}$ \\
\hline Se recomienda continuar el tratamiento con & I & C \\
bloqueadores de los canales de calcio durante & & \\
la cirugía no cardiaca en pacientes con angina & \\
de pecho tipo Prinzmetal &
\end{tabular}

Puede considerarse el uso de bloqueadores de los Illb C canales de calcio reductores de la frecuencia cardiaca (particularmente diltiazem) antes de la cirugía no cardiaca en pacientes con contraindicaciones para bloqueadores beta

No se recomienda el uso sistemático de bloqueadores III C de los canales de calcio para reducir el riesgo de complicaciones cardiovasculares perioperatorias

aClase de recomendación.

'Nivel de evidencia. 
objetivo compuesto de muerte y/o IM ( $\mathrm{RR}=0,35$; IC del 95\%, 0,08-0,83; p = 0,02). El análisis de subgrupos favoreció el uso de diltiazem. Otro estudio, que incluía a 1.000 pacientes sometidos a cirugía de aneurisma aórtico (urgente o electiva), mostró que el uso de dihidropiridina se asoció de forma independiente a un aumento de la mortalidad perioperatoria ${ }^{110}$. Debe evitarse el uso de dihidropiridinas de acción corta, particularmente nifedipino en cápsulas. Por todo ello, si bien los bloqueadores de los canales de calcio reductores de la frecuencia cardiaca no están indicados en pacientes con insuficiencia cardiaca o disfunción ventricular, puede considerarse la instauración o continuación de tratamiento con estos fármacos en pacientes para los que los bloqueadores beta están contraindicados.

\section{Ivabradina}

La ivabradina es un inhibidor específico del marcapasos en el nódulo sinoauricular y es un reductor de la frecuencia cardiaca independiente de la activación simpática. No afecta a la presión arterial ni a la contractilidad miocárdica.

En un estudio aleatorizado que incluía a 111 pacientes de cirugía vascular, se demostró que tanto la ivabradina como el succinato de metoprolol reducen significativamente la incidencia de isquemia e IM, comparado con el grupo placebo. Estos hallazgos preliminares deben ser confirmados en futuros estudios; puede considerarse el uso de ivabradina en pacientes con contraindicaciones estrictas para los bloqueadores beta ${ }^{111}$.

\section{Agonistas de los receptores alfa-2}

Los agonistas de los receptores alfa-2 reducen el gasto de noradrenalina posganglionar $\mathrm{y}$, por lo tanto, pueden reducir la liberación de catecolaminas durante la cirugía. Un estudio europeo sobre el mivazerol incluyó a 1.897 pacientes con cardiopatía isquémica sometidos a cirugía no cardiaca de riesgo intermedio o alto ${ }^{112}$. El mivazerol no redujo la incidencia de mortalidad o IM en la población total del estudio. Sin embargo, se observó una reducción de muerte o IM postoperatorios en un subgrupo de 904 pacientes de cirugía vascular. En un estudio más reciente, que incluía a 190 pacientes con factores clínicos de riesgo o cardiopatía isquémica, se observó una reducción de la mortalidad a los 30 días y a los 2 años con el uso perioperatorio de clinidina ${ }^{113}$. Sin embargo, no se observó una reducción en la incidencia de IM. En un metaanálisis se analizaron los resultados de 23 ensayos controlados, de los que 10 incluían cirugía cardiaca; 8, cirugía vascular, y 3 , cirugía no vascular ${ }^{114}$. El uso pe-

\section{Recomendaciones sobre el uso de agonistas de los receptores alfa-2}

\begin{tabular}{lcc}
\hline Recomendación & Clase $^{\mathbf{a}}$ & Nivel $^{\mathbf{b}}$ \\
\hline Puede considerarse el uso de agonistas de los & $\mathrm{llb}$ & $\mathrm{B}$ \\
receptores alfa-2 para la reducción del riesgo & & \\
de complicaciones cardiovasculares perioperatorias & & \\
en pacientes de cirugía vascular & & \\
\hline
\end{tabular}

aClase de recomendación.

${ }^{b}$ Nivel de evidencia.

rioperatorio de agonistas de los receptores alfa-2 se asoció a una reducción de la mortalidad y del IM solamente en el subgrupo de cirugía vascular, mientras que en el subgrupo de cirugía no vascular no se observó este beneficio.

\section{Diuréticos}

El uso de diuréticos es frecuente en pacientes con hipertensión o insuficiencia cardiaca como entidades subyacentes. En la hipertensión, los diuréticos se utilizan normalmente a bajas dosis con un efecto reductor moderado de la presión arterial. Por lo general, el tratamiento de la hipertensión con diuréticos puede interrumpirse el mismo día de la intervención quirúrgica y reiniciarse por vía oral cuando sea posible. Cuando es necesario controlar la presión arterial antes de que se pueda administrar el tratamiento por vía oral, son preferibles otros fármacos antihipertensivos intravenosos. En la insuficiencia cardiaca se utilizan diuréticos a dosis altas. Debe considerarse el aumento de la dosis en caso de signos de retención de líquidos. Si hay riesgo de hipovolemia, hipotensión y alteraciones de los electrolitos, se considerará la reducción de la dosis. En términos generales, cuando el tratamiento diurético está indicado para el control de la insuficiencia cardiaca, puede mantenerse hasta el día de la cirugía y reiniciarse por vía oral cuando sea posible. Durante el periodo perioperatorio debe vigilarse estrechamente el volumen en los pacientes con insuficiencia cardiaca, y si fuera necesario controlar el exceso de volumen, pueden administrarse diuréticos de asa por vía intravenosa.

En cualquier paciente tratado con diuréticos debe considerarse la posibilidad de alteraciones de los electrolitos, ya que los diuréticos aumentan la excreción renal de potasio y magnesio. La incidencia de la hipopotasemia es del $34 \%$ en los pacientes sometidos a cirugía (fundamentalmente no cardiaca) ${ }^{115}$. La hipopotasemia aumenta significativamente el riesgo de taquicardia ventricular (TV) y fibrilación ventricular (FV) en pacientes con enfermedad cardiaca ${ }^{116}$. En un estudio que incluía a 688 pacientes con enfermedad cardiaca sometidos a cirugía no cardiaca, la hipopotasemia estuvo asociada de forma indepen- 
diente a la mortalidad perioperatoria ${ }^{117}$. Por otra parte, en otro estudio con 150 pacientes sometidos a cirugía no cardiaca no se observó un aumento de arritmias intraoperatorias asociadas a la hipopotasemia $^{115}$. Sin embargo, este estudio era pequeño y la mayoría de los pacientes no tenían evidencia de enfermedad cardiaca. Por otra parte, el efecto de los diuréticos ahorradores de magnesio y tiacídicos - es decir, antagonistas de la aldosterona (espironolactona y eplerenona) - en la reducción de la mortalidad en la insuficiencia cardiaca grave está claramente establecido ${ }^{118}$. Por norma general, la homeostasis del potasio y del magnesio debe evaluarse en el periodo preoperatorio. Debe prestarse especial atención a los pacientes tratados con diuréticos y a los propensos a las arritmias. Cualquier alteración de los electrolitos, especialmente la hipopotasemia y la hipomagnesemia, debe corregirse a su debido tiempo antes de la cirugía. Se darán recomendaciones dietéticas al paciente para aumentar la ingesta de potasio y magnesio; siempre que sea posible, deberá reducirse el uso de diuréticos, y son preferibles los diuréticos ahorradores de $\mathrm{K}$ y $\mathrm{Mg}$; también se pueden prescribir suplementos dietéticos. La repleción aguda preoperatoria en pacientes asintomáticos puede conllevar más riesgos que beneficios. Por lo tanto, la presencia de alteraciones leves y asintomáticas de los electrolitos no debe retrasar la cirugía urgente.

\section{Recomendaciones sobre el uso de diuréticos}

\begin{tabular}{lcc}
\hline Recomendación & Clase $^{\mathbf{a}}$ & Nivel $^{\mathbf{b}}$ \\
\hline $\begin{array}{l}\text { Se recomienda la corrección de las alteraciones } \\
\text { de los electrolitos antes de la cirugía }\end{array}$ & I & B \\
Se recomienda la interrupción del tratamiento & । & C \\
de diuréticos a bajas dosis en pacientes hipertensos & & \\
el mismo día de la cirugía y reinstaurar el tratamiento & & \\
oral lo antes posible & & C \\
En pacientes con insuficiencia cardiaca, se recomienda \\
continuar el tratamiento con diuréticos hasta el día \\
de la cirugía y seguir con administración intravenosa \\
hasta que se pueda volver a la administración \\
por vía oral
\end{tabular}

aClase de recomendación.

bNivel de evidencia.

\section{Aspirina}

Aunque la aspirina se utiliza de forma generalizada en pacientes con cardiopatía isquémica y, especialmente, tras la implantación de stents coronarios, la evidencia del uso de la aspirina en el contexto perioperatorio es escasa. En un ensayo controlado con 232 pacientes sometidos a endarterectomía carotídea, la aspirina se demostró eficaz en la prevención de accidentes cerebrovasculares intraoperatorios y postoperatorios, pero no se ob- servó ningún efecto en mortalidad o $\mathrm{IM}^{119}$. Un metaanálisis realizado en 2001 demostró una reducción de los eventos vasculares graves y de la muerte por causas vasculares en pacientes de cirugía vascular ${ }^{120}$. Este metaanálisis incluyó 10 ensayos clínicos sobre el tratamiento antiplaquetario en pacientes de cirugía de bypass en las extremidades inferiores, y en 6 de ellos se utilizaba la aspirina. El beneficio del tratamiento antiplaquetario no alcanzó significación estadística para el objetivo compuesto de eventos vasculares $(\mathrm{OR}=0,8 ; \mathrm{IC}$ del 95\%, 0,5-1,1) en esta población.

En muchos casos, el temor a las complicaciones hemorrágicas en el periodo perioperatorio llevó a la interrupción del tratamiento con aspirina. Un importante metaanálisis, que incluía 41 estudios con un total de 49.590 pacientes, en el que se comparaba la interrupción de la aspirina en el perioperatorio frente a los riesgos de hemorragia de la aspirina, concluyó que el riesgo de complicaciones hemorrágicas con aspirina aumentó en un $1,5 \%$, pero que la aspirina no causó complicaciones hemorrágicas más graves ${ }^{121}$. Una revisión sistemática de pacientes con riesgo o cardiopatía isquémica conocida demostró que el incumplimiento o la interrupción del tratamiento con aspirina se asociaban a un riesgo de eventos cardiacos graves 3 veces mayor $\left(\mathrm{OR}=3,14\right.$; IC del 95\%, 1,8-5,6) ${ }^{122}$. Sólo debe retirarse la aspirina si el riesgo de hemorragia supera los beneficios cardiacos potenciales. Antes de la cirugía menor o de procedimientos endoscópicos, debe considerarse detenidamente la retirada del tratamiento antitrombótico. En principio, y según la evaluación individualizada del riesgo-beneficio, normalmente no es necesario interrumpir el tratamiento antiplaquetario antes de los procedimientos mencionados. En pacientes tratados con agentes antiplaquetarios (aspirina, clopidogrel o ambos) y con hemorragia perioperatoria excesiva o potencialmente mortal, se recomienda la transfusión de plaquetas o la administración de otros agentes prohemostáticos.

\section{Recomendaciones sobre el uso de aspirina}

\begin{tabular}{lccc}
\hline Recomendación & Clase $^{\mathbf{a}}$ & Nivel $^{\mathbf{b}}$ \\
\hline $\begin{array}{l}\text { Debe considerarse la continuación del tratamiento con } \\
\text { aspirina en pacientes previamente tratados con este }\end{array}$ & Ila & B \\
fármado durante el periodo perioperatorio & & \\
Sólo se considerará la interrupción de la aspirina & Ila & B \\
en pacientes previamente tratados con este fármaco & & \\
en los que el control de la hemostasis durante & & \\
la cirugía presente dificultades & & \\
\hline
\end{tabular}

aClase de recomendación.

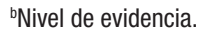

\section{Tratamiento anticoagulante}

El tratamiento anticoagulante se asocia a un aumento de hemorragias durante la cirugía no car- 
TABLA 8. Tratamiento puente de los VKA con HNF o HBPM en pacientes y procedimientos con riesgos alto y bajo

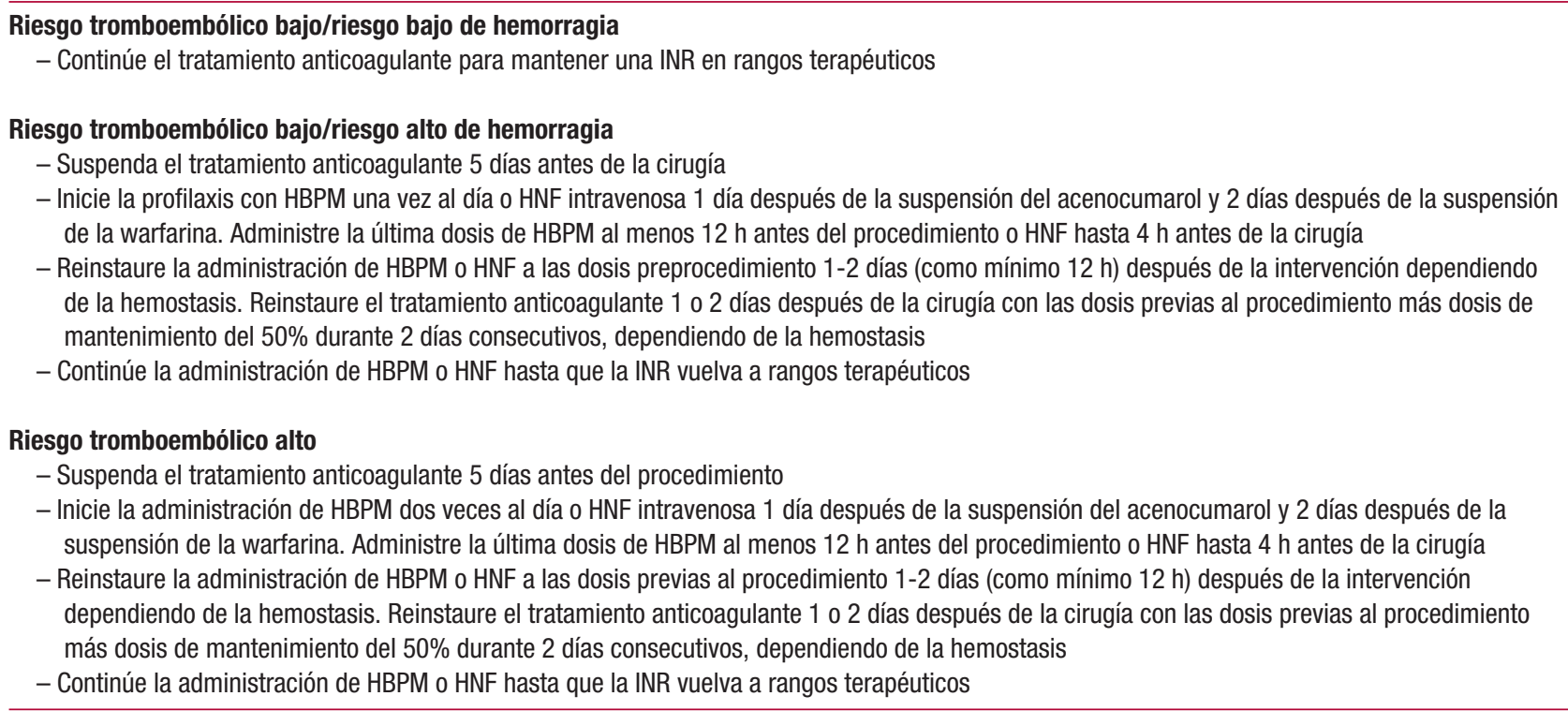

HBPM: heparina de bajo peso molecular; HNF: heparina no fraccionada; INR: razón internacional normalizada; VKA: antagonistas de la vitamina K.

TABLA 9. Protocolos para el tratamiento anticoagulante aplicados según el riesgo tromboembólico del paciente

\begin{tabular}{lccccc}
\hline & \multicolumn{2}{c}{ Pacientes con riesgo tromboembólico alto } & & \multicolumn{2}{c}{ Pacientes con riesgo tromboembólico bajo } \\
\cline { 1 - 2 } Peso (kg) & $\begin{array}{c}\text { Nadroparina } \\
\text { (dos veces al día, s.c.) (UI) }\end{array}$ & $\begin{array}{c}\text { Enoxaparina } \\
\text { (dos veces al día, s.c.) (UI) }\end{array}$ & & $\begin{array}{c}\text { Nadroparina } \\
\text { (una vez al día, s.c.) (UI) }\end{array}$ & $\begin{array}{c}\text { Enoxaparina } \\
\text { (Una vez al día, s.c.) (UI) }\end{array}$ \\
\hline$<50$ & 2.850 & 2.000 & 4.000 & 2.850 & 4.000 \\
$50-69$ & 3.800 & 6.000 & 3.800 & 4.000 \\
$70-89$ & 5.700 & 8.000 & & 5.700 & 4.000 \\
$90-110$ & 7.600 & 10.000 & 5.700 & 4.000 \\
$>110$ & 9.500 & 5.700 & 4.000 \\
\hline
\end{tabular}

HBPM: heparina de bajo peso molecular; HNF: heparina no fraccionada; s.c.: subcutánea.

diaca. En algunos pacientes, este riesgo es menor que los beneficios del tratamiento anticoagulante y, por lo tanto, debe mantenerse o modificarse, mientras que en pacientes con riesgo bajo de trombosis debe interrumpirse el tratamiento para minimizar las complicaciones de hemorragia.

Los pacientes que reciben tratamiento anticoagulante oral con antagonistas de la vitamina K (AVK) tienen un mayor riesgo de hemorragia peri y postoperatoria. Siempre que la razón internacional normalizada (INR) sea $<1,5$, puede realizarse la cirugía con seguridad (tabla 8). Sin embargo, en pacientes con riesgo tromboembólico alto, la interrupción de los AVK es peligrosa y es necesario un tratamiento puente con heparina no fraccionada (HNF) o heparina de bajo peso molecular (HBPM) a dosis terapéuticas, por vía intravenosa o subcutánea ${ }^{123-125}$. Los pacientes con fibrilación auricular (FA), prótesis valvular mecánica o biológica o reparación valvular mitral en los últimos 3 meses o tromboembolia venosa reciente $(<3$ meses) y trombofilia tienen un alto riesgo de complicaciones tromboembólicas. En la actualidad, el tratamiento puente más utilizado es la HBPM subcutánea en dosis terapéuticas. Para instaurar dicho tratamiento, se interrumpe la administración de AVK 5 días antes de la cirugía (es decir, 5 dosis); se inicia la administración de HBPM o HNF 1 día después de la retirada de acenocumarol y 2 días después de la retirada de warfarina. En los pacientes con riesgo tromboembólico alto, se recomienda la administración de $70 \mathrm{U} / \mathrm{kg}$ de antifactor Xa dos veces al día y una dosis profiláctica diaria en los pacientes con bajo riesgo (tabla 9) ${ }^{126}$. La última dosis de HBPM debe administrarse como mínimo $12 \mathrm{~h}$ antes del procedimiento. La HNF es más sólida y por ello, en algunos centros, se ingresa y se trata al paciente con HNF por vía intravenosa hasta $4 \mathrm{~h}$ antes de la cirugía y se reinicia el tratamiento tras la cirugía hasta que la INR alcance un rango terapéutico ${ }^{124}$. El día del procedimiento debe determinarse la INR.

Si la INR es $>1,5$, debe considerarse el aplazamiento de la intervención. El tratamiento con HBPM o HNF con la dosis preprocedimiento debe 
reiniciarse 1-2 días después de la intervención, dependiendo del estado hemostático del paciente, y como mínimo $12 \mathrm{~h}$ después del procedimiento. La anticoagulación oral debe reiniciarse 1-2 días después de la cirugía dependiendo del nivel de hemostasis (si el paciente puede tomarla por vía oral) con la dosis preoperatoria de mantenimiento además de una dosis de apoyo del $50 \%$ durante 2 días consecutivos; a partir de entonces se seguirá la dosis de mantenimiento. Se mantendrá la administración de HBPM o HNF hasta que la INR alcance niveles terapéuticos.

El tipo de cirugía es otro factor que tener en cuenta, ya que el riesgo de hemorragia varía considerablemente y afecta a la posibilidad de controlar la hemostasis. Los procedimientos de alto riesgo de hemorragia son aquellos en los que no se puede realizar compresión. En esos casos es necesaria la interrupción de los anticoagulantes orales y la instauración de tratamiento puente con HBPM. En pacientes programados para una cirugía de bajo riesgo de hemorragia (p. ej., una operación de cataratas), no es necesaria la modificación del tratamiento anticoagulante.

En pacientes tratados con AVK que requieren la reversión del efecto anticoagulante debido a una cirugía urgente, se recomienda la administración de una dosis baja $(2,5-5 \mathrm{mg})$ de vitamina $\mathrm{K}$ por vía oral o intravenosa. Para una reversión más inmediata del efecto anticoagulante de los AVK, se recomienda la administración de plasma fresco congelado u otro concentrado protrombina además de una dosis baja de vitamina $\mathrm{K}$ oral o intravenosa. Para los pacientes que reciben HNF y requieren la reversión del efecto anticoagulante debido a una intervención urgente, la suspensión del tratamiento es suficiente. El efecto anticoagulante de la HNF administrada en infusión alcanza la estabilidad a las 4-6 h. Por lo tanto, tras la suspensión de la infusión, la coagulación debería ser normal pasadas $4 \mathrm{~h}$. La HNF por vía subcutánea tiene un efecto anticoagulante más prolongado. Para la reversión inmediata de su efecto, el antídoto utilizado es el sulfato de protamina. No obstante, este fármaco podría originar una reacción anafiláctica con colapso cardiovascular, especialmente si la infusión es muy rápida. La dosis de sulfato de protamina puede calcularse según la heparina administrada en las últimas $2 \mathrm{~h}$. La dosis de sulfato de protamina para la reversión de la infusión de heparina es de $1 \mathrm{mg}$ cada $100 \mathrm{U}$ de heparina sódica. Si la infusión de heparina se interrumpió durante más de 30 min pero menos de $2 \mathrm{~h}$, se utiliza la mitad de la dosis de sulfato de protamina; si se interrumpió durante más de $2 \mathrm{~h}$ pero menos de $4 \mathrm{~h}$, se utiliza un cuarto de la dosis. La dosis máxima de sulfato de protamina es de $50 \mathrm{mg}$. En pacientes tratados con HBPM, el efecto anticoa- gulante puede revertirse en las $8 \mathrm{~h}$ posteriores a la última dosis, ya que su vida media es corta. En caso de requerirse una reversión inmediata, puede utilizarse sulfato de protamina intravenosa, aunque la actividad anti-Xa nunca se neutraliza completamente (máximo, 60-75\%).

En la tabla 8 se resumen las recomendaciones para minimizar la complicaciones tromboembólicas y hemorrágicas durante la cirugía.

\section{Revascularización}

El objetivo fundamental de la revascularización coronaria profiláctica es la prevención de un IM perioperatorio potencialmente mortal. Si bien la revascularización puede ser especialmente efectiva para el tratamiento de estenosis graves, no puede prevenir la rotura de placas vulnerables inducida por el estrés de la cirugía. Este mecanismo es la causa de al menos la mitad de los casos de IM perioperatorio mortal y podría explicar la falta de especificidad de las pruebas de estrés por técnicas de imagen para identificar las lesiones coronarias relacionadas con el infarto ${ }^{37,127}$.

Los pacientes que permanecen clínicamente estables durante los años posteriores a la cirugía de bypass aortocoronario (CABG) tienen menor riesgo de complicaciones cardiacas tras la cirugía no cardiaca. Los datos del registro CASS indican que esto puede aplicarse particularmente a los pacientes con enfermedad de triple vaso y/o la función del VI deprimida, incluso en el caso de cirugía de alto riesgo ${ }^{128}$. Por lo tanto, los pacientes sometidos a un CABG en los últimos 5 años pueden ser referidos a cirugía siempre que su estado clínico permanezca estable desde el último examen médico.

Los pacientes que han tenido una revascularización percutánea pueden presentar mayor riesgo de eventos cardiacos durante o después de la cirugía no cardiaca, especialmente en los casos de cirugía no programada o urgente tras la implantación coronaria de stents. La introducción de la angioplastia no tuvo como consecuencia un empeoramiento de los resultados quirúrgicos, incluso cuando la cirugía tenía lugar tan sólo 11 días después de dicha intervención coronaria percutánea (ICP) ${ }^{129}$. Sin embargo, a mediados de la década de los noventa, el desarrollo de la implantación de stents cambió la situación drásticamente y se han observado altas tasas de mortalidad (hasta el 20\%) asociadas a la trombosis aguda del stent en el momento de la cirugía, si ésta tenía lugar a las pocas semanas de la implantación y se suprimía el tratamiento antiplaquetario $^{130,131}$. Por este motivo se prefiere posponer la cirugía electiva como mínimo 6 semanas y mejor hasta 3 meses tras la implantación de stents sin recubrir y mantener el tratamiento an- 


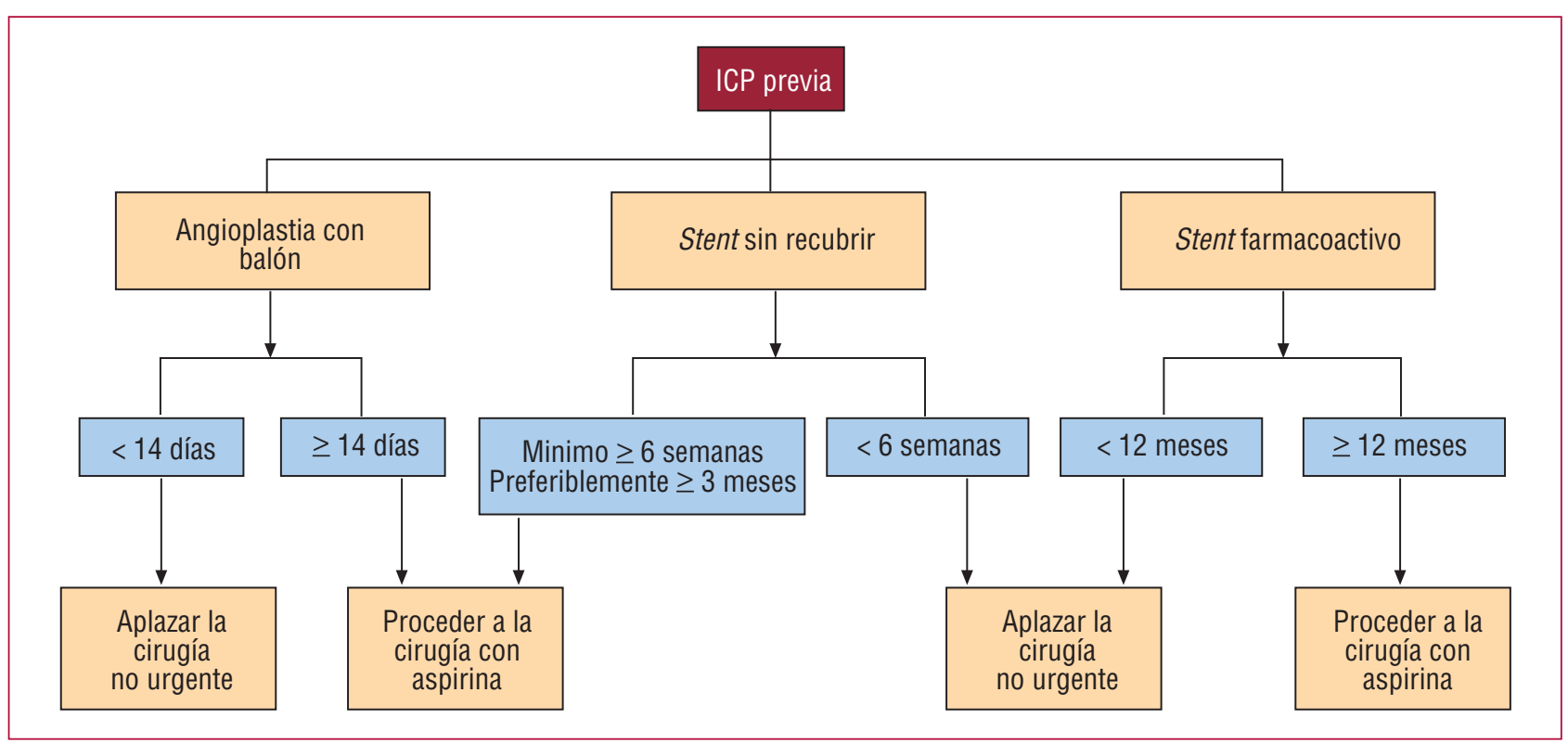

Fig. 3. Recomendaciones para la planificación temporal de la cirugía no cardiaca tras la intervención coronaria percutánea (ICP) ${ }^{133}$.

tiplaquetario doble. En los casos en que se respetó este periodo de espera, la interrupción del tratamiento antiplaquetario doble se asoció a un aumento de la incidencia de trombosis del stent ${ }^{130,131}$. Transcurridos 3 meses, los pacientes pueden ser sometidos a cirugía no cardiaca manteniéndose, como mínimo, el tratamiento con aspirina (fig. 3$)^{132}$.

En 2002 se introdujeron en Europa los stents farmacoactivos (SLF) con muy buena aceptación por su utilidad en la reducción de la reestenosis del stent. Sin embargo, su mayor inconveniente es la necesidad de un tratamiento prolongado a base de aspirina y clopidogrel durante al menos 12 meses. En los casos de cirugía durante este periodo, la suspensión del tratamiento antiplaquetario doble se asoció a un aumento de la incidencia de trombosis del stent. Hoy se acepta, en general, que tras la implantación de un SLF, la cirugía no debe realizarse durante 12 meses como mínimo, periodo en el que debe mantenerse el tratamiento con dos agentes antiplaquetarios (fig. 3) ${ }^{133}$. Transcurridos 12 meses, el paciente puede ser referido a cirugía no cardiaca, manteniéndose la administración de aspirina, como mínimo. Es preciso valorar el momento de realización de la cirugía y la patología específica (tumor maligno, reparación de aneurisma vascular, etc.) y el riesgo excesivo de trombosis del stent durante el primer año tras la implantación de un SLF, y es aconsejable una minuciosa valoración caso a caso. Se recomienda que el caso sea examinado conjuntamente por el cirujano, el anestesista y el cardiólogo para alcanzar un consenso de expertos.

En los pacientes que requieren la suspensión del tratamiento con aspirina o clopidogrel antes de la

\section{Recomendaciones sobre la planificación temporal de la cirugía no cardiaca en pacientes estables o asintomáticos con revascularización previa}

\begin{tabular}{|c|c|c|}
\hline Recomendación & Clase $^{a}$ & Nivel $^{b}$ \\
\hline $\begin{array}{l}\text { Se recomienda que los pacientes con una CABG } \\
\text { en los } 5 \text { años previos sean referidos a cirugía } \\
\text { no cardiaca sin más demora }\end{array}$ & I & C \\
\hline $\begin{array}{l}\text { Se recomienda que la cirugía no cardiaca se realice } \\
\text { transcurridos al menos } 6 \text { semanas y preferiblemente } \\
3 \text { meses tras la implantación de stents sin recubrir }\end{array}$ & I & B \\
\hline $\begin{array}{l}\text { Se recomienda que la cirugía no cardiaca se realice } \\
\text { transcurridos al menos } 12 \text { meses de la implantación } \\
\text { de stents farmacoactivos }\end{array}$ & I & B \\
\hline $\begin{array}{l}\text { Debe considerarse el aplazamiento de la cirugía no } \\
\text { cardiaca durante al menos } 2 \text { semanas en pacientes } \\
\text { sometidos a angioplastia con balón }\end{array}$ & Ila & $\mathrm{B}$ \\
\hline
\end{tabular}

CABG: cirugía de bypass aortocoronario.

aClase de recomendación.

${ }^{b}$ Nivel de evidencia.

cirugía, se recomienda la interrupción del tratamiento como mínimo 5 días - preferiblemente 10 días - antes de la intervención. El tratamiento puede reiniciarse aproximadamente $24 \mathrm{~h}$ después de la cirugía (o la mañana siguiente) si la hemostasis es adecuada. En pacientes que requieren cirugía u otro procedimiento invasivo urgente, con riesgo de hemorragia excesiva o potencialmente mortal, se recomienda la transfusión de plaquetas o la administración de otro agente prohemostático ${ }^{134}$. 


\section{Uso profiláctico de la revascularización en pacientes con cardiopatía isquémica estable}

Únicamente dos estudios han investigado el papel de la revascularización profiláctica antes de la cirugía no cardiaca en pacientes estables programados para cirugía vascular. El estudio CARP (Coronary Artery Revascularization Prophylaxis) fue el primero en comparar el tratamiento farmacológico óptimo frente a la revascularización (ICP o $\mathrm{CABG}$ ) en pacientes con miocardiopatía isquémica antes de cirugía vascular mayor ${ }^{135}$. De los 5.859 pacientes preseleccionados en 18 hospitales estadounidenses (Veterans Affairs Hospitals), 510 fueron asignados a una de las opciones de tratamiento. Los pacientes fueron incluidos en el estudio según una combinación de factores de riesgo cardiovascular y la detección de isquemia mediante pruebas no invasivas valoradas por el cardiólogo especialista. No se observaron diferencias en el objetivo primario de mortalidad a largo plazo a los 2,7 años tras la inclusión en el estudio (el 22\% en el grupo de revascularización y el $23 \%$ en el grupo sin ésta; $\mathrm{p}=0,92$ ); tampoco hubo diferencias en la incidencia de IM perioperatorio (el 12 frente al 14\%; $\mathrm{p}=0,37$ ).

En el segundo, el estudio piloto DECREASE-V, se aplicó una metodología más precisa para el cribado de los pacientes y un manejo perioperatorio más actualizado ${ }^{136}$. Un total de 1.880 pacientes fueron examinados para la identificación de los siguientes factores de riesgo: edad $>70$ años, angina de pecho, IM previo, insuficiencia cardiaca compensada o historia de insuficiencia cardiaca congestiva, tratamiento farmacológico para la diabetes mellitus, disfunción renal y accidente cerebrovascular previo o ataque isquémico transitorio. En presencia de tres o más factores de riesgo, se realizó una EED o prueba nuclear de estrés y, en caso de isquemia extensa ( $>5 / 16$ segmentos o $>3 / 6$ paredes), los pacientes fueron asignados de forma aleatoria al grupo de revascularización o al grupo sin revascularización. Es importante señalar que en todos los pacientes se inició el tratamiento con bloqueadores beta y se mantuvo la administración de aspirina durante la cirugía. El 75\% de los pacientes tenía enfermedad de triple vaso o del tronco común izquierdo. El 43\% tenía una fracción de eyección disminuida $\leq 35 \%$. La ICP se realizó en el $65 \%$ de los pacientes $(\mathrm{n}=32$, de los que 30 recibieron un SLF). No se observaron diferencias en el objetivo primario compuesto de mortalidad por todas las causas e IM no fatal a los 30 días: el $43 \%$ en el grupo asignado a revascularización frente al 33\% en el grupo sin revascularización ( $\mathrm{p}=0,30)$.

El estudio CARP fue el primero en indicar que el uso profiláctico de la revascularización antes de la cirugía vascular no mejora la evolución clínica de los pacientes estables. Sin embargo, los criterios de inclusión del estudio estaban basados en indicadores subjetivos y la población del estudio presentaba un riesgo relativamente bajo. El estudio DECREASE-V incluyó a pacientes de alto riesgo con isquemia extensa inducida por estrés, determinada mediante pruebas de estrés no invasivas. A pesar de que la cohorte era relativamente pequeña, el estudio DECREASE-V permite extender las conclusiones del estudio CARP a una población con riesgo más alto, en la que la mayoría de los pacientes tenía enfermedad de tres vasos y un porcentaje importante, disfunción del VI asintomática.

El éxito de un procedimiento quirúrgico vascular sin el uso profiláctico de la revascularización en un paciente estable no implica que este paciente no vaya a requerir un procedimiento de revascularización en el futuro. De hecho, los datos del estudio DECREASE-V, aunque limitados, indican la posibilidad de este fenómeno en el grupo asignado a tratamiento farmacológico ${ }^{136}$. A pesar de la falta de evidencia científica concluyente, podría realizarse revascularización coronaria sin complicaciones a pacientes en que previsiblemente se requerirá cirugía no cardiaca y tengan signos persistentes de isquemia extensa, de acuerdo con la guías de la ESC para un contexto no quirúrgico.

Ambos estudios, CARP y DECREASE-V, se realizaron en pacientes de cirugía vascular, un tipo de cirugía que comporta un riesgo más alto para el paciente con enfermedad coronaria. A pesar de esta limitación, las conclusiones de estos estudios pueden extrapolarse a otros tipos de cirugía.

\section{Recomendaciones sobre la revascularización} profiláctica en pacientes estables o asintomáticos

\begin{tabular}{lcc}
\hline Recomendación & Clase $^{\mathrm{a}}$ & Nivel $^{\mathrm{b}}$ \\
\hline $\begin{array}{l}\text { Debe considerarse la revascularización tardía tras } \\
\text { el éxito del procedimiento quirúrgico no cardiaco } \\
\text { de acuerdo con las guías de ESC sobre }\end{array}$ & Ila & C \\
angina estable & & \\
$\begin{array}{l}\text { Puede considerarse la revascularización miocárdica } \\
\text { profiláctica antes de la cirugía de alto riesgo }\end{array}$ & Ilb & B \\
en pacientes con cardiopatía isquémica & & \\
documentada & & \\
No se recomienda la revascularización miocárdica & III & B \\
profiláctica antes de la cirugía de riesgo intermedio & & \\
en pacientes con cardiopatía isquémica & & \\
documentada & & \\
No se recomienda la revascularización miocárdica & III & C \\
profiláctica antes de la cirugía de bajo riesgo & & \\
en pacientes con cardiopatía isquémica & & \\
documentada & &
\end{tabular}

aClase de recomendación.

${ }^{b}$ Nivel de evidencia. 


\section{Tipo de revascularización profiláctica en pacientes con cardiopatía isquémica estable}

En algunas ocasiones, los pacientes con cardiopatía isquémica estable requieren cirugía electiva que puede posponerse durante varios meses o incluso 1 año. No hay suficientes datos que permitan establecer una estrategia de revascularización para estos casos y las recomendaciones sólo están fundadas en la opinión de expertos. Sin embargo, en cierto modo, estos pacientes pueden ser comparables a los que ya se han sometido a revascularización. Por ello, parece razonable proponer una estrategia cardiovascular de acuerdo con las guías de práctica clínica de la ESC sobre angina estable ${ }^{47}$. Según estas guías, deberá realizarse $\mathrm{CABG}$ para mejorar el pronóstico y aliviar los síntomas en pacientes con enfermedad significativa del tronco común izquierdo y en pacientes con enfermedad de tres vasos, especialmente cuando la función del VI esté afectada. Deberá realizarse ICP en pacientes estables sintomáticos con enfermedad de uno o más vasos en los que la intervención sea técnicamente factible y siempre que los riesgos del procedimiento no sean superiores a los beneficios potenciales ${ }^{70}$.

La elección entre ICP o CABG depende de varios factores y suele ser motivo de debate. Recientemente se han publicado los resultados del primer año del estudio SYNTAX, en el que 1.800 pacientes con enfermedad de tres vasos o de tronco común izquierdo fueron asignados de forma aleatoria a CABG o $\mathrm{ICP}^{137}$. Los datos indican que la $\mathrm{CABG}$ sigue siendo el tratamiento de elección en estos pacientes, pero que la ICP es una alternativa que tener en cuenta. Como se ha mencionado antes, las guías sobre el manejo de la angina estable reconocen que ambos tratamientos tienen un papel. Sin embargo, cuando se realiza una ICP antes de cirugía no cardiaca, se recomienda la implantación de stents sin recubrir para evitar un aplazamiento innecesario de la cirugía.

\section{Revascularización de pacientes con cardiopatía isquémica inestable}

No se ha investigado el uso profiláctico de la revascularización en pacientes con angina inestable

\section{Recomendaciones sobre el tipo de revascularización profiláctica en pacientes estables}

\begin{tabular}{lcc}
\hline Recomendación & Clase $^{\mathbf{a}}$ & Nivel $^{\mathbf{b}}$ \\
\hline Se recomienda la realización de intervención coronaria & $\mathrm{I}$ & $\mathrm{A}$ \\
percutánea o cirugía de bypass aortocoronario, & & \\
de acuerdo con las guías vigentes sobre el manejo & & \\
de la angina de pecho estable & \\
\hline
\end{tabular}

aclase de recomendación.

bNivel de evidencia. que requieren cirugía no cardiaca. La angina de pecho inestable, especialmente los SCA sin elevación del segmento ST, se considera una entidad clínica de alto riesgo que requiere un diagnóstico inmediato, estratificación del riesgo y revascularización. Por lo tanto, siempre que la entidad clínica que requiere cirugía no cardiaca no ponga la vida en peligro, debe darse prioridad al diagnóstico y el tratamiento de la angina inestable. En este caso, se procederá de acuerdo con las últimas guías de práctica clínica de la ESC sobre el manejo de los SCA sin elevación del segmento $\mathrm{ST}^{69}$. El tratamiento incluye, básicamente, la administración de agentes antiplaquetarios y anticoagulantes, bloqueadores beta y revascularización precoz. En los pacientes con angina inestable y una entidad quirúrgica concomitante, se debe actuar con especial cuidado evitando el tratamiento anticoagulante y/o antitrombótico muy intensivo, debido al aumento del riesgo de hemorragia secundaria a la entidad quirúrgica subyacente (tumor maligno, etc.). Excepto en los casos mencionados anteriormente, en los que las indicaciones para la CABG están claramente establecidas, la mayoría de los pacientes son sometidos a una ICP. En el caso excepcional de angina inestable y ulterior cirugía no cardiaca, se recomienda el uso de stents $\sin$ recubrir al objeto de no retrasar la cirugía más de 3 meses.

\section{ENFERMEDADES ESPECÍFICAS}

Hasta aquí se han tratado los marcadores de riesgo cardiaco y las estrategias de reducción del

Recomendaciones sobre la revascularización miocárdica profiláctica en pacientes con cardiopatía isquémica inestable

\begin{tabular}{|c|c|c|}
\hline Recomendación & Clase $^{\mathrm{a}}$ & Nivel $^{b}$ \\
\hline $\begin{array}{l}\text { Siempre que la cirugía pueda aplazarse sin peligro } \\
\text { para el paciente, se recomienda diagnosticarlo } \\
\text { y tratarlo de acuerdo con las guías para el manejo } \\
\text { de la angina inestable }\end{array}$ & I & $A$ \\
\hline $\begin{array}{l}\text { En el caso poco probable de que concomiten una } \\
\text { entidad clínica potencialmente mortal que requiere } \\
\text { cirugía no cardiaca urgente y SCA, debe darse } \\
\text { prioridad a la cirugía }\end{array}$ & I & C \\
\hline $\begin{array}{l}\text { En el seguimiento de dichos casos, se recomienda } \\
\text { tratamiento farmacológico intensivo y } \\
\text { revascularización miocárdica de acuerdo con } \\
\text { las guías para el manejo de la angina inestable }\end{array}$ & I & B \\
\hline $\begin{array}{l}\text { Si está indicada una ICP, se recomienda el uso } \\
\text { de stents sin recubrir o angioplastia con balón }\end{array}$ & I & C \\
\hline
\end{tabular}


riesgo. Sin embargo, los pacientes con enfermedades específicas antes de la cirugía se pueden beneficiar de una estrategia integrada de evaluación y manejo específico para su enfermedad en el periodo perioperatorio. En este capítulo se trata de las enfermedades cardiovasculares más comunes.

\section{Insuficiencia cardiaca crónica}

Se estima que la prevalencia de la insuficiencia cardiaca crónica en la población adulta del Reino Unido es del 1,8\% y este porcentaje aumenta con la edad. En pacientes mayores de 75 años, la prevalencia alcanza el $8 \%$.

El valor predictivo de la insuficiencia cardiaca para los eventos cardiacos perioperatorios está bien establecido y es un factor importante en los índices de riesgo, como la escala Goldman o la Detsky ${ }^{31,32}$. En un estudio realizado en 1988, en el que se valoraba la función del VI antes de cirugía vascular, se demostró que una fracción de eyección $\leq 35 \%$ era un buen predictor de eventos cardiacos postoperatorios $^{138}$. En 2008, otro estudio confirmó estos hallazgos y llegó a la conclusión de que los pacientes de edad avanzada con insuficiencia cardiaca crónica programados para cirugía vascular tenían un riesgo de mortalidad operatoria y reingresos mayor que otros pacientes sometidos al mismo procedimiento (incluidos los pacientes con cardiopatía isquémica) ${ }^{139}$. Sin embargo, el valor pronóstico preoperatorio de la insuficiencia cardiaca con la función del VI conservada no está claramente definido. El resultado a largo plazo es similar al de los pacientes con insuficiencia cardiaca con la fracción de eyección reducida ${ }^{140}$. Estos pacientes pueden estar en mayor riesgo cuando son sometidos a cirugía. A falta de evidencia basada en estudios clínicos, el comité para la elaboración de guías de práctica clínica recomienda el manejo perioperatorio de los pacientes con fracción de eyección conservada similar al de los que la tienen reducida.

La valoración de la viabilidad miocárdica durante las pruebas de estrés permite una mejor estratificación del riesgo en los casos de disfunción del VI. Como se demuestra en un estudio con 295 pacientes con fracción de eyección $<35 \%$ programados para cirugía, la incidencia de eventos cardiacos postoperatorios estaba relacionada con la presencia de isquemia inducida por estrés y tejido cicatrizado ${ }^{141}$. Sin embargo, se observó una relación inversa a la presencia de segmentos disfuncionantes pero viables y el grado de disfunción, con función mejorada, sin signos de isquemia, durante la estimulación inotrópica.

Mediante análisis multivariable se demostró que el número de segmentos isquémicos se asociaba a la incidencia de eventos perioperatorios (OR por seg- mento $=1,6 ;$ IC del 95\%, 1,05-1,8), mientras que el número de segmentos con mejoría persistente se asociaba a mejores resultados (OR por segmento $=0,2$; IC del 95\%, 0,04-0,7). La estratificación del riesgo por medio de pruebas de estrés permite identificar a un subgrupo de pacientes con mejoría mantenida que podría tener resultados postoperatorios relativamente benignos, al contrario de los pacientes con una respuesta predominantemente isquémica.

Las guías de la ESC recomiendan el uso de IECA (o BRA, en caso de intolerancia) y bloqueadores beta como primer tratamiento en la insuficiencia cardiaca para mejorar la morbimortalidad ${ }^{91}$. Excepto cuando haya contraindicaciones o intolerancia, el tratamiento debe administrarse en dosis óptimas a todos los pacientes con insuficiencia cardiaca sintomática y fracción de eyección del VI $\leq 40 \%$. Dependiendo del estado clínico y de las características del paciente, puede añadirse después un BRA o un antagonista de la aldosterona. En todos los pacientes con fracción de eyección $\leq 35 \%$ y síntomas persistentes (clase funcional de la NYHA III o IV), debe considerarse la adición de un antagonista de la aldosterona a dosis bajas (en ausencia de hiperpotasemia y disfunción renal significativa). Como alternativa se recomienda la adición de un BRA en pacientes con insuficiencia cardiaca, fracción de eyección $\leq 40 \%$ y síntomas persistentes a pesar de recibir tratamiento farmacológico óptimo a base de IECA y bloqueadores beta, excepto cuando se administre un antagonista de la aldosterona. Se recomienda la administración de diuréticos a los pacientes con insuficiencia cardiaca y signos o síntomas de congestión.

Se ha demostrado que el uso perioperatorio de IECA, bloqueadores beta, estatinas y aspirina se asocia de forma independiente a una reducción de la incidencia de la mortalidad intrahospitalaria en pacientes con disfunción del VI sometidos a cirugía vascular mayor ${ }^{142}$. Por ello se considera que esta estrategia de tratamiento es vital para los pacientes con insuficiencia cardiaca estable, y se debe mantenerla hasta el momento de la cirugía y reiniciarla posteriormente en cuanto lo permitan las condiciones clínicas.

Normalmente, el diagnóstico de insuficiencia cardiaca postoperatoria presenta dificultades, ya que suele tener una presentación atípica y una etiología diferente de las del contexto clínico no quirúrgico. La valoración del paciente debe incluir exploración física, ECG, determinaciones seriadas de biomarcadores, radiografía y ecocardiografía. Debe prestarse especial atención al estado volumétrico del paciente, ya que durante la cirugía y en el periodo postoperatorio inmediato son necesarias infusiones de gran volumen. Tras la cirugía, los fluidos administrados pueden movilizarse y causar 
hipervolemia e incluso insuficiencia cardiaca si no se controlan adecuadamente. La sobrecarga de fluidos puede causar una descompensación de la insuficiencia cardiaca crónica o la aparición de insuficiencia cardiaca aguda. La insuficiencia cardiaca puede presentarse inmediatamente después de la cirugía (procedimiento prolongado, isquemia miocárdica, alteración rápida de fluidos) o unos días más tarde (debido a la reabsorción de fluidos de tercer espacio). Según las guías de la ESC sobre insuficiencia cardiaca, es necesario optimizar el tratamiento farmacológico antes de la cirugía, especialmente el tratamiento con bloqueadores beta, cuya administración perioperatoria está recomendada en todos los pacientes con alto riesgo. Para evitar la hipotensión descontrolada no se recomienda el uso sistemático de bloqueadores beta por vía intravenosa. En los pacientes que no reciben tratamiento con bloqueadores beta, es importante iniciar su administración con antelación suficiente a la cirugía para que pueda alcanzarse la dosis óptima.

Cuando se establezca la etiología de la insuficiencia cardiaca postoperatoria, el tratamiento es similar al de los pacientes en un contexto clínico no quirúrgico. Los pacientes con insuficiencia cardiaca tienen mayor riesgo de reingreso tras un procedimiento quirúrgico. Esto confirma la necesidad de una buena planificación del alta y de un seguimiento estrecho, preferiblemente mediante una estrategia multidisciplinaria.

\section{Hipertensión arterial}

En general, la hipertensión arterial no se considera un factor independiente de riesgo de complicaciones cardiovasculares en la cirugía no cardiaca. La evaluación preoperatoria permite la identificación de los pacientes con hipertensión, la búsqueda de daño orgánico y evidencia de enfermedad cardiovascular asociada y, consiguientemente, la instauración del tratamiento adecuado. Esto es particularmente importante en los pacientes con factores de riesgo concomitantes.

La evidencia disponible no es definitiva en cuanto al uso de un modo u otro de tratamiento hipertensivo en los pacientes programados para cirugía no cardiaca, y se aconseja seguir las recomendaciones de las guías de la ESC para el manejo de la hipertensión arterial $^{143}$. En pacientes hipertensos con cardiopatía isquémica concomitante y riesgo alto de complicaciones cardiovasculares, se recomienda la administración perioperatoria de bloqueadores beta. En pacientes hipertensos, debe mantenerse el tratamiento antihipertensivo hasta la mañana del día de la cirugía y reiniciarlo tan pronto como sea posible después de la intervención ${ }^{144}$. En pacientes con hipertensión de grado 1 o 2, no hay evidencia de que el aplazamiento de la cirugía para optimizar el tratamiento farmacológico sea beneficioso ${ }^{143}$. En estos casos, debe mantenerse el tratamiento antihipertensivo durante el periodo perioperatorio. En pacientes con hipertensión de grado 3 (presión sistólica $\geq 180 \mathrm{mmHg}$ y/o presión diastólica $\geq 110$ $\mathrm{mmHg}$ ), deben valorarse los beneficios potenciales de un aplazamiento de la cirugía que permita optimizar el tratamiento farmacológico y el riesgo que conlleva dicho aplazamiento ${ }^{20,144}$.

\section{Valvulopatías}

Los pacientes con enfermedad valvular tienen mayor riesgo de complicaciones cardiovasculares perioperatorias en el contexto de la cirugía no cardiaca $^{124}$. En los pacientes con enfermedad valvular conocida o sospechada debe realizarse una ecocardiografía para valorar la severidad de la enfermedad y sus posibles consecuencias. Con base en los datos disponibles, deberán aplicarse las siguientes recomendaciones a este grupo de pacientes ${ }^{20,124}$

\section{Recomendaciones para las valvulopatías}

\begin{tabular}{lcc}
\hline Recomendación & Clase $^{\mathrm{a}}$ & Nivel $^{\mathrm{b}}$ \\
\hline $\begin{array}{l}\text { En presencia de valvulopatía grave, se recomienda } \\
\text { evaluación clínica y ecocardiográfica y, si estuviera } \\
\text { indicado, tratamiento antes de la cirugía no cardiaca }\end{array}$ & $\mathrm{C}$ \\
\hline aClase de recomendación. & \\
bNivel de evidencia.
\end{tabular}

\section{Estenosis aórtica}

La estenosis aórtica (EA) es la valvulopatía más frecuente en Europa, especialmente entre la población de edad avanzada. La EA grave (definida como área valvular aórtica $<1 \mathrm{~cm}^{2}$, superficie corporal $<0,6 \mathrm{~cm}^{2} / \mathrm{m}^{2}$ ) es un factor de riesgo demostrado de mortalidad e IM perioperatorios ${ }^{146}$. En caso de cirugía no cardiaca urgente en estos pacientes, el procedimiento deberá realizarse con monitorización hemodinámica ${ }^{124}$. En caso de cirugía electiva, la presencia de síntomas es un elemento fundamental para la toma de decisiones.

En pacientes sintomáticos debe considerarse el reemplazo de la válvula aórtica antes de la cirugía electiva. En pacientes que no son candidatos a reemplazo de la válvula aórtica, bien por un exceso de riesgos asociados a comorbilidades, bien por rechazo del paciente, sólo debe realizarse el procedimiento quirúrgico si es absolutamente necesario. En estos pacientes, la valvuloplastia con balón o la implantación percutánea de válvula aórtica podrían 
ser opciones terapéuticas razonables antes de la cirugía $^{124-147}$.

Los pacientes asintomáticos pueden someterse con seguridad a cirugía de riesgo bajo o intermedio. En caso de cirugía de alto riesgo, deberá explorarse la posibilidad de reemplazo de válvula aórtica. En los pacientes para los que el reemplazo valvular suponga un riesgo muy alto, se considerará la cirugía electiva con un estricto control hemodinámico y sólo cuando sea absolutamente necesaria. Para el resto de los pacientes el reemplazo de válvula aórtica debería ser el procedimiento inicial ${ }^{124}$.

\section{Estenosis mitral}

La cirugía no cardiaca puede realizarse con un riesgo relativamente bajo en los pacientes con estenosis mitral (EM) no significativa (área valvular $>1,5 \mathrm{~cm}^{2}$ ) y en pacientes asintomáticos con EM significativa (área valvular $<1,5 \mathrm{~cm}^{2}$ ) y una presión pulmonar sistólica $<50 \mathrm{mmHg}$. En estos pacientes no está indicada la corrección de la EM antes de la cirugía. Hay que recordar la importancia del control de la frecuencia cardiaca para evitar la taquicardia, que podría causar un edema pulmonar. También es importante mantener un control estricto de la sobrecarga de fluidos. El desarrollo de FA podría deteriorar gravemente el estado clínico del paciente ${ }^{20,124}$. Debido al alto riesgo de embolias, el control de la anticoagulación también es muy importante. En pacientes asintomáticos con EM significativa y una presión pulmonar sistólica $>50$ $\mathrm{mmHg}$ y en pacientes sintomáticos, el riesgo que comporta la cirugía no cardiaca es significativamente mayor; en estos pacientes debe considerarse el beneficio de una comisurotomía mitral percutánea (o reparación quirúrgica), especialmente antes de una cirugía de alto riesgo ${ }^{20,124}$.

\section{Regurgitación aórtica y regurgitación mitral}

La regurgitación aórtica no significativa y la regurgitación mitral son factores independientes de riesgo de complicaciones cardiovasculares en la cirugía no cardiaca. En pacientes asintomáticos con regurgitación aórtica o mitral grave y la función del VI conservada, la cirugía no cardiaca puede realizarse sin riesgos adicionales. Los pacientes sintomáticos y los asintomáticos con la fracción de eyección muy afectada $(<30 \%)$ tienen alto riesgo de complicaciones cardiovasculares, por lo que la cirugía sólo debe realizarse si es absolutamente necesaria ${ }^{124}$. Los pacientes con regurgitación aórtica o mitral grave podrían beneficiarse de la optimización del tratamiento farmacológico que asegure la máxima estabilización hemodinámica antes de la cirugía de alto riesgo.

\section{Pacientes con prótesis valvulares}

Los pacientes que han sido sometidos a reparación quirúrgica de una valvulopatía y tienen una prótesis valvular pueden ser referidos a cirugía no cardiaca sin riesgos adicionales, siempre que no haya evidencia de disfunción valvular o ventricular. En estos pacientes, se recomienda la profilaxis de la endocarditis y la modificación del tratamiento anticoagulante perioperatorio sustituyendo temporalmente los anticoagulantes orales por HNF por vía intravenosa o subcutánea o HBPM por vía subcutánea a dosis terapéuticas.

\section{Profilaxis de la endocarditis infecciosa}

En los pacientes con valvulopatía y pacientes con prótesis valvulares que van a someterse a cirugía no cardiaca con riesgo de bacteriemia, debe iniciarse un régimen antibiótico profiláctico contra la endocarditis infecciosa. Esta cuestión se trata en detalle en las guías de práctica clínica de la ESC y la $\mathrm{AHA}^{148,149}$.

\section{Arritmias}

La incidencia de arritmias perioperatorias afecta al $70 \%$ de los pacientes sometidos a anestesia general en distintos tipos de procedimientos quirúrgicos ${ }^{150,151}$. La tasa de incidencia varía entre el 16 y el $62 \%$ con monitorización por ECG intermitente $^{152}$ y el $89 \%$ con monitorización continua $\left(\right.$ Holter) ${ }^{153}$.

\section{Arritmias ventriculares}

Casi la mitad de los pacientes en alto riesgo sometidos a cirugía no cardiaca tiene latidos ventriculares prematuros frecuentes o taquicardia ventricular (TV) no mantenida, pero ninguna de ambas entidades se asocia a un peor pronóstico. Las guías de práctica clínica de la ACC/AHA/ESC para el manejo de pacientes con arritmias ventriculares y para la prevención de la muerte súbita recomiendan una serie de estrategias terapéuticas basadas en grandes ensayos $\operatorname{clínicos}^{154}$. Independientemente de la causa subyacente, la taquicardia ventricular monomórfica mantenida (TVMM) con deterioro hemodinámico significativo debe tratarse a la mayor brevedad con cardioversión eléctrica ${ }^{154}$. Para el tratamiento inicial de los pacientes con TVMM, puede administrarse amiodarona intravenosa ${ }^{154}$. Éste es también un tratamiento razonable para los pacientes con TVMM hemodinámicamente inestable, resistente a la conversión eléctrica o recurrente a pesar de la administración de otros agentes. En caso de taquicardia 
ventricular polimórfica mantenida (TVPM) con deterioro hemodinámico, debe realizarse cardioversión eléctrica sin dilación. Los bloqueadores beta son útiles en los pacientes con TVPM, especialmente si hay sospecha de isquemia o no se puede descartarla. La administración de amiodarona es una opción razonable en pacientes con TVPM recurrente, en ausencia del síndrome de QT largo (SQTL) ${ }^{154}$. Las arritmias del tipo torsades de pointes ocurren rara vez; en caso de presentación se recomienda la suspensión de fármacos que pudieran agravarlas y la corrección de las alteraciones de los electrolitos. El tratamiento con sulfato de magnesio es una buena opción para los pacientes con arritmias tipo torsades de pointes y SQTL. Para los pacientes con arritmias tipo torsades de pointes y bradicardia sinusal se propone el uso de bloqueadores beta y marcapasos. La administración de isoproterenol está recomendada en pacientes con torsades de pointes dependientes de pausas y recurrentes que no tienen SQTL congénito ${ }^{154}$. En el caso de TV sin pulso o fibrilación ventricular, es imprescindible la desfibrilación inmediata.

\section{Arritmias supraventriculares}

Son más los pacientes que sufren taquicardia supraventricular (TSV) y FA que los que tienen arritmias ventriculares ${ }^{153-158}$. La actividad simpática es el mecanismo autonómico primario que origina la $\mathrm{FA}^{159}$. En algunos casos, las maniobras vagales pueden resolver la TSV y estas arritmias responden bien al tratamiento con adenosina. Cuando la TSV es resistente a la adenosina, el tratamiento efectivo para la reversión de la arritmia incluye la administración de un bloqueador beta de acción corta o un bloqueador de los canales de calcio no dihidropiridínico (diltiazem y verapamilo) o amiodarona intravenosa ${ }^{160-162}$. El verapamilo, debido a su efecto inotrópico negativo, debe usarse con precaución. No se recomienda el uso de bloqueadores de los canales de calcio en caso de TSV/FA preexcitadas. El objetivo del manejo de la FA perioperatoria es el control de la frecuencia ventricular ${ }^{163}$. Los bloqueadores beta y los bloqueadores de los antagonistas del calcio no dihidropiridínicos (diltiazem y verapamilo) son los fármacos de elección para el control de la frecuencia cardiaca en la FA. La digoxina puede usarse como tratamiento de primera línea sólo en pacientes con insuficiencia cardiaca crónica, ya que no es efectiva en estados adrenérgicos elevados, como es el caso en la cirugía. Se ha demostrado que los bloqueadores beta aceleran la conversión de la FA a ritmo sinusal tras la cirugía no cardiaca $^{164}$. En varios ensayos clínicos, la adminis- tración de bloqueadores beta se asoció a un mejor control de las arritmias ${ }^{165,166}$.

\section{Bradiarritmias}

En un estudio multicéntrico, la incidencia de bradiarritmias perioperatorias graves fue del $0,4 \%$ de un total de 17.021 pacientes, de los que el 6,4\% presentaba un estado físico 1 o 2 , según la clasificación de la American Association of Anaesthesiologists ${ }^{151}$. Los pacientes fueron monitorizados mediante ECG intraoperatorio y en el postoperatorio inmediato. En general, las bradiarritimias perioperatorias responden bien a tratamiento farmacológico corto, estimulación eléctrica auricular transesofágica en pacientes anestesiados o estimulación eléctrica transcutánea en pacientes despiertos o anestesiados ${ }^{160}$. Raras veces es necesario el uso de marcapasos temporal, incluso en presencia de bloqueo bifascicular asintomático o bloqueo de rama izquierda preoperatorios ${ }^{167}$. Las indicaciones para el uso de marcapasos temporal perioperatorio son, en términos generales, las mismas que para el marcapasos permanente ${ }^{168}$. La presencia de bloqueo bifascicular asintomático con/sin bloqueo auriculoventricular de primer grado no es una indicación para el uso de marcapasos temporal ${ }^{169,170}$.

\section{Marcapasos/desfibrilador automático implantable}

El uso de bisturí eléctrico unipolar representa un riesgo importante para los pacientes dependientes de marcapasos. El estímulo eléctrico producido por el bisturí puede inhibir la respuesta del marcapasos a demanda o reprogramar el marcapasos. Sin embargo, estos problemas pueden evitarse colocando la placa neutra del circuito eléctrico de forma que la corriente eléctrica no se acerque al generador. Las interferencias pueden reducirse colocando el bisturí eléctrico lo más alejado posible del marcapasos y usando descargas cortas y de baja amplitud. En muchos estudios los autores recomiendan programar el marcapasos en modo asíncrono o sin sensor en los pacientes dependientes de marcapasos cuyo ritmo subyacente no sea fiable y, tras la cirugía, reprogramarlo comprobando todos los parámetros y umbrales de estimulación ${ }^{171-174}$. Durante la cirugía también pueden ocurrir interferencias con la función del desfibrilador automático implantable (DAI) producidas por la corriente eléctrica generada por el bisturí eléctrico ${ }^{175,176}$. Durante la cirugía debe desactivarse el desfibrilador implantable y volver a activarlo durante la recuperación antes de que el paciente sea enviado a planta. Se recomienda dejar instrucciones escritas sobre la supervisión y la reactivación del DAI. 


\section{Recomendaciones para las arritmias ventriculares}

\begin{tabular}{lcc}
\hline Recomendación & Clase $^{\mathrm{a}}$ & Nivel $^{\mathrm{b}}$ \\
\hline $\begin{array}{l}\text { Se recomienda el uso de fármacos antiarrítmicos } \\
\text { en pacientes con TV recurrente mantenida }\end{array}$ & I & B \\
$\begin{array}{l}\text { Se recomienda mantener el tratamiento con } \\
\text { amiodarona y bloqueadores beta antes } \\
\text { de la cirugía }\end{array}$ & I & C \\
$\begin{array}{l}\text { En caso de diagnóstico poco claro, se recomienda } \\
\text { que la taquicardia por SQR ancho se considere } \\
\text { como TV }\end{array}$ & । & C \\
$\begin{array}{l}\text { Se recomienda cardioversión eléctrica inmediata } \\
\text { en pacientes con TV mantenida con deterioro }\end{array}$ & I & C \\
hemodinámico & & \\
$\begin{array}{l}\text { Debe considerarse el uso de fármacos antiarrítmicos } \\
\text { para el tratamiento inicial de los pacientes } \\
\text { con TV monomórfica mantenida }\end{array}$ & IIIa & B \\
$\begin{array}{l}\text { No se recomienda el uso de fármacos antiarrítmicos } \\
\text { en pacientes con TV no mantenida }\end{array}$ & III & B \\
$\begin{array}{l}\text { No se recomienda el uso de fármacos antiarrítmicos } \\
\text { en pacientes con LVP }\end{array}$ & III & A \\
\hline
\end{tabular}

LVP: latido ventricular prematuro; TV: taquicardia ventricular.

${ }^{a}$ Clase de recomendación.

'Nivel de evidencia.

\section{Recomendaciones para las arritmias} supraventriculares

\begin{tabular}{|c|c|c|}
\hline Recomendación & Clase $^{a}$ & Nivel $^{b}$ \\
\hline $\begin{array}{l}\text { Se recomienda el control de la frecuencia ventricular } \\
\text { en pacientes con FA sin inestabilidad hemodinámica }\end{array}$ & I & A \\
\hline $\begin{array}{l}\text { Se recomienda mantener el tratamiento antiarrítmico } \\
\text { oral antes de la cirugía }\end{array}$ & I & C \\
\hline $\begin{array}{l}\text { Se recomienda la cardioversión eléctrica en caso } \\
\text { de inestabilidad hemodinámica }\end{array}$ & I & C \\
\hline $\begin{array}{l}\text { En pacientes hemodinámicamente estables, } \\
\text { se recomiendan las maniobras vagales } \\
\text { y el tratamiento antiarrítmico }\end{array}$ & I & C \\
\hline \multicolumn{3}{|l|}{$\begin{array}{l}{ }^{a} \text { Clase de recomendación. } \\
\text { 'Nivel de evidencia. } \\
\text { FA: fibrilación auricular. }\end{array}$} \\
\hline \multicolumn{3}{|c|}{$\begin{array}{l}\text { Recomendaciones sobre el uso de dispositivos } \\
\text { implantables }\end{array}$} \\
\hline Recomendación & Clase $^{\mathrm{a}}$ & Nivel $^{b}$ \\
\hline $\begin{array}{l}\text { Debe considerarse el uso de dispositivos implantables } \\
\text { antes y después de la cirugía }\end{array}$ & 1 & C \\
\hline $\begin{array}{l}\text { Se recomienda que la gerencia del hospital nombre } \\
\text { a un responsable para la programación de los } \\
\text { dispositivos implantables antes y después } \\
\text { de la cirugía }\end{array}$ & I & C \\
\hline
\end{tabular}

aClase de recomendación.

bNivel de evidencia.

\section{Enfermedad renal}

Una función renal afectada es un factor independiente de riesgo de eventos cardiovasculares adversos postoperatorios, entre ellos IM, accidente cerebro- vascular e insuficiencia cardiaca. Tradicionalmente, la función renal se determina mediante la concentración de creatinina sérica. Por ejemplo, en el índice Lee se utiliza un valor de corte de la creatinina sérica $>2 \mathrm{mg} / \mathrm{dl}(177 \mu \mathrm{mol} / \mathrm{l})^{5}$. Sin embargo, la estimación del aclaramiento de creatinina $(\mathrm{ml} / \mathrm{min})$, que incorpora la concentración sérica de creatinina, la edad y el peso, proporciona una valoración más adecuada de la función renal que la creatinina sérica en sí. La fórmula Cockcroft-Gault ${ }^{177}$ es la más utilizada, definida como: $\{[(140-$ años de edad $) \times$ (peso en $\mathrm{kg})] /[72 \times$ creatinina sérica en $\mathrm{mg} / \mathrm{dl}]\} \times$ (0,85 para mujeres). En un estudio con 852 pacientes sometidos a cirugía vascular mayor, se demostró un aumento de la mortalidad en individuos con creatinina sérica $>2 \mathrm{mg} / \mathrm{dl}$ (OR para la mortalidad perioperatoria $=5,2 ; \mathrm{IC}$ del 95\%, 2,9-10,8 ${ }^{178}$. No obstante, podría argumentarse que los pacientes con insuficiencia renal menos pronunciada también tienen malos resultados, comparados con los pacientes con cifras de creatinina sérica normales. Una reducción de $10 \mathrm{ml} / \mathrm{min}$ del aclaramiento de creatinina se asoció a un aumento del riesgo de la mortalidad postoperatoria del 40\% (OR $=1,4$; IC del 95\%, 1,2-1,5; área bajo la curva ROC, 0,70; IC del 95\%, 0,63-0,76). El análisis de la curva ROC demuestra que un valor de corte del aclaramiento de creatinina de $64 \mathrm{ml} / \mathrm{min}$ tiene las mayores sensibilidad y especificidad para la predicción de la mortalidad postoperatoria ${ }^{178}$.

Además de la función renal preoperatoria, el empeoramiento de la función renal tras la cirugía es un factor pronóstico de eventos adversos tardíos. En un estudio con 1.324 pacientes sometidos a cirugía abierta electiva de aneurisma aórtico abdominal, se determinó el aclaramiento de creatinina antes de la operación y 1, 2 y 3 días después ${ }^{179}$. Los pacientes fueron divididos en tres grupos según los cambios en la función renal comparada con los valores basales. El primer grupo tuvo una mejoría o no tuvo cambios (cambios en el aclaramiento de la creatinina, $\pm 10 \%$ de la función comparado con valores basales); el segundo grupo tuvo un empeoramiento temporal (empeoramiento $>10 \%$ los días 1 o 2 y una recuperación completa en un rango del 10\% de los valores basales), y el tercer grupo tuvo un empeoramiento persistente (una reducción $>10 \%$ respecto a los valores basales). La mortalidad a los 30 días fue del 1,3, el 5 y 12,6\% de los grupos 1, 2 y 3 , respectivamente. Ajustada a los valores basales y las complicaciones postoperatorias, la mortalidad a los 30 días fue superior en los pacientes con un empeoramiento persistente de la función renal $(\mathrm{HR}=7,3$; IC del 95\%, 2,7-19,8), seguidos de los pacientes con empeoramiento temporal $(\mathrm{HR}=3,7$; IC del 95\%, 1,4-9,9). Durante los $6 \pm 3,4$ años de seguimiento, fallecieron 348 pacientes $(36,5 \%)$. El 
riesgo de mortalidad tardía fue de 1,7 (IC del 95\%, 1,3-2,3) en el grupo con empeoramiento persistente, seguido del grupo con empeoramiento temporal $(\mathrm{HR}=1,5$; IC del 95\%, 1,2-1,4). Este estudio demostró que, aunque la función renal se recupere totalmente tras la cirugía aórtica, el empeoramiento temporal se asocia a un aumento de la mortalidad a largo plazo $^{179}$.

Es importante identificar a los pacientes cuya función renal perioperatoria puede empeorar para instaurar medidas de apoyo, como el mantenimiento de un volumen intravascular adecuado para la perfusión renal y el uso de vasopresores. En un importante estudio retrospectivo, se evaluaron los factores de riesgo de insuficiencia renal postoperatoria durante los 7 días posteriores a la cirugía no cardiaca en pacientes con una función renal preoperatoria normal ${ }^{180}$. También se evaluó la mortalidad por todas las causas a los 30 días, a los 60 días y al año. Se revisó un total de 65.043 casos realizados entre 2003 y 2006. Del número total, 15.102 pacientes cumplían los criterios de inclusión; 121 pacientes desarrollaron insuficiencia renal aguda $(0,8 \%)$ y 14 requirieron terapia de reemplazo renal $(0,1 \%)$. Se identificaron siete predictores preoperatorios independientes $(p<0,05)$ : edad, cirugía urgente, enfermedad hepática, índice de masa corporal elevado, cirugía de alto riesgo, enfermedad arterial periférica oclusiva y EPOC que requiere tratamiento broncodilatador indefinidamente.

La nefropatía inducida por contraste, causada por hipoperfusión renal y toxicidad tubular directa, ocurre en el $15 \%$ de los pacientes con disfunción renal crónica sometidos a procedimientos radiográficos $^{181}$. Entre el 0,5 y el $12 \%$ de estos pacientes requieren hemodiálisis y hospitalización prolongada. Un número considerable de pacientes sufren un empeoramiento de la función renal con posible evolución a insuficiencia renal terminal. El tratamiento preventivo consiste, fundamentalmente, en una buena hidratación periprocedimiento y la administración de antioxidantes. En tres estudios controlados realizados recientemente, se compararon los efectos del bicarbonato sódico frente al salino isotónico en humanos, y se observó una impresionante reducción de la nefropatía por contraste en el grupo asignado a bicarbonato sódico, con una incidencia $<2 \%{ }^{182}$. Estos resultados fueron evaluados en otro estudio con suficiente poder estadístico, en el que se comparó la eficacia de la hidratación con bicarbonato sódico frente a salino isotónico además de $\mathrm{N}$-acetilcisteína para la profilaxis de la nefropatía inducida por contraste, en una población de pacientes con disfunción renal crónica programados para angiografía coronaria o intervención. Un total de 502 pacientes con un aclaramiento estimado de creatinina $<60 \mathrm{ml} / \mathrm{min}$ fueron asignados de forma aleatoria a infusión con suero salino $(\mathrm{NaCl}$ al $0,9 \%)$ o bicarbonato sódico antes y después de la administración de contraste, además de $\mathrm{N}$-acetilcisteína oral $(600 \mathrm{mg} / 12 \mathrm{~h})^{183}$. El tratamiento con salino isotónico consistió en $1 \mathrm{ml} / \mathrm{kg} / \mathrm{h}$ de cloruro sódico al $0,9 \%$ durante $12 \mathrm{~h}$ antes y después del procedimiento; el tratamiento con bicarbonato sódico (154 mEq/l en dextrosa y agua) consistió en $3 \mathrm{ml} / \mathrm{kg}$ durante $1 \mathrm{~h}$ antes de la administración de contraste seguido de infusión de $1 \mathrm{ml} / \mathrm{kg}$ durante $6 \mathrm{~h}$ tras el procedimiento. La nefropatía inducida por contraste se definió como un incremento absoluto de la creatinina sérica $\geq 0,5 \mathrm{mg} / \mathrm{dl}$ determinado durante los 5 días posteriores a la exposición al contraste. No se observaron diferencias entre los dos grupos; la nefropatía por contraste ocurrió en 54 pacientes $(10,8 \%)$, de los que $25(10 \%)$ fueron tratados con bicarbonato sódico y $29(11,5 \%)$ con salino $(\mathrm{p}=0,60)$. Por lo tanto, la hidratación con bicarbonato sódico, además de $\mathrm{N}$-acetilcisteína antes de la exposición al medio de contraste, no fue más efectiva que la hidratación con cloruro sódico isotónico además de $\mathrm{N}$-acetilcisteína para la profilaxis de la nefropatía inducida por contraste en pacientes con disfunción renal moderada. Las discrepancias entre los distintos estudios aleatorizados pueden explicarse por las diferencias en el uso concomitante de $\mathrm{N}$-acetilcisteína, el uso de medio de contraste o la disfunción renal de base entre los pacientes estudiados. El bicarbonato sódico sólo requiere $1 \mathrm{~h}$ de pretratamiento y puede ser una opción para pacientes en los que es necesario el uso urgente de un agente de contraste o para la realización de procedimientos ambulatorios.

\section{Recomendación/declaración sobre la función renal}

\begin{tabular}{lcc}
\hline Recomendación/declaración & Clase $^{\mathbf{a}}$ & Nivel $^{\mathbf{b}}$ \\
\hline $\begin{array}{l}\text { Se recomienda considerar la función renal } \\
\text { preoperatoria como un factor independiente }\end{array}$ & B \\
de riesgo cardiaco para el pronóstico perioperatorio & & \\
y a largo plazo & & B \\
En los pacientes con riesgo de nefropatía inducida & & \\
por contraste, se recomienda la hidratación con \\
cloruro sódico isotónico (con/sin N-acetilcisteína oral) \\
para su profilaxis antes de la realización de pruebas \\
de imagen cardiaca que requieran la administración \\
de contraste (angiografía coronaria/periférica)
\end{tabular}

${ }^{a}$ Clase de recomendación.

bNivel de evidencia.

\section{Enfermedad cerebrovascular}

En los países occidentales la enfermedad cerebrovascular es la tercera causa de muerte, con 500 ataques isquémicos transitorios (AIT) y 2.400 nuevos accidentes cerebrovasculares por millón de habitantes, aproximadamente. Un tercio de los pa- 
cientes que sufren un accidente cerebrovascular muere en el periodo de 1 año y menos del $50 \%$ se recupera totalmente y recobra la independencia. Hoy se refiere a un mayor número de pacientes de edad avanzada a cirugía no cardiaca; entre ellos se encuentran los pacientes con enfermedades vasculares concomitantes que afectan a la circulación cerebral. Los factores de riesgo de eventos cerebrovasculares perioperatorios, tanto sintomáticos como asintomáticos, así como transitorios o permanentes (AIT/ictus), son la embolia o el deterioro hemodinámico de vasos grandes (aorta, arterias carotídeas y vertebrales y principales arterias cerebrales intracraneales) o de vasos pequeños (arteriolas perforantes y penetrantes y capilares). Aunque los accidentes cerebrovasculares fatales o no fatales pueden reducirse significativamente en pacientes sintomáticos con estenosis carotídea moderada o grave asociada a síntomas homolaterales, especialmente si se tratan precozmente (2-4 semanas, como mínimo 3-6 meses tras la aparición de los síntomas), el beneficio del tratamiento intervencionista/quirúrgico es menor en sujetos con síntomas neurológicos. Por lo tanto, las medidas de prevención de los accidentes cerebrovasculares son de suma importancia e incluyen una estrategia multidisciplinaria orientada al control de la hipertensión, la hiperlipemia, la diabetes mellitus, etc. La utilidad de agentes antiplaquetarios y anticoagulantes específicos se ha demostrado en numerosos ensayos clínicos sobre prevención primaria y secundaria. El uso de estos fármacos puede intensificarse en pacientes de edad avanzada que requieren cirugía no cardiaca y anestesia $^{184}$.

Además de los accidentes cerebrovasculares y los AIT, también pueden presentarse cambios transitorios o permanentes del estado mental del paciente, caracterizados por las alteraciones de atención, orientación, disfunción de la memoria, ilusiones, alucinaciones, afasia, etc. (características diagnósticas típicas del delirio), además de la ansiedad y la depresión, que no suelen diagnosticarse o reconocerse adecuadamente. Estos cambios pueden causarlos medicación perioperatoria, cirugía, hipotensión o hipertensión intraoperatoria y microembolias cerebrales que causan oclusiones múltiples en vasos pequeños e isquemia y pueden ser identificadas por Doppler intracraneal o imágenes de RM ponderadas por difusión. En la cirugía cardiaca, los cambios del estado mental suelen ser frecuentes y están asociados a disfunción cognitiva transitoria o incluso permanente (25-30\%). La probabilidad de que se presenten en pacientes de edad avanzada sometidos a cirugía no cardiaca es alta.

La prevalencia actual de los accidentes cerebrovasculares perioperatorios aparece resumida en tres grandes estudios de revisión ${ }^{185-187}$ en los que se com- para la incidencia de esta entidad en varios tipos de cirugía (un $0,08-0,07 \%$ en cirugía general, un $1-5 \%$ en cirugía periférica y carotídea y un $2-10 \%$ en cirugía cardiaca). Al contrario de lo que se cree normalmente, la mayoría de los accidentes cerebrovasculares no están relacionados con la hipoperfusión, sino que ocurren más frecuentemente en presencia de una autorregulación cerebral intacta ${ }^{187}$. Los mecanismos isquémicos y embólicos son mucho más comunes que el deterioro hemodinámico. Los accidentes cerebrovasculares que se presentan tardíamente se atribuyen fundamentalmente a varios tipos de embolia cardiaca, seguido de hipercoagulación y de un aumento de riesgo de eventos trombogénicos. Muchos accidentes cerebrovasculares no se diagnostican debido a la ausencia de síntomas motores y sensoriales importantes o porque los déficit neuropsicológicos son leves y, por lo tanto, difíciles de diagnosticar. Varios factores de riesgo del paciente y del procedimiento están asociados a un aumento de riesgo de accidente cerebrovascular perioperatorio. Estos riesgos deben ser analizados detenidamente para realizar una estimación de la razón riesgo/beneficio en cada paciente, optimizar el tratamiento, modificar los factores de riesgo y planificar la intervención en el momento más conveniente. Una historia de accidente cerebrovascular o AIT reciente es el predictor más poderoso de riesgo perioperatorio, por lo que se debe identificarlos en la evaluación de la historia del paciente y de su estado neurológico. En este contexto y en caso de duda, está indicada la realización de pruebas de imagen cerebrovascular adicionales. En pacientes con enfermedad carotídea y enfermedad cardiaca, las tasas de mortalidad por causas cardiacas superan el riesgo de accidente cerebrovascular. Una revisión de la literatura publicada entre 1970 y 2000 muestra que los pacientes con estenosis carotídea asintomática significativa tienen un alto riesgo de eventos cardiacos fatales y no fatales (el $8 \%$ anual), pero no de accidente cerebrovascular (un $1-2 \%$ anual) ${ }^{96}$. Sin embargo, hay tendencia a subestimar el riesgo de accidente cerebrovascular perioperatorio.

No puede proponerse una recomendación basada en la evidencia para el tratamiento de la estenosis carotídea antes de la cirugía no cardiaca, pero puede considerarse en casos excepcionales antes de cirugía cardiaca.

La suspensión del tratamiento con warfarina o agentes antiplaquetarios como preparación para la cirugía expone al paciente a un aumento de riesgo de accidente cerebrovascular perioperatorio. En una revisión de los resultados perioperatorios de pacientes tratados con warfarina, se observó una tasa del $0,6 \%$ de eventos tromboembólicos en los pacientes que mantuvieron el tratamiento frente al $7 \%$ en pacientes que recibieron heparina intrave- 
nosa como tratamiento puente a la cirugía ${ }^{188}$. No se ha establecido si estos resultados se deben a un control inadecuado de la administración del tratamiento o a dosis insuficientes de heparina. En la cirugía de reemplazo de rodilla o cadera, el uso continuado de warfarina a dosis bajas durante el periodo perioperatorio se demostró seguro y eficaz, al igual que en pacientes sometidos a procedimientos dentales, operación de cataratas y endoscopia diagnóstica en los que no se suspendió el régimen antiplaquetario o anticoagulante oral. Las intervenciones largas se asocian a un mayor riesgo de accidente cerebrovascular perioperatorio; la elección de la técnica quirúrgica es importante; además, el tipo de anestesia y de agentes anestésicos requieren especial consideración. Para reducir las tasas de accidente cerebrovascular incidental y muerte, se aconseja un control adecuado de la presión arterial adaptado a cada paciente y el manejo de la temperatura corporal y la glucosa sanguínea. Asimismo, es útil el uso de agentes antiplaquetarios antes, durante y después de la intervención. El uso de los llamados agentes neuroprotectores es motivo de controversia.

\section{Recomendaciones sobre el ictus/accidente isquémico transitorio (AIT)}

\begin{tabular}{|c|c|c|}
\hline Recomendación & Clase $^{a}$ & Nivel $^{b}$ \\
\hline $\begin{array}{l}\text { En caso de estenosis carotídea }>70 \% \text {, se recomienda } \\
\text { la instauración de tratamiento adicional, como } \\
\text { el tratamiento antiplaquetario y/o la cirugía }\end{array}$ & I & A \\
\hline $\begin{array}{l}\text { Puede considerarse la exploración sistemática de la } \\
\text { estenosis carotídea sintomática o asintomática }\end{array}$ & $\mathrm{llb}$ & C \\
\hline
\end{tabular}

\section{Enfermedad pulmonar}

La enfermedad pulmonar concomitante en pacientes programados para cirugía no cardiaca puede aumentar el riesgo de la operación. Entre estas enfermedades se incluyen infecciones respiratorias agudas, EPOC, asma, fibrosis quística, enfermedad pulmonar intersticial y otras entidades que afectan a la función respiratoria. La presencia de enfermedad pulmonar tiene un impacto significativo en el riesgo perioperatorio, especialmente un aumento de riesgo de complicaciones pulmonares postoperatorias. Estas complicaciones son fundamentalmente una consecuencia de la aparición de atelectasias durante la anestesia general. La respiración débil postoperatoria y la reducción de la expansión pulmonar, entre otros factores, pueden causar un colapso pulmonar con las consiguientes aparición o persistencia de infecciones respiratorias. Estas complicaciones ocurren principalmente tras la cirugía abdominal o torácica y el riesgo aumenta en los fumadores. Es necesario adoptar medidas de manejo específicas para reducir el riesgo de complicaciones pulmonares. Algunas enfermedades respiratorias asociadas a enfermedades cardiovasculares requieren una evaluación del riesgo cardiovascular y un manejo específico, además del manejo de la complicación respiratoria. Dos de estas enfermedades son la EPOC y la hipertensión arterial pulmonar (HAP).

La EPOC, definida como una obstrucción de las vías aéreas que no es completamente reversible, es una causa importante de morbimortalidad. La prevalencia de EPOC en adultos en Europa varía entre el 5 y el 10\%, aproximadamente, con una tendencia más elevada en varones que en mujeres. Por lo tanto, 1 de cada 10 pacientes que requiere cirugía podría tener EPOC.

El cor pulmonale con insuficiencia cardiaca derecha es una complicación directa de la EPOC grave. Además, la EPOC también está asociada a un aumento del riesgo de enfermedad coronaria. En una revisión sistemática de doce estudios de cohortes, los pacientes con un volumen espiratorio forzado el primer segundo $\left(\mathrm{VEF}_{1}\right)$ reducido tuvieron un aumento del $75 \%$ del riesgo de mortalidad cardiovascular, comparados con los pacientes con $\mathrm{VEF}_{1}$ normal $^{189}$. Un flujo espiratorio reducido también se asocia a una mayor incidencia de enfermedad coronaria no fatal y accidentes cerebrovasculares, estenosis carotídea, bajo índice tobillobrazo y lesiones cerebrales en la materia blanca. Esta asociación ocurre tanto en varones como en mujeres y, a pesar de la fuerte relación entre el tabaquismo y la EPOC y las ECV, es independiente de otros factores típicos de riesgo cardiovascular. Por cada reducción del $10 \%$ en el $\mathrm{VEF}_{1}$, la mortalidad cardiovascular aumenta un $30 \%$ y el número de eventos coronarios no fatales, un $20 \%$.

En los pacientes de cirugía de reparación de aneurisma aórtico los resultados son menos claros en lo que se refiere a la mortalidad a corto plazo (normalmente causada por complicaciones cardiacas). Como ejemplo, la EPOC se asocia con la mortalidad operatoria pero no con la mortalidad a los 30 días. En los pacientes de cirugía vascular, la EPOC no se asocia a un aumento de la mortalidad a los 30 días. Por lo tanto, y a pesar de su relación con las $\mathrm{ECV}$, no hay evidencia clara de que la EPOC se relacione con un mayor riesgo de complicaciones cardiacas perioperatorias.

La HAP puede ser idiopática, secundaria a enfermedad cardiaca congénita o familiar o puede estar asociada a entidades específicas, como la enfermedad vascular del colágeno. Hay que distinguir otras causas de la HAP como EPOC, tromboembolia y enfermedad congénita. El diagnóstico se 
basa en una presión arterial pulmonar media $>25$ $\mathrm{mmHg}$ en reposo y en una presión de enclavamiento pulmonar $\leq 15 \mathrm{mmHg}$. En registros europeos, la prevalencia varía entre 15 y 50 casos por millón de adultos; la mitad de estos casos son de HAP idiopática. La prevalencia es baja y, por lo tanto, esta enfermedad no es frecuente en el contexto quirúrgico.

La HAP aumenta el riesgo de complicaciones quirúrgicas, especialmente la insuficiencia ventricular derecha, la isquemia miocárdica y la hipoxia postoperatoria. En pacientes que requieren cirugía de bypass cardiopulmonar, una presión arterial preoperatoria media $>30 \mathrm{mmHg}$ es un predictor independiente de mortalidad. En un estudio en pacientes con hipertensión pulmonar sometidos a cirugía no cardiaca, de los que la mitad tenían HAP, los predictores de resultados incluían una clase funcional de la NYHA $\geq$ II, cirugía de riesgo intermedio o alto, la función ventricular derecha y la duración de la anestesia ${ }^{190}$. Aunque son necesarios más estudios, el mencionado confirmó que estos pacientes tienen un riesgo alto, ya que la tasa de complicaciones cardiopulmonares perioperatorias fue del $38 \%$ y la mortalidad, del $7 \%$.

La presencia de EPOC se considera normalmente en términos de riesgo de complicaciones pulmonares postoperatorias. En cuanto al riesgo cardiaco perioperatorio, la falta de evidencia sólida de que la EPOC aumente el riesgo puede obedecer a que los pacientes con EPOC han sido manejados con especial cuidado y, por lo tanto, no puede establecerse ninguna asociación.

En cualquier caso, la EPOC no está incluida en los índices de riesgo cardiaco preoperatorio, como los de Goldman, Detsky y Lee; de hecho, no se observaron ventajas en el valor pronóstico del índice Lee en pacientes de cirugía vascular cuando se incluía la EPOC ${ }^{191}$. Por otra parte, la HAP es tan infrecuente que no se ha considerado su inclusión en un modelo integrado de riesgo.

En los pacientes con enfermedad pulmonar programados para cirugía no cardiaca, los objetivos del manejo preoperatorio son optimizar la función pulmonar y minimizar las complicaciones respiratorias. Los objetivos del tratamiento de la EPOC son eliminar la infección activa con antibióticos, minimizar sibilancias por causas reversibles mediante broncodilatadores inhalados o esteroides, reducir la insuficiencia cardiaca derecha y del VI con diuréticos y asegurar una oxigenación adecuada; finalmente, se debe insistir sobre el abandono del tabaco antes de la intervención. En cuanto al manejo cardiaco perioperatorio, es similar en los pacientes con o sin EPOC; no hay contraindicaciones para el uso de bloqueadores beta cardioselectivos o estatinas en pacientes con EPOC $^{93,192}$.
La HAP es una enfermedad incurable y los objetivos de su tratamiento son reducir los síntomas y mejorar la capacidad de ejercicio y la función ventricular derecha. La anestesia y la cirugía pueden complicarse por insuficiencia cardiaca derecha aguda causada por un aumento de la resistencia pulmonar vascular, relacionada con la alteración de la ventilación pulmonar típica de los periodos operatorio y postoperatorio de la cirugía torácica y abdominal. El tratamiento farmacológico específico de la HAP incluye la administración de bloqueadores de los canales de calcio (sólo a los pacientes respondedores al test de vasorreactividad aguda), prostanoides, antagonistas de los receptores de la endotelina e inhibidores de la fosfodiesterasa tipo $5^{143,193}$. Antes de una intervención quirúrgica es recomendable optimizar el tratamiento farmacológico de los pacientes con HAP; además, el régimen de tratamiento específico de la HAP no debe suspenderse durante más de $12 \mathrm{~h}$ debido al ayuno perioperatorio. En caso de evolución a insuficiencia cardiaca en el postoperatorio, se recomienda ajustar la dosis de diuréticos y, si fuera necesario, instaurar un régimen de apoyo inotrópico con dobutamina. No se ha establecido la utilidad de instaurar un nuevo tratamiento específico de la HAP en el perioperatorio. En caso de insuficiencia cardiaca derecha grave que no responde a tratamiento de apoyo, puede considerarse la administración temporal de óxido nítrico inhalado o epoprostenol intravenoso con la ayuda de un especialista en el tratamiento de la HAP. En este caso, podría ser necesaria la suspensión progresiva de esta medicación.

\section{Recomendaciones sobre la enfermedad pulmonar}

\begin{tabular}{|c|c|c|}
\hline Recomendación & Clase $^{a}$ & Nivel $^{b}$ \\
\hline $\begin{array}{l}\text { En pacientes con hipertensión arterial pulmonar se } \\
\text { recomienda la optimización del tratamiento } \\
\text { farmacológico antes de cualquier intervención } \\
\text { quirúrgica }\end{array}$ & I & C \\
\hline $\begin{array}{l}\text { En caso de progresión de la insuficiencia derecha } \\
\text { en el postoperatorio de los pacientes con hipertensión } \\
\text { arterial pulmonar, se recomienda optimizar la dosis } \\
\text { de diuréticos y, si fuera necesario, iniciar apoyo } \\
\text { inotrópico con dobutamina }\end{array}$ & n & C \\
\hline $\begin{array}{l}\text { En caso de insuficiencia derecha resistente al } \\
\text { tratamiento de apoyo, puede considerarse la } \\
\text { administración de óxido nítrico inhalado o } \\
\text { epoprostenol intravenoso con la colaboración } \\
\text { de un experto en el tratamiento de la hipertensión } \\
\text { arterial pulmonar }\end{array}$ & llb & C \\
\hline $\begin{array}{l}\text { No se recomienda un manejo perioperatorio especial } \\
\text { del riesgo cardiaco en pacientes con enfermedad } \\
\text { pulmonar obstructiva crónica }\end{array}$ & III & C \\
\hline
\end{tabular}

aClase de recomendación.

bNivel de evidencia. 
En los pacientes con EPOC o HAP la incidencia de insuficiencia cardiaca y enfermedad coronaria es relativamente alta. No hay evidencia clara de que los pacientes con EPOC tengan mayor riesgo de complicaciones cardiacas perioperatorias y muerte, por lo que el manejo de estos pacientes es similar al de los pacientes sin esta enfermedad. Por otro lado, la HAP aumenta el riesgo perioperatorio, por lo que requiere una evaluación preoperatoria del riesgo y, si es grave, requiere tratamiento perioperatorio.

\section{MONITORIZACIÓN PERIOPERATORIA}

\section{Electrocardiografía}

Si bien un electrocardiograma con signos de isquemia realizado en la sala de recuperación es un predictor de complicaciones cardiacas graves durante la estancia en el hospital, la monitorización electrocardiográfica por sí sola no es el método adecuado para la detección de la isquemia a tiempo real en la unidad de cuidados intensivos (UCI) ni durante la intervención quirúrgica ${ }^{194-196}$. La monitorización electrocardiográfica convencional para la detección de los cambios transitorios del segmento ST es inexacta ${ }^{196}$. Aunque durante años la derivación V5 se consideró la mejor opción para la detección de la isquemia intraoperatoria ${ }^{197,198}$, en un ensayo clínico se demostró que la derivación V4 es más sensible y apropiada que la V5 para la detección de la isquemia postoperatoria prolongada y el infarto $^{199}$. No hay derivaciones específicas para determinados eventos isquémicos y, lo que es más, éstos son dinámicos y no siempre aparecen en la misma derivación. Si se utiliza una determinada derivación, se corre el riesgo de no identificar eventos isquémicos. Con el uso de una combinación de derivaciones se puede diagnosticar con más precisión más eventos isquémicos en el contexto intraoperatorio. En un estudio, aunque la mayor sensibilidad se obtuvo con la derivación V5 (75\%), seguida de la V4 (61\%), la combinación de V5 y V4 aumentó la sensibilidad al $90 \%{ }^{198}$. En ese mismo estudio, cuando se usaron tres derivaciones simultáneamente (II, V4 y V5), la sensibilidad alcanzó el $96 \%{ }^{198}$. De forma similar, en otro estudio en el que se utilizaron dos o más derivaciones precordiales, la sensibilidad del ECG fue del 95\% para la detección de la isquemia perioperatoria y el infarto ${ }^{199}$. También se ha demostrado que la monitorización electrocardiográfica con un número bajo de derivaciones (tres) tiene menos sensibilidad que la monitorización con 12 derivaciones y que hay relación estadísticamente significativa, independiente de las cifras perioperatorias de troponina, entre la isquemia perioperatoria detectada en el ECG de 12 derivaciones y la mortalidad a largo plazo $^{200-202}$. Por todo ello, se recomienda la utilización de monitorización electrocardiográfica con 12 derivaciones, especialmente en pacientes con alto riesgo.

En pacientes con trastornos de la conducción intraventricular (como bloqueo completo de rama izquierda) y marcapasos ventricular, la monitorización de los cambios del segmento ST está limitada $^{203}$. Los cambios secundarios ST-T en estos pacientes se debían a una despolarización anormal que distorsionaba también el proceso de repolarización. Los segmentos ST distorsionados limitan la sensibilidad del sistema de monitorización del segmento $\mathrm{ST}^{203}$. Debido a que la detección de los cambios del segmento ST por inspección visual del ECG es pobre, los monitores modernos incorporan un sistema de análisis computarizado. Para facilitar la detección de la isquemia, actualmente la mayoría de los quirófanos incorporan equipos de electrocardiografía con un sistema automático continuo de detección de los cambios del ST. Este sistema aumenta la sensibilidad del ECG para la detección de la isquemia ${ }^{196}$. En un estudio se utilizó el Holter como referencia estándar para la detección de la isquemia intraoperatoria, y se observó que la monitorización automática de los cambios del ST tenía una sensibilidad y una especificidad del 74 y el $73 \%$ respectivamente. Varios factores contribuyeron a la falta de precisión de los sistemas de monitorización del ST y fue necesario modificar su funcionamiento para lograr una mayor concordancia con el análisis del Holter ${ }^{196}$.

En una serie de estudios realizados en la década de los noventa, la presencia de cambios en el ECG durante la monitorización de cohortes de alto riesgo se relacionó con una mayor incidencia del IM y eventos cardiacos perioperatorios. Además, la duración de los cambios del ST tiene una correlación positiva con la incidencia del IM perioperatorio ${ }^{204}$. Por lo tanto, cuando ocurren alteraciones del segmento ST, el médico debe asumir que hay isquemia miocárdica ${ }^{205}$. Sin embargo, no se ha establecido claramente si la monitorización electrocardiográfica es suficientemente sensible para identificar a los pacientes en bajo riesgo ${ }^{206,207}$. Además, la utilidad de

\section{Recomendaciones sobre la monitorización electrocardiográfica}

\begin{tabular}{lcc}
\hline Recomendación & Clase $^{\mathbf{a}}$ & Nivel $^{\mathbf{b}}$ \\
\hline $\begin{array}{l}\text { Se recomienda la monitorización electrocardiográfica } \\
\text { de } 12 \text { derivaciones en todos los pacientes }\end{array}$ & C \\
$\begin{array}{l}\text { sometidos a cirugía } \\
\begin{array}{l}\text { Debe considerarse la utilización de determinadas } \\
\text { combinaciones de derivaciones que permitan una } \\
\text { mejor detección de la isquemia durante la cirugía }\end{array}\end{array}$ & lla & B \\
\hline
\end{tabular}

aClase de recomendación.

${ }^{b}$ Nivel de evidencia. 
esta prueba en la población general es escasa, ya que en muchos estudios se excluyó a los pacientes con cambios electrocardiográficos que interfiriesen con la valoración de la isquemia.

\section{Ecocardiografía transesofágica}

Desde mediados de la década de los ochenta, la ecocardiografía transesofágica (ETE) se ha utilizado como instrumento de monitorización en la cirugía cardiaca. Sin embargo, hay pocos datos basados en la evidencia que respalden el uso de esta técnica en la cirugía no cardiaca. La ETE ofrece una serie de ventajas respecto a otros métodos de monitorización, como la cateterización arterial pulmonar. La ETE puede utilizarse con rapidez, es una técnica relativamente no invasiva y ofrece información versátil e integral. Aunque generalmente es un procedimiento seguro, pueden ocurrir eventos adversos graves. La tasa de complicaciones se relaciona con la experiencia del operador y con la presencia de enfermedad esofágica o gástrica. Es imprescindible el entrenamiento de los operadores para evitar una interpretación inadecuada de los resultados.

La isquemia miocárdica se puede identificar por alteraciones en la movilidad regional y engrosamiento de la pared. La concordancia entre la ETE y el ECG intraoperatorios es baja ${ }^{208}$. Las alteraciones del segmento ST y de la movilidad regional de la pared pueden darse en ausencia de isquemia aguda. Las alteraciones de la movilidad regional pueden ser difíciles de interpretar en presencia de bloqueo completo de rama izquierda, marcapasos ventricular, FA o sobrecarga ventricular derecha. La resolución de la isquemia no siempre es detectable si se sigue de aturdimiento miocárdico. Los episodios de nuevas alteraciones de la movilidad regional o su empeoramiento no son frecuentes $(20 \%)$ en pacientes con alto riesgo sometidos a cirugía no cardiaca $^{208}$, y sí lo son en pacientes de cirugía vascular aórtica. Estos episodios tienen poca relación con la incidencia de complicaciones cardiacas postoperatorias ${ }^{208}$.

\section{Recomendaciones sobre ecocardiografía transesofágica intraoperatoria y/o perioperatoria para la detección de la isquemia miocárdica}

\begin{tabular}{lcc}
\hline Recomendación & Clase $^{\mathbf{a}}$ & Nivel $^{\mathbf{b}}$ \\
\hline $\begin{array}{l}\text { Debe considerarse la realización de ETE en pacientes } \\
\text { con cambios del segmento ST detectados en el ECG } \\
\text { intraoperatorio o perioperatorio }\end{array}$ & Ila & \\
$\begin{array}{l}\text { Puede considerarse el uso de ETE en pacientes con } \\
\text { alto riesgo de isquemia miocárdica sometidos }\end{array}$ & Ilb & C \\
a cirugía mayor no cardiaca & & \\
\hline
\end{tabular}

ECG: electrocardiograma; ETE: ecocardiografía transesofágica. aClase de recomendación.

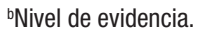

Si se la compara con los datos clínicos preoperatorios y la monitorización electrocardiográfica intraoperatoria de dos derivaciones, la monitorización sistemática con ETE o ECG de 12 derivaciones tiene escasa utilidad en la identificación de pacientes con alto riesgo de eventos isquémicos perioperatorios ${ }^{209}$.

El uso de la ETE está recomendado en caso de inestabilidad hemodinámica aguda y grave o de alteraciones potencialmente mortales durante o después de la cirugía ${ }^{210}$. La ventaja de la ETE frente a la cateterización arterial pulmonar es que permite una evaluación más comprehensiva de la función y la estructura cardiacas. Además, ofrece rápidamente información sobre la presencia de disfunción regional o general, ventricular derecha o izquierda, sobre la presencia de taponamiento cardiaco o trombos y una estimación de la precarga mediante la determinación del volumen diastólico final. Se han propuesto numerosos índices para la función ventricular y auricular, pero la mayoría de los parámetros dependen de la carga.

La utilidad de la ETE para la monitorización hemodinámica en pacientes en riesgo es más controvertida. Existen sistemas de análisis automático, pero no están suficientemente validados. No hay evidencia de que la monitorización hemodinámica mediante ETE permita estratificar el riesgo o predecir los resultados de forma adecuada.

La ETE puede ser de utilidad durante la cirugía en pacientes con lesiones valvulares graves. Las condiciones de carga durante la anestesia general son diferentes de las que se encuentran en la evaluación preoperatoria. La regurgitación mitral, funcional o isquémica, suele reducirse durante la anestesia general, mientras que la regurgitación mitral orgánica puede aumentar. En caso de regurgitación mitral grave, la fracción de eyección del VI sobrestima la función del VI, por lo que otros parámetros podrían ser más precisos, como las velocidades miocárdicas o la deformación obtenida mediante imagen tisular por Doppler o mediante la técnica $2 D$ speckle tracking (un método independiente del ángulo). Estas técnicas son prometedoras, pero son necesarios más estudios de validación antes de que se pueda utilizarlas en este contexto. En pacientes con estenosis aórtica grave es importante mantener una precarga adecuada durante la cirugía. La monitorización del volumen diastólico final del VI es más precisa que la presión de enclavamiento pulmonar. El control adecuado de la frecuencia cardiaca es crucial en pacientes con estenosis mitral o regurgitación aórtica: en los primeros es deseable una diástole larga, mientras que en los segundos lo es una diástole más corta. Si el control de la frecuencia cardiaca no es adecuado, se precisa valorar las consecuencias: los cambios en el gradiente trans- 
mitral y las presiones arteriales pulmonares en caso de estenosis mitral y los cambios en los volúmenes del VI y los índices de función del VI en caso de regurgitación aórtica.

\section{Recomendaciones sobre ecocardiografía transesofágica intraoperatoria y/o perioperatoria en pacientes con inestabilidad hemodinámica o riesgo de sufrirla}

\begin{tabular}{lcc}
\hline Recomendación & Clase $^{\mathrm{a}}$ & Nivel $^{\mathrm{b}}$ \\
\hline $\begin{array}{l}\text { Se recomienda la realización de ETE siempre que } \\
\text { aparezcan alteraciones hemodinámicas agudas, }\end{array}$ & $\mathrm{I}$ & $\mathrm{C}$ \\
$\begin{array}{l}\text { graves y persistentes durante la cirugía o en } \\
\text { el periodo perioperatorio }\end{array}$ & & \\
$\begin{array}{l}\text { Puede considerarse la monitorización con ETE en } \\
\text { pacientes con alto riesgo de alteraciones } \\
\text { hemodinámicas importantes durante y después }\end{array}$ & Ilb & $\mathrm{C}$ \\
de la cirugía mayor no cardiaca & & \\
$\begin{array}{l}\text { En pacientes con lesiones valvulares graves, } \\
\text { puede considerarse la monitorización con ETE } \\
\text { durante la cirugía mayor no cardiaca con estrés }\end{array}$ & Ilb & $\mathrm{C}$ \\
hemodinámico significativo & \\
\hline
\end{tabular}

ETE: ecocardiografía transesofágica.

aClase de recomendación.

bNivel de evidencia

\section{Cateterización de corazón derecho}

La mayoría de los episodios isquémicos son silentes y no van acompañados de cambios en la presión de enclavamiento capilar pulmonar. La cateterización de corazón derecho no está recomendada para la monitorización de pacientes con isquemia intraoperatoria. En dos importantes estudios, uno observacional y otro multicéntrico aleatorizado, no se observaron beneficios asociados al uso de cateterización de corazón derecho tras cirugía mayor no cardiaca ${ }^{211,212}$. Se realizó un análisis de casos y controles en el subgrupo de pacientes incluidos en dicho estudio observacional, en los que se había realizado la inserción de un catéter arterial pulmonar, comparándolos con un grupo similar de pacientes en los que no se había realizado cateterismo derecho. En el grupo en el que se realizó cateterismo derecho se observó una mayor incidencia de insuficiencia cardiaca postoperatoria y eventos no cardiacos, aun tras realizar ajuste por procedimiento quirúrgico y necesidad de cateterismo ${ }^{211}$.

En el estudio aleatorizado, no se observaron diferencias en la mortalidad ni en la duración de la hospitalización, pero los pacientes asignados a cateterización derecha tuvieron una mayor incidencia de embolia pulmonar ${ }^{212}$.

\section{Alteraciones del metabolismo de la glucosa}

La diabetes mellitus es un importante factor de riesgo de complicaciones cardiacas perioperatorias y muerte. Esta entidad promueve aterosclerosis, disfunción endotelial y activación de plaquetas y citocinas proinflamatorias. El estrés quirúrgico se asocia al estrés hemodinámico y el vasospasmo, al tiempo que acentúa el estado protrombótico inhibiendo la fibrinolisis. Esto puede llevar a inestabilidad de placas coronarias preexistentes, formación de trombos, oclusión vascular e IM. En ausencia de diabetes, la hiperglucemia tiene un papel importante y, siempre que sea posible, requiere un manejo preoperatorio. Su importancia quedó demostrada en estudios realizados en pacientes con concentraciones prediabéticas de glucosa sometidos a cirugía no cardiaca (vascular y no vascular), en los que se observó un aumento de 2 a 4 veces del riesgo de isquemia miocárdica, liberación de troponinas, eventos cardiacos a los 30 días y tardíos y del riesgo de mortalidad, especialmente de la mortalidad cardiovascular ${ }^{213,214}$. Hay que recordar que la tolerancia disminuida a la glucosa normalmente sólo se identifica tras la carga de glucosa. Las enfermedades críticas son entidades caracterizadas por la alteración de la homeostasis de la glucosa («diabetes de estrés» o «diabetes del trauma»), que se desarrolla independientemente de que haya una diabetes previamente diagnosticada $\mathrm{y}$ ha sido identificada como un factor de riesgo importante de morbilidad y/o mortalidad.

Los datos de la International Diabetes Foundation revelan una prevalencia alta y en aumento de la diabetes en Europa, del 7,8 al 8,4\% entre 2003 y 2007, con una prevalencia estimada de al menos el $9,1 \%$ en $2025^{215}$. Más del $30 \%$ de los casos no se habían diagnosticado previamente, lo cual indica que el problema está infravalorado. Con una población afectada de 48 millones de personas aproximadamente, la diabetes es una de las causas de morbilidad y mortalidad más importantes en Europa. Según la Organización Mundial de la Salud, alrededor del $50 \%$ de estos pacientes fallecen por enfermedades cardiovasculares. Está claramente establecido que la cirugía en pacientes con diabetes se asocia a hospitalización más larga, mayor utilización de recursos médicos y mortalidad perioperatoria más elevada. Recientemente se ha señalado la importancia de la hiperglucemia por sí sola. La hiperglucemia de nueva aparición, comparada con la hiperglucemia en diabéticos conocidos, puede suponer un riesgo mucho mayor de resultados adversos ${ }^{216}$.

La evidencia para el estricto control de la glucemia en pacientes sin diabetes conocida sometidos a cirugía no cardiaca deriva fundamentalmente de estudios realizados en pacientes $\operatorname{críticos}^{217}$. En 2001, el importante estudio de Leuven (estudio prospectivo, aleatorizado y controlado) demostró beneficios clínicos significativos en pacientes quirúrgicos de la UCI en los que la glucemia se mantuvo en va- 
lores normales $(5-5,6 \mathrm{mmol} / \mathrm{l} ; 90-100 \mathrm{mg} / \mathrm{dl}) \mathrm{me}-$ diante tratamiento intensivo con insulina, comparados con pacientes en los que se aplicó un manejo convencional de la glucosa y sufrieron hiperglucemia $(8,3-8,9 \mathrm{mmol} / \mathrm{l} ; 150-160 \mathrm{mg} / \mathrm{dl})^{218}$. Entre estos beneficios, una menor mortalidad (intrahospitalaria y en la UCI) y la prevención de complicaciones asociadas a la enfermedad crítica (polineuropatía de enfermedad crítica, infecciones graves, insuficiencia renal aguda y dependencia prolongada de la ventilación mecánica y de los cuidados intensivos). También mejoraron los resultados a largo plazo, como se demostró en el subgrupo de pacientes de cirugía cardiaca. Cinco años más tarde, el grupo de Leuven publicó los resultados en pacientes de la UCI, en los que se observó un beneficio en la prevención de la morbilidad, pero no en la mortalidad, mediante el control intensivo de la glucosa, excepto en un subgrupo de pacientes que necesitó cuidados intensivos durante al menos 3 días $^{219}$. Con base en estos dos estudios, se establecieron recomendaciones para el estricto control de la glucosa. Varios estudios observacionales de implementación del manejo estricto de la glucosa y otros estudios aleatorizados realizados en grupos seleccionados de pacientes de la UCI confirmaron los beneficios clínicos observados en los estudios de Leuven ${ }^{217}$. El análisis conjunto de los estudios de Leuven confirmó una reducción de la morbimortalidad tras el ingreso en la UCI en todos los subgrupos más importantes de diagnóstico clínico: enfermedad o cirugía cardiovascular, respiratoria, gastrointestinal/ hepática, enfermedad maligna activa o sepsis. Los pacientes con diabetes conocida tuvieron una morbilidad menor, pero sin beneficios en cuanto a la supervivencia. En todos los estudios citados anteriormente se inició el control de la glucosa tras el ingreso en la UCI. El momento de instauración del tratamiento con insulina es un tema controvertido, aunque en un estudio reciente se observaron mejores resultados cuando el tratamiento se inició durante las primeras $48 \mathrm{~h}$ que transcurridas las $48 \mathrm{~h}$. El control intraoperatorio de la glucosa podría aportar beneficios adicionales pero, por su dificultad, hasta la fecha sólo se han realizado estudios en cirugía cardiaca. Un moderado control intraoperatorio de la glucosa durante la cirugía de bypass aortocoronario (no mantenido en la UCI) resultó en reducción de la necesidad de marcapasos, menor incidencia de FA e infecciones y reducción de la estancia en el hospital/UCI y de los eventos de isquemia recurrente a largo plazo. Sin embargo, el control de la glucosa durante la cirugía cardiaca y en la UCI no resultó en una reducción adicional de la morbimortalidad ${ }^{220}$. En un estudio observacional, el estricto control de la glucosa durante la cirugía de trasplante de hígado se asoció a menores tasas de infecciones y de mortalidad al año que un control menos intensivo de la glucosa ${ }^{221}$.

Estudios realizados en el campo de los cuidados intensivos han demostrado el efecto perjudicial de la hiperglucemia por su efecto adverso en la función renal y hepática, la función endotelial y la respuesta inmunitaria, especialmente en los pacientes sin diabetes subyacente. En los estudios de Leuven, el riesgo de muerte y el grado de hiperglucemia se correlacionaban positivamente. La demostración inequívoca de que el control de la hiperglucemia, más que los efectos directos de la insulina, mediaba en la supervivencia y los beneficios en la morbilidad con el tratamiento con insulina se obtuvo en un estudio en modelos animales (conejos) de enfermedad crítica $^{222}$. Varios factores de riesgo cardiaco tras la cirugía no cardiaca se atenúan con un estricto control de la glucemia en la UCI, entre ellos la disfunción/daño endotelial, la proteína $\mathrm{C}$ reactiva y la dimetilarginina asimétrica, además de los efectos en el daño mitocondrial, el perfil lipídico sérico y la respuesta del cortisol. No se observaron efectos o sólo fueron marginales en las citocinas, la coagulación y la fibrinolisis.

Recientemente se cuestionaron los resultados de los estudios de Leuven sobre los beneficios del uso de un control estricto de la glucemia. En el estudio NICE-SUGAR más de 6.000 pacientes (el 63\% pacientes no quirúrgicos y el $37 \%$ pacientes quirúrgicos, ambos de la UCI) fueron asignados a un estricto control glucémico (objetivo de glucosa, 4,5-6 $\mathrm{mmol} / \mathrm{l} ; 81-108 \mathrm{mg} / \mathrm{dl}$ ) o a un control convencional de la glucosa (objetivo de glucosa, 8-10 mmol/l; $144-180 \mathrm{mg} / \mathrm{dl})^{223}$. En el grupo de control de la glucosa, el tratamiento con infusión de insulina intravenosa se instauró en las primeras $24 \mathrm{~h}$ tras el ingreso. El objetivo primario de muerte a los 90 días de la inclusión aumentó en el grupo de control estricto de la glucosa $(27,5 \%)$, comparado con el $24,9 \%$ del grupo de control convencional. No se observaron diferencias en la morbilidad entre los grupos, por lo que no se explica el exceso de mortalidad. Como cabría esperar, la hipoglucemia $(<40$ $\mathrm{mg} / \mathrm{dl}$ ) ocurrió en más pacientes del grupo de control intensivo que en el grupo de control convencional (el 6,8 frente al 0,5\%; p < 0,001). La fuerza del estudio NICE-SUGAR fue su gran dimensión y el diseño multicéntrico con un protocolo para la infusión de insulina guiado por un sistema informático. Sin embargo, el estudio utilizaba un algoritmo «si (condición), entonces» basado en glucómetros inexactos no estandarizados para la determinación de la glucosa en sangre. Además de esto, el estudio tenía un diseño abierto, un pequeño desequilibrio entre los dos grupos con respecto al tratamiento con corticoides y un $10 \%$ de los pacientes asignados al grupo de control intensivo de la glucosa que 
abandonaron el estudio prematuramente. Las diferencias entre los resultados de estos estudios requieren explicación.

1. Los estudios de Leuven fueron realizados en un solo centro con atención estandarizada que incluía nutrición parenteral como suplemento de la nutrición enteral, mientras que en el estudio NICESUGAR predominaba la nutrición enteral, que resultaba en un aporte hipocalórico, especialmente durante la primera semana tras el ingreso en la UCI.

2. La glucemia objetivo para la instauración de la insulina en el grupo convencional fue diferente; en el estudio de Leuven sólo se iniciaba la administración de insulina cuando la glucosa en sangre excedía el umbral renal $>215 \mathrm{mg} / \mathrm{dl}$ (considerando la hiperglucemia como una posible adaptación beneficiosa), mientras que en el NICE-SUGAR se utilizó un objetivo de $144-180 \mathrm{mg} / \mathrm{dl}$ en el grupo convencional, que resultó en un $70 \%$ de pacientes tratados con insulina y una media de glucemia de $8 \mathrm{mmol} / \mathrm{l}(144 \mathrm{mg} / \mathrm{dl})$.

3. En el grupo de control intensivo del estudio NICE-SUGAR, el cumplimiento del tratamiento fue peor que en los estudios de Leuven, lo cual resultó en una media de glucemia de $6,6 \mathrm{mmol} / \mathrm{l}(118$ $\mathrm{mg} / \mathrm{dl}$ ) y una superposición importante con las glucemias del grupo control.

4. El uso de glucómetros inadecuados en el estudio NICE-SUGAR pudo influir negativamente en el tratamiento con insulina y pasar por alto la hipopotasemia, una causa posible del exceso de mortalidad cardiovascular, que se previene con el uso de analizadores de gases en sangre para la determinación de la glucosa.

5. La experiencia del personal de enfermería para el control intensivo en el estudio NICE-SUGAR fue menor que en los estudios de Leuven, a la vista del escaso número de pacientes reclutados por centro $(<15 \%$ de todos los pacientes cribados en la UCI participante), comparado con un $70-95 \%$ en los estudios de Leuven.

Los resultados del estudio NICE-SUGAR indican que el control intensivo de la glucosa puede ser perjudicial para la mortalidad de los pacientes ingresados en la UCI cuando las cifras de glucosa son $<7,8-10 \mathrm{mmol} / 1$ (140-180 mg/dl). Por el contrario, la evidencia derivada de estudios previos indica que mantener la normoglucemia (4,4-6,1 $\mathrm{mmol} / \mathrm{l} ; 80-110 \mathrm{mg} / \mathrm{dl}$ ) ofrece beneficio clínico, comparado con la tolerancia de la hiperglucemia hasta $11,9 \mathrm{mmol} / \mathrm{l}(215 \mathrm{mg} / \mathrm{dl})$ en pacientes adultos con enfermedad crítica (tabla 10).

Hasta que dispongamos de datos que puedan explicar las diferencias entre los resultados de ambos estudios, se recomienda la optimización del manejo de la glucemia en la UCI, evitando tanto la hiper-
TABLA 10. Beneficios clínicos del tratamiento intensivo con insulina en pacientes con enfermedades críticas de diagnóstico no cardiaco tras el ingreso en la $\mathrm{UCl}^{218,219}$

\begin{tabular}{|c|c|c|c|}
\hline & \multicolumn{2}{|c|}{$\begin{array}{c}\text { Estancia en la UCI } \\
\geq \mathbf{3} \text { días }\end{array}$} & \multirow[t]{2}{*}{$\mathbf{p}$} \\
\hline & $\begin{array}{c}\text { TCI } \\
(n=643)\end{array}$ & $\begin{array}{c}\text { TII } \\
(n=648)\end{array}$ & \\
\hline Mortalidad en la UCI, \% & 27,4 & 22,7 & 0,05 \\
\hline Mortalidad intrahospitalaria, \% & 38,7 & 32,1 & 0,01 \\
\hline Terapia de reemplazo renal, \% & 11,2 & 7,3 & 0,02 \\
\hline Enfermedad crítica o polineuropatía ${ }^{a}, \%$ & 51,3 & 34,4 & $<0,01$ \\
\hline Bacteriemia & 13,5 & 10,6 & 0,11 \\
\hline Ventilación mecánica (días) ${ }^{\mathrm{b}}$ & $8[4-17]$ & 7 [3-13] & 0,01 \\
\hline Estancia en la UCI (días) ${ }^{\text {b }}$ & $9[4-18]$ & $8[4-15]$ & 0,05 \\
\hline
\end{tabular}

TCl: tratamiento convencional con insulina; TII: tratamiento intensivo con insulina; UCl: unidad de cuidados intensivos.

aPorcentaje de pacientes cribados.

'Los datos expresan mediana [intervalo intercuartílico].

glucemia como la hipoglucemia. Los datos disponibles indican que esta estrategia debe iniciarse inmediatamente después del ingreso en la UCI. Podría ser aconsejable una glucemia objetivo alrededor de $8 \mathrm{mmol} / \mathrm{l}(144 \mathrm{mg} / \mathrm{dl})$ en un contexto y una población comparables a los utilizados en el estudio NICE-SUGAR.

\section{Recomendaciones sobre el control de la glucemia}

\begin{tabular}{|c|c|c|}
\hline Recomendación & Clase $^{a}$ & Nivel $^{b}$ \\
\hline $\begin{array}{l}\text { Se recomienda la prevención postoperatoria de la } \\
\text { hiperglucemia (objetivo al menos }<10 \mathrm{mmol} / \mathrm{l} \\
\text { [180 mg/dl]) mediante tratamiento intensivo con } \\
\text { insulina en adultos tras la cirugía mayor de alto } \\
\text { riesgo o complicada que requiere ingreso en la UCl }\end{array}$ & I & $\mathrm{B}$ \\
\hline $\begin{array}{l}\text { Puede considerarse la prevención intraoperatoria } \\
\text { de la hiperglucemia mediante la administración } \\
\text { de insulina }\end{array}$ & Ilb & C \\
\hline $\begin{array}{l}\text { Puede considerarse la prevención postoperatoria } \\
\text { de la hiperglucemia mediante la administración } \\
\text { de insulina tras la cirugía electiva y sin } \\
\text { complicaciones }\end{array}$ & Ilb & C \\
\hline
\end{tabular}

UCl: unidad de cuidados intensivos.

aClase de recomendación.

bNivel de evidencia.

\section{Anestesia}

Un manejo perioperatorio óptimo requiere la estrecha colaboración entre cardiólogos, cirujanos, neumólogos y anestesistas. La evaluación del riesgo y la optimización del manejo de la enfermedad cardiaca en el periodo preoperatorio deben realizarse conjuntamente. 
No disponemos de datos basados en la evidencia que respalden la elección de una estrategia perioperatoria determinada, por lo que es preciso considerar distintas opciones. En cuanto a los pacientes cardiacos que requieren cirugía no cardiaca, no se han realizado estudios aleatorizados con el poder estadístico suficiente que investiguen la relación entre los resultados del paciente y el manejo perioperatorio.

\section{Manejo intraoperatorio de la anestesia}

Se considera que la elección del agente anestésico tiene poca relevancia para el curso evolutivo del paciente siempre que se mantenga un soporte vital adecuado. En el campo de la cirugía cardiaca hay evidencia contradictoria sobre cuál es el método más ventajoso en los pacientes cardiacos, pero en el de la cirugía no cardiaca no hay evidencia respecto a la superioridad de un determinado agente anestésico ${ }^{224,225}$.

La mayoría de las técnicas anestésicas disminuyen el tono del sistema nervioso simpático produciendo vasodilatación y una disminución de la presión sanguínea sistémica. Por ello, el manejo de la anestesia debe garantizar el mantenimiento de una adecuada presión de perfusión en los distintos órganos.

\section{Técnicas neuraxiales}

Tanto la anestesia espinal como la epidural inducen un bloqueo del sistema nervioso simpático. Del nivel al que se realice el bloqueo dependerán la vasodilatación periférica y el descenso de la presión arterial. Si alcanza el dermatoma torácico (cuarto nivel), se producirá una reducción de la estimulación simpática del corazón, con ulteriores disminución de la contractilidad miocárdica y la frecuencia cardiaca y cambios en las condiciones de carga. La velocidad de instauración y la intensidad del bloqueo simpático dependerán de la dosis y el agente utilizado, así como del estado del paciente. Hay evidencia contradictoria respecto al efecto del bloqueo neuraxial en la evolución del paciente sometido a cirugía no cardiaca. En un metaanálisis se observó que, en comparación con la anestesia general, el bloqueo neuraxial se asociaba a una mejoría significativa de la supervivencia y una menor incidencia de complicaciones tromboembólicas, cardiacas y pulmonares postoperatorias ${ }^{226}$. La mayor crítica a dicho metaanálisis es la inclusión de estudios antiguos y que, por consiguiente, los resultados podrían no ser aplicables a la práctica actual. Un reciente análisis de una gran cohorte de pacientes (10.564 pacientes sin epidural y 2.253 pacientes con epidural) en los que se practicó resección de colon con- firmó una mayor supervivencia a los 7 y 30 días de la cirugía asociada a la analgesia epidural, aunque no fue posible determinar las causas de muerte ${ }^{227}$. No se observaron diferencias en la morbilidad cardiaca entre ambos grupos.

Varios estudios aleatorizados y un metaanálisis de ensayos clínicos aleatorizados realizados en pacientes de cirugía no cardiaca y en los que se comparaba la anestesia regional con la general han proporcionado una evidencia muy limitada sobre la superioridad de la anestesia regional para la evolución del paciente y la reducción de la morbimortalidad postoperatoria ${ }^{228-230}$. Se estima que el número de pacientes necesarios para que un estudio aleatorizado pueda determinar si la anestesia o la analgesia epidural afecta a la mortalidad en pacientes sometidos a cirugía vascular de alto riesgo es de, aproximadamente, 24.000 pacientes y que serían necesarios 1,2 millones de pacientes para realizarlo en los procedimientos de bajo riesgo ${ }^{227}$. Los ensayos clínicos llevados a cabo hasta la fecha no tienen suficiente poder estadístico para realizar un análisis válido del riesgo de muerte en procedimientos con bajo riesgo quirúrgico. Ningún estudio ha demostrado claramente una modificación de los resultados mediante el uso de distintas técnicas de monitorización, manejo de fluidos o estrategias de transfusión. La mayoría de los estudios han utilizado objetivos terapéuticos predeterminados que, generalmente, requieren apoyo inotrópico, un factor que podría influir en los resultados ${ }^{212}$. Frecuentemente se señala la importancia de un manejo anestésico experto en el mantenimiento de una circulación adecuada ${ }^{231}$.

\section{Manejo del dolor postoperatorio}

El dolor postoperatorio, que sufre un $5-10 \%$ de los pacientes, es un motivo de preocupación. Puede aumentar el impulso simpático y retrasar la recuperación ${ }^{232,233}$. No está claro si el dolor postoperatorio puede causar complicaciones orgánicas. La analgesia neuraxial con anestésicos/opiáceos locales y/o agonistas alfa-2, opiáceos intravenosos, solos o combinados con antiinflamatorios no esteroideos, parece ser el método más efectivo. Debe sopesarse el beneficio de las técnicas analgésicas invasivas frente a los peligros potenciales. Esta cuestión tiene especial interés cuando se considera el uso de bloqueo neuraxial en pacientes con tratamiento antitrombótico por tiempo indefinido debido al aumento de la probabilidad de hematoma neuraxial. Esta guía no incluye recomendaciones para el uso de bloqueo neuraxial en pacientes con trastornos de la coagulación.

La analgesia controlada por el paciente es una alternativa para el alivio del dolor postoperatorio. 
Recientes metaanálisis de estudios controlados muestran que la analgesia controlada por el paciente ofrece ventajas en lo que se refiere a la satisfacción del paciente frente a la analgesia controlada por el personal de enfermería o la analgesia a demanda $^{234}$. No se han demostrado diferencias en morbilidad o resultados finales. La analgesia controlada por el paciente es una buena alternativa en pacientes y circunstancias en los que no se puede utilizar la anestesia regional. Debe establecerse un protocolo para el seguimiento y la documentación de los efectos $^{232,235-237}$. Los antiinflamatorios no esteroideos y los inhibidores de la ciclooxigenasa 2 (COX-2) pueden promover la insuficiencia cardiaca y renal, así como eventos tromboembólicos, y no deben ser utilizados en pacientes con isquemia miocárdica. Los inhibidores de la COX-2 causan menos ulceración gastrointestinal y broncospasmo. El papel de estos fármacos en el tratamiento del dolor postoperatorio en pacientes cardiacos sometidos a cirugía no cardiaca no ha sido definido. El uso de estos fármacos debe evitarse en pacientes con insuficiencia renal o cardiaca, pacientes de edad avanzada, pacientes tratados con diuréticos y pacientes con inestabilidad hemodinámica ${ }^{238}$.

\section{Recomendaciones sobre la anestesia}

\begin{tabular}{lcc}
\hline Recomendación & Clase $^{\mathrm{a}}$ & Nivel $^{\mathrm{b}}$ \\
\hline $\begin{array}{l}\text { Debe considerarse la utilización de anestesia epidural } \\
\text { torácica para la cirugía de alto riesgo en pacientes }\end{array}$ & Ila & A \\
con enfermedad cardiaca & & \\
No se recomienda el uso de antiinflamatorios no & III & B \\
esteroideos ni inhibidores de la ciclooxigenasa 2 & & \\
para el manejo del dolor postoperatorio en pacientes & & \\
con insuficiencia renal o cardiaca, con isquemia & & \\
miocárdica o de edad avanzada ni en los tratados & & \\
con diuréticos o en inestabilidad hemodinámica & & \\
\hline
\end{tabular}

aClase de recomendación.

${ }^{\mathrm{D}}$ Nivel de evidencia.

\section{ARMAR LAS PIEZAS DEL ROMPECABEZAS}

La figura 4 muestra un algoritmo que describe paso a paso la estrategia, basada en la evidencia, para determinar qué paciente se beneficia de la evaluación cardiaca, de la revascularización coronaria y del tratamiento cardiovascular antes de un procedimiento quirúrgico. El grado de recomendación y el nivel de evidencia para cada paso se incluyen en la tabla 11 .

Paso 1. Debe valorarse la urgencia del procedimiento quirúrgico. En casos urgentes, los factores específicos del paciente o de la cirugía determinan la estrategia y no permiten la realización de pruebas o tratamientos cardiacos adicionales. En estos casos, el médico responsable dicta las recomenda- ciones para el manejo farmacológico perioperatorio, supervisión de eventos cardiacos y continuación del tratamiento cardiovascular.

Paso 2. Si el paciente está inestable, esta circunstancia debe ser aclarada y tratada antes de la cirugía (tabla 12). Como ejemplo de inestabilidad están los síndromes coronarios inestables, la insuficiencia cardiaca descompensada, las arritmias graves y la valvulopatía sintomática. Normalmente requieren la cancelación o el aplazamiento de la cirugía. Por ejemplo, los pacientes con angina inestable deben ser referidos a angiografía coronaria para valorar las opciones terapéuticas. Un equipo multidisciplinario que incluya todos los médicos responsables de la atención perioperatoria debe discutir las opciones de tratamiento, ya que éstas pueden tener consecuencias en la anestesia o en la cirugía. Éste sería el caso del tratamiento antiplaquetario doble instaurado tras la implantación de stents que puede complicar la anestesia locorregional o determinados procedimientos quirúrgicos. Dependiendo de los resultados de la discusión, los pacientes serán referidos a una intervención coronaria $(\mathrm{CABG}$, angioplastia con balón o implantación de stents con tratamiento antiplaquetario doble), siempre que el procedimiento quirúrgico índice pueda esperar, o serán referidos directamente a cirugía si el aplazamiento se considera incompatible con la mejor opción médica.

Paso 3. Debe determinarse el riesgo del procedimiento quirúrgico (tabla 4). Si se estima que el riesgo cardiaco a los 30 días es bajo $(<1 \%)$, es poco probable que los resultados de las pruebas cambien el manejo preoperatorio y, por lo tanto, se puede proceder con la cirugía planeada. El médico puede identificar los factores de riesgo y hacer recomendaciones sobre estilo de vida y tratamiento médico de acuerdo con las guías de la ESC sobre el manejo postoperatorio para mejorar los resultados a largo plazo.

Paso 4. Debe considerarse la capacidad funcional del paciente. Si un paciente asintomático o estable presenta una capacidad funcional moderada o buena ( $>4$ MET), es poco probable que los resultados de las pruebas cambien el manejo preoperatorio, independientemente del procedimiento quirúrgico programado. Incluso en presencia de factores de riesgo es apropiado referir al paciente a cirugía. En pacientes con cardiopatía isquémica o factores de riesgo, puede instaurarse un régimen con estatinas y bloqueadores beta con ajuste gradual de la dosis antes de la cirugía, como se describe en la tabla 11.

Paso 5. Se recomienda mantener el tratamiento indefinido con aspirina. La interrupción del tratamiento con aspirina sólo debe considerarse en pacientes en los que el control de la hemostasis durante la cirugía presente dificultades. 


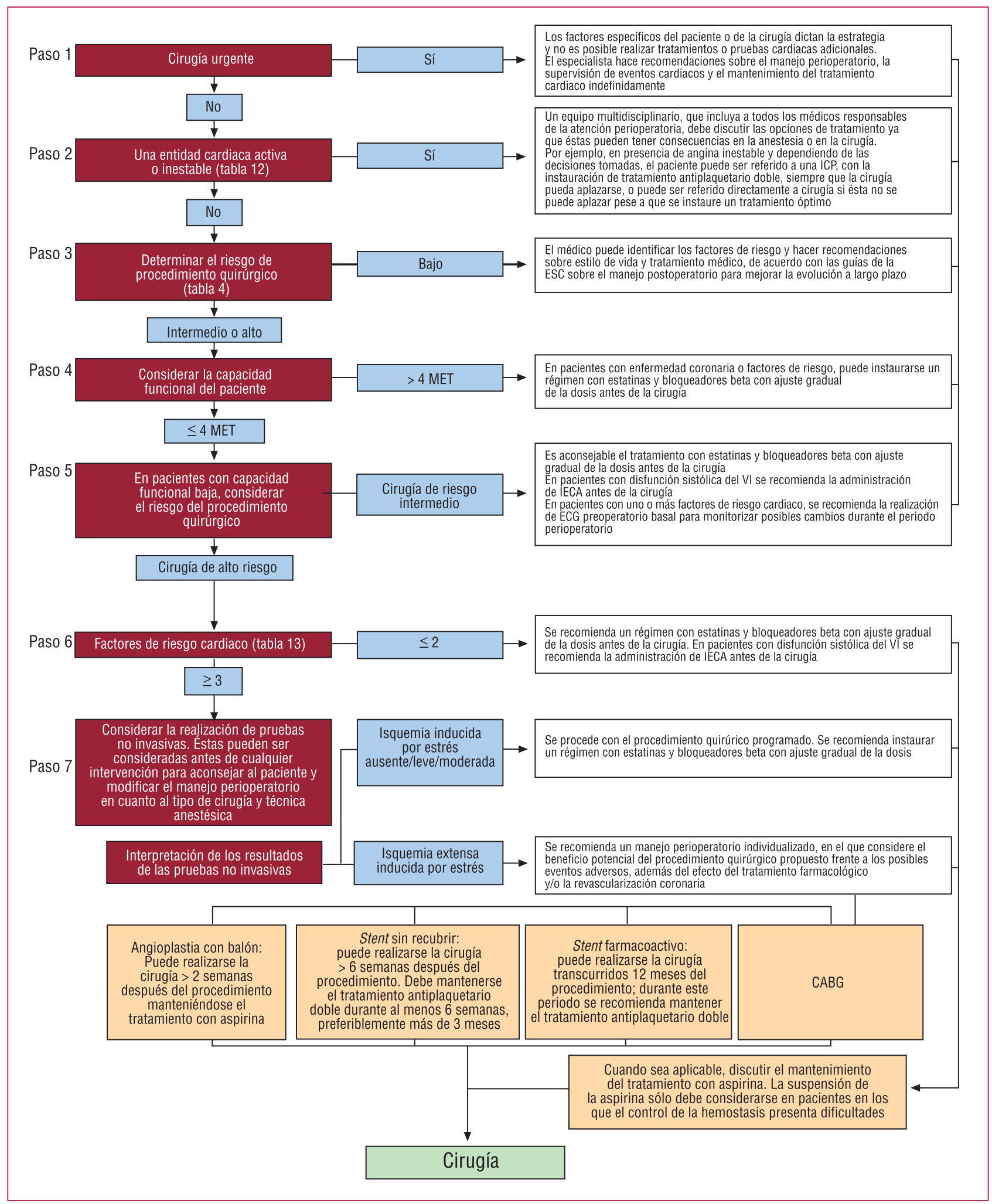

Fig. 4. Resumen de la evaluación preoperatoria de riesgo cardiaco y el manejo perioperatorio.

Paso 6. Debe considerarse el riesgo de la cirugía en pacientes con una capacidad funcional moderada $o$ baja (tabla 4). Los pacientes programados para cirugía de riesgo intermedio o alto pueden ser referidos a cirugía; es apropiado el tratamiento preoperatorio con estatinas y bloqueadores beta con ajuste gradual de la dosis. En pacientes con disfunción sistólica del VI, determinada por una fracción de eyección $<40 \%$, 
TABLA 11. Resumen de la evaluación preoperatoria de riesgo cardiaco y manejo perioperatorio

\begin{tabular}{|c|c|c|c|c|c|c|c|c|c|c|c|c|c|}
\hline Paso & Urgencia & \begin{tabular}{c|} 
Estado \\
cardiaco
\end{tabular} & \begin{tabular}{|c|} 
Tipo \\
de cirugía
\end{tabular} & $\begin{array}{l}\text { Capacidad } \\
\text { funcional }\end{array}$ & $\begin{array}{l}\text { Número } \\
\text { de factores } \\
\text { clínicos } \\
\text { de riesgo }^{\mathrm{b}}\end{array}$ & $\begin{array}{l}\text { Eco } \\
\text { del VI }\end{array}$ & ECG & $\begin{array}{l}\text { Pruebas } \\
\text { de estrés }^{c}\end{array}$ & \begin{tabular}{|c|} 
Bloqueadores \\
beta $^{\mathrm{d}}$
\end{tabular} & IECA $A^{\mathrm{d}, e}$ & Aspirina $^{d}$ & Estatinas $^{d}$ & $\begin{array}{l}\text { Revascularización } \\
\text { coronaria }\end{array}$ \\
\hline 1 & $\begin{array}{l}\text { Cirugía } \\
\text { urgente }\end{array}$ & & & & & III C & Illa C & III C & IC & IC & IC & IC & III C \\
\hline 2 & $\begin{array}{l}\text { Cirugía } \\
\text { electiva }\end{array}$ & Inestable & & & & IC & IC & III C & & 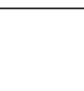 & & & IC \\
\hline 3 & $\begin{array}{l}\text { Cirugía } \\
\text { electiva }\end{array}$ & Estable & $\begin{array}{c}\text { Bajo } \\
\text { riesgo } \\
(<1 \%) \\
\end{array}$ & & Ninguno & III B & III B & III C & III B & Ila C & $\mathrm{Ilb} C$ & Ila B & III C \\
\hline & & & & & $\geq 1$ & III B & Illa B & III C & $\begin{array}{c}\text { Ilb B } \\
\text { (ajuste } \\
\text { de dosis) } \\
\text { III A } \\
\text { (sin ajuste } \\
\text { de dosis) }\end{array}$ & Ila C & $\mathrm{Ilb} C$ & Ila B & III C \\
\hline 4 & & & & $\begin{array}{c}\text { Excelente } \\
\text { o buena }\end{array}$ & & III B & Illa B & $\mathrm{IIIC}$ & $\begin{array}{c}\text { Ilb B } \\
\text { (ajuste } \\
\text { de dosis) } \\
\text { III A } \\
\text { (sin ajuste } \\
\text { de dosis) }\end{array}$ & Illa C & $\mathrm{llb} C$ & Ila B & $I I I C$ \\
\hline 5 & $\begin{array}{l}\text { Cirugía } \\
\text { electiva }\end{array}$ & & $\begin{array}{c}\text { Riesgo } \\
\text { intermedio } \\
(1-5 \%)\end{array}$ & $\begin{array}{c}\text { Moderada } \\
\text { o mala }\end{array}$ & Ninguno & III B & llb B & Ilb C & $\begin{array}{c}\text { Ila B } \\
\text { (ajuste } \\
\text { de dosis) } \\
\text { III A } \\
\text { (sin ajuste } \\
\text { de dosis) }\end{array}$ & IC & Ilb C & Ila B & III B \\
\hline & & & & & $\geq 1$ & III B & IB & Ilb C & $\begin{array}{c}\text { Ila B } \\
\text { (ajuste } \\
\text { de dosis) } \\
\text { III A } \\
\text { (sin ajuste } \\
\text { de dosis) }\end{array}$ & IC & Ilb C & Ila B & III B \\
\hline 6 & $\begin{array}{l}\text { Cirugía } \\
\text { electiva }\end{array}$ & & $\begin{array}{c}\text { Alto } \\
\text { riesgo } \\
(>5 \%)\end{array}$ & $\begin{array}{l}\text { Moderada } \\
\text { o mala }\end{array}$ & $\leq 2$ & Ila C & IB & $\mathrm{Ilb} C$ & $\begin{array}{c}\text { I B } \\
\text { (ajuste } \\
\text { de dosis) }\end{array}$ & IC & $\mathrm{Ilb} C$ & IB & Ilb B \\
\hline & & & & & $\geq 3$ & Ila C & IB & IC & $\begin{array}{c}\text { I B } \\
\text { (ajuste } \\
\text { de dosis) } \\
\text { III A } \\
\text { (sin ajuste } \\
\text { de dosis) }\end{array}$ & IC & $\mathrm{Ilb} C$ & IB & Illb B \\
\hline
\end{tabular}

aTipo de cirugía (tabla 4): riesgo de infarto de miocardio y muerte cardiaca a los 30 días de la cirugía.

'Factores de riesgo (tabla 13): angina de pecho, infarto de miocardio, insuficiencia cardiaca, ictus/accidente isquémico transitorio, disfunción renal (creatinina > 170 umol// 0 $2 \mathrm{mg} / \mathrm{dl} 0$ aclaramiento de creatinina $<60 \mathrm{ml} / \mathrm{min}$ ), diabetes mellitus.

cPruebas no invasivas no sólo para para la revascularización, sino también para aconsejar al paciente y modificar el manejo perioperatorio en cuanto a tipo de cirugía y técnica anestésica.

Instauración de tratamiento farmacológico, pero mantenimiento de la medicación previa en caso de cirugía urgente. Debe mantenerse el tratamiento con aspirina tras la implantación de stents.

eEn presencia de disfunción del ventrículo izquierdo (VI) (fracción de eyección $\leq 40 \%$ ).

'Las recomendaciones de clase I concuerdan con las guías de la ACC/AHA de 2004: 1 = angina estable y enfermedad de tronco común izquierdo significativa; 2 = angina estable y enfermedad de tres vasos, particularmente cuando la fracción de eyección del Vl es $<50 \% ; 3=$ angina estable y enfermedad de dos vasos con estenosis proximal significativa en la descendente anterior izquierda y una fracción de eyección $<50 \% 0$ isquemia demostrable mediante pruebas no invasivas; $4=$ angina inestable de alto riesgo o IAMSEST; 5 = IAMCEST. 
TABLA 12. Entidades cardiacas inestables

Angina de pecho inestable

Insuficiencia cardiaca aguda

Arritmias cardiacas significativas

Enfermedad valvular sintomática

Infarto de miocardio reciente (en los últimos 30 días, según la definición

universal ${ }^{34}$ ) e isquemia miocárdica residual

se recomienda la administración de IECA (o BRA en caso de intolerancia a IECA) antes de la cirugía. En pacientes con uno o más factores clínicos de riesgo, se recomienda la realización de un ECG preoperatorio basal para monitorizar los cambios electrocardiográficos durante el periodo perioperatorio. En pacientes programados para cirugía de alto riesgo (tabla 4), se toman en consideración los factores clínicos de riesgo (tabla 13). En pacientes con 1 o 2 factores clínicos de riesgo, se recomienda el tratamiento preoperatorio con estatinas y bloqueadores beta con ajuste gradual de la dosis. Debe considerarse la indicación de pruebas no invasivas en pacientes con 3 o más factores clínicos de riesgo (tabla 13). Antes de cualquier procedimiento quirúrgico pueden realizarse pruebas no invasivas para proporcionar consejos al paciente o modificar el manejo perioperatorio en cuanto a tipo de cirugía y técnica anestésica.

Paso 7. Interpretación de los resultados de las pruebas de estrés no invasivas. Los pacientes sin isquemia inducida por estrés o con isquemia leve o moderada compatible con enfermedad de 1 o 2 vasos pueden ser referidos a la cirugía programada. Se recomienda la instauración de tratamiento con estatinas y bloqueadores beta con ajuste gradual de la dosis. En pacientes con isquemia extensa inducida por estrés y determinada por pruebas no
TABLA 13. Factores clínicos de riesgo

\author{
Angina de pecho \\ Infarto de miocardio previo (según la definición universal ${ }^{34}$ ) \\ Insuficiencia cardiaca \\ Ictus/accidente isquémico transitorio \\ Disfunción renal (creatinina sérica $>170 \mu \mathrm{mol} / \mathrm{l} 02 \mathrm{mg} / \mathrm{dl} 0$ un \\ aclaramiento de creatinina $<60 \mathrm{ml} / \mathrm{min}$ ) \\ Diabetes mellitus que requiere tratamiento con insulina
}

invasivas, se recomienda un manejo perioperatorio individualizado, teniendo en cuenta el beneficio potencial del procedimiento quirúrgico y los posibles resultados adversos. También debe valorarse el efecto del tratamiento farmacológico y/o la revascularización coronaria no sólo en el resultado postoperatorio inmediato, sino también a largo plazo. En pacientes referidos a una intervención percutánea coronaria, la instauración y la duración del tratamiento antiplaquetario interfieren con el procedimiento quirúrgico programado. En pacientes referidos a angioplastia, la cirugía no cardiaca puede tener lugar a las 2 semanas de la revascularización sin interrupción del tratamiento con aspirina. En pacientes sometidos a implantación de stents $\sin$ recubrir, la cirugía no cardiaca puede realizarse de 6 semanas a 3 meses tras la implantación. El tratamiento antiplaquetario doble debe mantenerse durante al menos 6 semanas y preferiblemente durante 3 meses. Tras este periodo, debe continuarse tratamiento con aspirina como mínimo. En pacientes en los que se ha implantado recientemente un SLF, la cirugía no cardiaca puede realizarse transcurridos 12 meses de la implantación, periodo en el que se recomienda el tratamiento antiplaquetario doble. Tras este periodo, debe continuarse tratamiento con aspirina como mínimo.

\footnotetext{
El texto CME de «Guías de la ESC para la valoración del riesgo cardiaco preoperatorio y el manejo cardiaco perioperatorio en la cirugía no cardiaca» está acreditado por el European Board for Accreditation in Cardiology (EBAC). EI EBAC trabaja de acuerdo con los estándares de calidad del European Accreditation Council for Continuing Medical Education (EACCME), institución dependiente de la European Union of Medical Specialists (UEMS). En cumplimiento con las guías EBAC/EACCME, todos los autores participantes en este programa han declarado sus potenciales conflictos de intereses que pudieran afectar a este documento. El Comité Organizador es responsable de asegurar que todos los potenciales conflictos de intereses relevantes al programa sean declarados a los participantes antes de iniciar las actividades CME.

Las preguntas sobre esta CME para este artículo están disponibles en European Heart Journal (http://cme.oxfordjournals.org/cgi/hierarchy/oupcme node; ehj) y en la página web de la Sociedad Europea de Cardiología.

(http://www.escardio.org/knowledge/guidelines)
} 


\section{BIBLIOGRAFÍA}

1. Schwartz PJ, Breithardt G, Howard AJ, Julian DG, Rehnqvist Ahlberg N. Task Force Report: the legal implications of medical guidelines - a Task Force of the European Society of Cardiology. Eur Heart J. 1999;20:1152-7.

2. Almanaseer Y, Mukherjee D, Kline-Rogers EM, Kesterson SK, Sonnad SS, Rogers B, et al. Implementation of the ACC/ AHA guidelines for preoperative cardiac risk assessment in a general medicine preoperative clinic: improving efficiency and preserving outcomes. Cardiology. 2005;103:24-9.

3. Poldermans D, Hoeks SE, Feringa HH. Pre-operative risk assessment and risk reduction before surgery. J Am Coll Cardiol. 2008;51:1913-24.

4. Prismant. Ziekenhuisstatistiek-Verrichtingen. 2008. Disponible en: http://www.prismant.nl/

5. Lee TH, Marcantonio ER, Mangione CM, Thomas EJ, Polanczyk CA, Cook EF, et al. Derivation and prospective validation of a simple index for prediction of cardiac risk of major noncardiac surgery. Circulation. 1999;100:1043-9.

6. Boersma E, Kertai MD, Schouten O, Bax JJ, Noordzij P, Steyerberg EW, et al. Perioperative cardiovascular mortality in noncardiac surgery: validation of the Lee cardiac risk index. Am J Med. 2005;118:1134-41.

7. Poldermans D, Bax JJ, Kertai MD, Krenning B, Westerhout $\mathrm{CM}$, Schinkel AF, et al. Statins are associated with a reduced incidence of perioperative mortality in patients undergoing major noncardiac vascular surgery. Circulation. 2003; 107:1848-51.

8. Poldermans D, Bax JJ, Schouten O, Neskovic AN, Paelinck B, Rocci G, et al. Should major vascular surgery be delayed because of preoperative cardiac testing in intermediate-risk patients receiving beta-blocker therapy with tight heart rate control? J Am Coll Cardiol. 2006;48:964-9.

9. Poldermans D, Boersma E, Bax JJ, Thomson IR, Van de Ven LL, Blankensteijn JD, et al. The effect of bisoprolol on perioperative mortality and myocardial infarction in high-risk patients undergoing vascular surgery. Dutch Echocardiographic Cardiac Risk Evaluation Applying Stress Echocardiography Study Group. N Engl J Med. 1999;341:1789-94.

10. Devereaux PJ, Yang H, Yusuf S, Guyatt G, Leslie K, Villar $\mathrm{JC}$, et al. Effects of extended-release metoprolol succinate in patients undergoing non-cardiac surgery (POISE trial): a randomised controlled trial. Lancet. 2008;371:1839-47.

11. Naughton C, Feneck RO. The impact of age on 6-month survival in patients with cardiovascular risk factors undergoing elective non-cardiac surgery. Int J Clin Pract. 2007;61:76876.

12. Mangano DT. Perioperative medicine: NHLBI working group deliberations and recommendations. J Cardiothorac Vasc Anesth. 2004;18:1-6.

13. Ferguson TB Jr, Hammill BG, Peterson ED, DeLong ER, Grover FL. A decade of change-risk profiles and outcomes for isolated coronary artery bypass grafting procedures, 19901999: a report from the STS National Database Committee and the Duke Clinical Research Institute. Society of Thoracic Surgeons. Ann Thorac Surg. 2002;73:480-9.

14. Carroll K, Majeed A, Firth C, Gray J. Prevalence and management of coronary heart disease in primary care: population-based cross-sectional study using a disease register. J Public Health Med. 2003;25:29-35.

15. National Center for Health Statistics. Health, Unites States; 2007.

16. Hoeks SE, Scholte op Reimer WJ, Lenzen MJ, Van Urk $\mathrm{H}$, Jorning PJ, Boersma E, et al. Guidelines for cardiac management in noncardiac surgery are poorly implemented in clinical practice: results from a peripheral vascular survey in the Netherlands. Anesthesiology. 2007;107:537-44.
17. Hoeks SE, Scholte Op Reimer WJ, Schouten O, Lenzen MJ, Van Urk H, Poldermans D. Statin use in the elderly: results from a peripheral vascular survey in The Netherlands. J Vasc Surg. 2008;48:891-5.

18. Hoeks SE, Scholte op Reimer WJM, Van Gestel YRBM, Schouten O, Lenzen MJ, Flu W-J, et al. Medication underuse during long-term follow-up in patients with peripheral arterial disease. Circ Cardiovasc Qual Outcomes. 2009:CIRCOUTCOMES.109.868505.

19. Wirthlin DJ, Cambria RP. Surgery-specific considerations in the cardiac patient undergoing noncardiac surgery. Prog Cardiovasc Dis. 1998;40:453-68.

20. Fleisher LA, Beckman JA, Brown KA, Calkins H, Chaikof E, Fleischmann KE, Freeman WK, et al. ACC/AHA 2007 Guidelines on Perioperative Cardiovascular Evaluation and Care for Noncardiac Surgery: Executive Summary: A Report of the American College of Cardiology/American Heart Association Task Force on Practice Guidelines (Writing Committee to Revise the 2002 Guidelines on Perioperative Cardiovascular Evaluation for Noncardiac Surgery): Developed in Collaboration With the American Society of Echocardiography, American Society of Nuclear Cardiology, Heart Rhythm Society, Society of Cardiovascular Anesthesiologists, Society for Cardiovascular Angiography and Interventions, Society for Vascular Medicine and Biology, and Society for Vascular Surgery. Circulation. 2007;116:1971-96.

21. Schouten O, Dunkelgrun M, Feringa HH, Kok NF, Vidakovic R, Bax JJ, et al. Myocardial damage in high-risk patients undergoing elective endovascular or open infrarenal abdominal aortic aneurysm repair. Eur J Vasc Endovasc Surg. 2007;33:544-9.

22. Blankensteijn JD, De Jong SE, Prinssen M, Van der Ham AC, Buth J, Van Sterkenburg SM, et al. Two-year outcomes after conventional or endovascular repair of abdominal aortic aneurysms. N Engl J Med. 2005;352:2398-405.

23. Holte K, Kehlet H. Postoperative ileus: a preventable event. Br J Surg. 2000;87:1480-93.

24. Nguyen NT, Wolfe BM. The physiologic effects of pneumoperitoneum in the morbidly obese. Ann Surg. 2005;241:219-26.

25. Gurusamy KS, Samraj K, Davidson BR. Abdominal lift for laparoscopic cholecystectomy. Cochrane Database Syst Rev 2008;(2):CD006574.

26. Hlatky MA, Boineau RE, Higginbotham MB, Lee KL, Mark DB, Califf RM, et al. A brief self-administered questionnaire to determine functional capacity (the Duke Activity Status Index). Am J Cardiol. 1989;64:651-4.

27. Fletcher GF, Balady GJ, Amsterdam EA, Chaitman B, Eckel $\mathrm{R}$, Fleg J, et al. Exercise standards for testing and training: a statement for healthcare professionals from the American Heart Association. Circulation. 2001;104:1694-740.

28. Biccard BM. Relationship between the inability to climb two flights of stairs and outcome after major non-cardiac surgery: implications for the pre-operative assessment of functional capacity. Anaesthesia. 2005;60:588-93.

29. Wiklund RA, Stein HD, Rosenbaum SH. Activities of daily living and cardiovascular complications following elective, noncardiac surgery. Yale J Biol Med. 2001;74:75-87.

30. Morris CK, Ueshima K, Kawaguchi T, Hideg A, Froelicher VF. The prognostic value of exercise capacity: a review of the literature. Am Heart J. 1991;122:1423-31.

31. Detsky AS, Abrams HB, Forbath N, Scott JG, Hilliard JR. Cardiac assessment for patients undergoing noncardiac surgery. A multifactorial clinical risk index. Arch Intern Med. 1986;146:2131-4.

32. Goldman L, Caldera DL, Nussbaum SR, Southwick FS, Krogstad D, Murray B, et al. Multifactorial index of cardiac risk in noncardiac surgical procedures. $N$ Engl $\mathrm{J}$ Med. 1977;297:845-50. 
33. Maisel AS, Bhalla V, Braunwald E. Cardiac biomarkers: a contemporary status report. Nat Clin Pract Cardiovasc Med. 2006;3:24-34.

34. Thygesen K, Alpert JS, White HD. Universal definition of myocardial infarction. Eur Heart J. 2007;28:2525-38.

35. Sabatine MS, Morrow DA, Giugliano RP, Murphy SA, Demopoulos LA, DiBattiste PM, et al. Implications of upstream glycoprotein IIb/IIIa inhibition and coronary artery stenting in the invasive management of unstable angina/ nonST-elevation myocardial infarction: a comparison of the Thrombolysis In Myocardial Infarction (TIMI) IIIB trial and the Treat angina with Aggrastat and determine Cost of Therapy with Invasive or Conservative Strategy (TACTICS)TIMI 18 trial. Circulation. 2004;109:874-80.

36. Cannon CP, McCabe CH, Wilcox RG, Langer A, Caspi A, Berink $\mathrm{P}$, et al. Oral glycoprotein IIb/IIIa inhibition with orbofiban in patients with unstable coronary syndromes (OPUS-TIMI 16) trial. Circulation. 2000;102:149-56.

37. Priebe HJ. Perioperative myocardial infarction-aetiology and prevention. Br J Anaesth. 2005;95:3-19.

38. Tsimikas S, Willerson JT, Ridker PM. C-reactive protein and other emerging blood biomarkers to optimize risk stratification of vulnerable patients. J Am Coll Cardiol. 2006;47 Suppl 8:C19-31.

39. Wang TJ, Larson MG, Levy D, Benjamin EJ, Leip EP, Omland T, et al. Plasma natriuretic peptide levels and the risk of cardiovascular events and death. $\mathrm{N}$ Engl $\mathrm{J}$ Med. 2004;350:655-63.

40. Omland T, Sabatine MS, Jablonski KA, Rice MM, Hsia J, Wergeland R, et al. Prognostic value of B-type natriuretic peptides in patients with stable coronary artery disease: the PEACE Trial. J Am Coll Cardiol. 2007;50:205-14.

41. Bibbins-Domingo K, Gupta R, Na B, Wu AHB, Schiller $\mathrm{NB}$, Whooley MA. N-Terminal fragment of the prohormone brain-type natriuretic peptide (NT-proBNP), cardiovascular events, and mortality in patients with stable coronary heart disease. JAMA. 2007;297:169-76.

42. Feringa HHH, Bax JJ, Elhendy A, De Jonge R, Lindemans $\mathrm{J}$, Schouten $\mathrm{O}$, et al. Association of plasma Nterminal pro-Btype natriuretic peptide with postoperative cardiac events in patients undergoing surgery for abdominal aortic aneurysm or leg bypass. Am J Cardiol. 2006;98:111-5.

43. Dernellis J, Panaretou M. Assessment of cardiac risk before non-cardiac surgery: brain natriuretic peptide in 1590 patients. Heart. 2006;92:1645-50.

44. Rodseth RN, Padayachee L, Biccard BM. A meta-analysis of the utility of preoperative brain natriuretic peptide in predicting early and intermediate-term mortality and major adverse cardiac events in vascular surgical patients. Anaesthesia. 2008;63:1226-33.

45. Cuthbertson BH, Card G, Croal BL, McNeilly J, Hillis GS. The utility of B-type natriuretic peptide in predicting postoperative cardiac events and mortality in patients undergoing major emergency non-cardiac surgery. Anaesthesia. 2007;62:87581.

46. Cuthbertson BH, Amiri AR, Croal BL, Rajagopalan S, Alozairi $\mathrm{O}$, Brittenden $\mathrm{J}$, et al. Utility of B-type natriuretic peptide in predicting perioperative cardiac events in patients undergoing major non-cardiac surgery. $\mathrm{Br} \mathrm{J}$ Anaesth. 2007;99:170-6

47. Fox K, Garcia MA, Ardissino D, Buszman P, Camici PG, Crea F, et al. Guidelines on the management of stable angina pectoris: executive summary: the Task Force on the Management of Stable Angina Pectoris of the European Society of Cardiology. Eur Heart J. 2006;27:1341-81.

48. Jeger RV, Probst C, Arsenic R, Lippuner T, Pfisterer $\mathrm{ME}$, Seeberger MD, et al. Long-term prognostic value of the preoperative 12-lead electrocardiogram before major noncardiac surgery in coronary artery disease. Am Heart J. 2006;151:508-13.
49. Noordzij PG, Boersma E, Bax JJ, Feringa HH, Schreiner F, Schouten $\mathrm{O}$, et al. Prognostic value of routine preoperative electrocardiography in patients undergoing noncardiac surgery. Am J Cardiol. 2006;97:1103-6.

50. Klocke FJ, Baird MG, Lorell BH, Bateman TM, Messer JV, Berman DS, et al. ACC/AHA/ASNC guidelines for the clinical use of cardiac radionuclide imaging - executive summary: a report of the American College of Cardiology/American Heart Association Task Force on Practice Guidelines (ACC/ AHA/ASNC Committee to Revise the 1995 Guidelines for the Clinical Use of Cardiac Radionuclide Imaging). J Am Coll Cardiol. 2003;42:1318-33.

51. Kertai MD, Boersma E, Bax JJ, Heijenbrok-Kal MH, Hunink MG, L'Talien GJ, et al. A meta-analysis comparing the prognostic accuracy of six diagnostic tests for predicting perioperative cardiac risk in patients undergoing major vascular surgery. Heart. 2003;89:1327-34.

52. Etchells E, Meade M, Tomlinson G, Cook D. Semiquantitative dipyridamole myocardial stress perfusion imaging for cardiac risk assessment before noncardiac vascular surgery: a metaanalysis. J Vasc Surg. 2002;36:534-40.

53. Shaw LJ, Eagle KA, Gersh BJ, Douglas Miller D. Metaanalysis of intravenous dipyridamole-thallium-201 imaging (1985 to 1994) and dobutamine echocardiography (1991 to 1994) for risk stratification before vascular surgery. J Am Coll Cardiol. 1996;27:787-98.

54. Elhendy A, Valkema R, Van Domburg RT, Bax JJ, Nierop PR, Cornel JH, et al. Safety of dobutamine-atropine stress myocardial perfusion scintigraphy. J Nucl Med. 1998;39:1662-6.

55. Sicari R, Nihoyannopoulos P, Evangelista A, Kasprzak J, Lancellotti P, Poldermans D, et al. Stress Echocardiography Expert Consensus Statement-Executive Summary: European Association of Echocardiography (EAE) (a registered branch of the ESC). Eur Heart J. 2009;30:278-89.

56. Das MK, Pellikka PA, Mahoney DW, Roger VL, Oh JK, McCully RB, et al. Assessment of cardiac risk before nonvascular surgery: dobutamine stress echocardiography in 530 patients. J Am Coll Cardiol. 2000;35:1647-53.

57. Nandalur KR, Dwamena BA, Choudhri AF, Nandalur MR, Carlos RC. Diagnostic performance of stress cardiac magnetic resonance imaging in the detection of coronary artery disease: a meta-analysis. J Am Coll Cardiol. 2007;50:1343-53.

58. Rerkpattanapipat P, Morgan TM, Neagle CM, Link KM, Hamilton CA, Hundley WG. Assessment of preoperative cardiac risk with magnetic resonance imaging. Am J Cardiol. 2002;90:416-9.

59. Danias PG, Roussakis A, Ioannidis JP. Diagnostic performance of coronary magnetic resonance angiography as compared against conventional X-ray angiography: a metaanalysis. J Am Coll Cardiol. 2004;44:1867-76.

60. Hamon M, Biondi-Zoccai GG, Malagutti P, Agostoni P, Morello R, Valgimigli M, et al. Diagnostic performance of multislice spiral computed tomography of coronary arteries as compared with conventional invasive coronary angiography: a meta-analysis. J Am Coll Cardiol. 2006;48:1896-910.

61. Gerber TC, Carr JJ, Arai AE, Dixon RL, Ferrari VA, Gomes $\mathrm{AS}$, et al. Ionizing radiation in cardiac imaging: a science advisory from the American Heart Association Committee on Cardiac Imaging of the Council on Clinical Cardiology and Committee on Cardiovascular Imaging and Intervention of the Council on Cardiovascular Radiology and Intervention. Circulation. 2009;119:1056-65.

62. Pouleur AC, Le Polain de Waroux JB, Kefer J, Pasquet A, Coche E, Vanoverschelde JL, et al. Usefulness of 40-slice multidetector row computed tomography to detect coronary disease in patients prior to cardiac valve surgery. Eur Radiol. 2007;17:3199-207.

63. Boersma E, Poldermans D, Bax JJ, Steyerberg EW, Thomson IR, Banga JD, et al. Predictors of cardiac events after major 
vascular surgery: role of clinical characteristics, dobutamine echocardiography, and beta-blocker therapy. JAMA. 2001;285:1865-73.

64. ATS/ACCP Statement on Cardiopulmonary Exercise Testing. Am J Respir Crit Care Med. 2003;167:211-77.

65. Reilly CS. Can we accurately assess an individual's perioperative risk? Br J Anaesth. 2008;101:747-9.

66. Brunelli A, Belardinelli R, Refai M, Salati M, Socci L, Pompili $\mathrm{C}$, et al. Peak oxygen consumption during cardiopulmonary exercise test improves risk stratification in candidates to major lung resection. Chest. 2009;135:1260-7.

67. Older P, Smith R, Courtney P, Hone R. Preoperative evaluation of cardiac failure and ischemia in elderly patients by cardiopulmonary exercise testing. Chest. 1993;104:701-4.

68. Piepoli MF, Corra U, Agostoni PG, Belardinelli R, CohenSolal A, Hambrecht R, et al. Statement on cardiopulmonary exercise testing in chronic heart failure due to left ventricular dysfunction. Recommendations for performance and interpretation. Eur J Cardiovasc Prev Rehabil. 2006;13:10-2.

69. Bassand JP, Hamm CW, Ardissino D, Boersma E, Budaj A, Fernandez-Aviles F, et al. Guidelines for the diagnosis and treatment of non-ST-segment elevation acute coronary syndromes. Eur Heart J. 2007;28:1598-660.

70. Silber S, Albertsson P, Aviles FF, Camici PG, Colombo A, Hamm C, et al. Guidelines for percutaneous coronary interventions. The Task Force for Percutaneous Coronary Interventions of the European Society of Cardiology. Eur Heart J. 2005;26:804-47.

71. Van de Werf F, Bax J, Betriu A, Blomstrom-Lundqvist C, Crea F, Falk V, et al. Management of acute myocardial infarction in patients presenting with persistent ST-segment elevation: the Task Force on the management of ST-segment elevation acute myocardial infarction of the European Society of Cardiology. Eur Heart J. 2008;29:2909-45.

72. Cruickshank JM. Are we misunderstanding beta-blockers. Int J Cardiol. 2007;120:10-27.

73. Raby KE, Brull SJ, Timimi F, Akhtar S, Rosenbaum S, Naimi C, et al. The effect of heart rate control on myocardial ischemia among high-risk patients after vascular surgery. Anesth Analg. 1999;88:477-82.

74. Brady AR, Gibbs JS, Greenhalgh RM, Powell JT, Sydes MR. Perioperative betablockade(POBBLE)for patientsundergoing infrarenal vascular surgery: results of a randomized doubleblind controlled trial. J Vasc Surg. 2005;41:602-9.

75. Juul AB, Wetterslev J, Gluud C, Kofoed-Enevoldsen A, Jensen $\mathrm{G}$, Callesen T, et al. Effect of perioperative beta blockade in patients with diabetes undergoing major non-cardiac surgery: randomised placebo controlled, blinded multicentre trial. BMJ. 2006;332:1482.

76. Mangano DT, Layug EL, Wallace A, Tateo I. Effect of atenolol on mortality and cardiovascular morbidity after noncardiac surgery. Multicenter Study of Perioperative Ischemia Research Group. N Engl J Med. 1996;335:1713-20.

77. Yang H, Raymer K, Butler R, Parlow J, Roberts R. The effects of perioperative beta-blockade: results of the Metoprolol after Vascular Surgery (MaVS) study, a randomized controlled trial. Am Heart J. 2006;152:983-90.

78. Zaugg M, Bestmann L, Wacker J, Lucchinetti E, Boltres A, Schulz C, et al. Adrenergic receptor genotype but not perioperative bisoprolol therapy maydetermine cardiovascular outcome in at-risk patients undergoing surgery with spinal block: the Swiss Beta Blocker in Spinal Anesthesia (BBSA) study: a double-blinded, placebo-controlled, multicenter trial with 1-year follow-up. Anesthesiology. 2007;107:33-44.

79. Auerbach AD, Goldman L. $\beta$-Blockers and reduction of cardiac events in noncardiac surgery: scientific review. JAMA. 2002;287:1435-44

80. McGory ML, Maggard MA, Ko CY. A meta-analysis of perioperative beta blockade: what is the actual risk reduction? Surgery. 2005;138:171-9.
81. Schouten O, Shaw LJ, Boersma E, Bax JJ, Kertai MD, Feringa $\mathrm{HH}$, et al. A meta-analysis of safety and effectiveness of perioperative beta-blocker use for the prevention of cardiac events in different types of noncardiac surgery. Coron Artery Dis. 2006; 17:173-9.

82. Stevens RD, Burri H, Tramer MR. Pharmacologic myocardial protection in patients undergoing noncardiac surgery: a quantitative systematic review. Anesth Analg. 2003;97:62333.

83. Bangalore S,Wetterslev J, Pranesh S, Sahney S, Gluud C, Messerli FH. Perioperative b blockers in patients having noncardiac surgery: a meta-analysis. Lancet. 2008;372:1962-76.

84. Devereaux PJ, Beattie WS, Choi PT, Badner NH, Guyatt $\mathrm{GH}$, Villar JC, et al. How strong is the evidence for the use of perioperative beta blockers in non-cardiac surgery? Systematic review and meta-analysis of randomised controlled trials. BMJ. 2005;331:313-21.

85. Wiesbauer F, Schlager O, Domanovits H, Wildner B, Maurer G, Muellner M, et al. Perioperative beta-blockers for preventing surgery-related mortality and morbidity: a systematic review and meta-analysis. Anesth Analg. 2007;104:27-41.

86. Beattie WS, Wijeysundera DN, Karkouti K, McCluskey S, Tait G. Does tight heart rate control improve beta-blocker efficacy? An updated analysis of the noncardiac surgical randomized trials. Anesth Analg. 2008;106:1039-48.

87. Lindenauer PK, Pekow P, Wang K, Mamidi DK, Gutierrez B, Benjamin EM. Perioperative beta-blocker therapy and mortality after major noncardiac surgery. N Engl J Med. 2005;353:349-61.

88. Dunkelgrun M, Boersma E, Schouten O, Koopman-Van Gemert AWMM, Van Poorten F, Bax JJ, et al. Bisoprolol and fluvastin for the reduction of perioperative cardiac mortality and myocardial infarction in intermediaterisk patients undergoing non-cardiovascular surgery; a randomized controlled trial (DECREASE-IV). Ann Surg. 2009;249:921-6.

89. Hoeks SE, Scholte Op Reimer WJ, Van Urk H, Jorning PJ, Boersma E, Simoons ML, et al. Increase of 1-year mortality after perioperative beta-blocker withdrawal in endovascular and vascular surgery patients. Eur J Vasc Endovasc Surg. 2007;33:13-9.

90. Shammash JB, Trost JC, Gold JM, Berlin JA, Golden MA, Kimmel SE. Perioperative beta-blocker withdrawal and mortality in vascular surgical patients. Am Heart J. 2001;41:148-53.

91. Dickstein K, Cohen-Solal A, Filippatos G, McMurray JJ, Ponikowski P, Poole-Wilson PA, et al. ESC Guidelines for the diagnosis and treatment of acute and chronic heart failure 2008: The Task Force for the Diagnosis and Treatment of Acute and Chronic Heart Failure 2008 of the European Society of Cardiology. Developed in collaboration with the Heart Failure Association of the ESC (HFA) and endorsed by the European Society of Intensive Care Medicine (ESICM). Eur Heart J. 2008;29:2388-442.

92. Paravastu SC, Mendonca D, Da Silva A. Beta blockers for peripheral arterial disease. Cochrane Database Syst Rev 2008;(4):CD005508.

93. Van Gestel YRBM, Hoeks SE, Sin DD, Welten GMJM, Schouten O, Witteveen HJ, et al. Impact of cardioselective b-blockers on mortality in patients with chronic obstructive pulmonary disease and atherosclerosis. Am J Respir Crit Care Med. 2008;178:695-700.

94. Feringa HHH, Bax JJ, Boersma E, Kertai MD, Meij SH, Galal W, et al. High-dose beta-blockers and tight heart rate control reduce myocardial ischemia and troponin $\mathrm{T}$ release in vascular surgery patients. Circulation. 2006;114 Suppl 1:I344-9.

95. Boersma E, Poldermans D. Beta blockers in non-cardiac surgery: haemodynamic data needed. Lancet. 2008;372:1930-2. 
96. Graham I, Atar D, Borch-Johnsen K, Boysen G, Burell G, Cifkova R, et al. European guidelines on cardiovascular disease prevention in clinical practice: executive summary. Eur Heart J. 2007;28:2375-414.

97. Rosenson RS, Tangney CC. Antiatherothrombotic properties of statins: implications for cardiovascular event reduction. JAMA. 1998;279:1643-50.

98. Hindler K, Shaw AD, Samuels J, Fulton S, Collard CD, Riedel B. Improved postoperative outcomes associated with preoperative statin therapy. Anesthesiology. 2006;105:1260-72.

99. Williams TM, Harken AH. Statins for surgical patients. Ann Surg. 2008;247:30-7.

100. Durazzo AE, Machado FS, Ikeoka DT, De Bernoche C, Monachini MC, Puech-Leao P, et al. Reduction in cardiovascular events after vascular surgery with atorvastatin: a randomized trial. J Vasc Surg. 2004;39:967-75.

101. Schouten O, Boersma E, Hoeks S, Benner R, Van Urk H, Van Sambeek MRHM, et al. Fluvastatin XL use is associated with improved cardiac outcome after major vascular surgery. Results from a randomized placebo controlled trial: DECREASE III. Eur Heart J. 2008;29 Suppl.

102. Schouten O, Kertai MD, Bax JJ, Durazzo AE, Biagini E, Boersma E, et al. Safety of perioperative statin use in high-risk patients undergoing major vascular surgery. Am J Cardiol. 2005;95:658-60.

103. Schouten O, Hoeks SE, Welten GM, Davignon J, Kastelein JJ, Vidakovic R, et al. Effect of statin withdrawal on frequency of cardiac events after vascular surgery. Am J Cardiol. 2007;100:316-20.

104. Coriat P, Daloz M, Bousseau D, Fusciardi J, Echter E, Viars P. Prevention of intraoperative myocardial ischemia during noncardiac surgery with intravenous nitroglycerin. Anesthesiology. 1984;61:193-6.

105. Dodds TM, Stone JG, Coromilas J, Weinberger M, Levy DG. Prophylactic nitroglycerin infusion during noncardiac surgery does not reduce perioperative ischemia. Anesth Analg. 1993;76:705-13.

106. Sun YP, Zhu BQ, Browne AE, Pulukurthy S, Chou TM, Sudhir K, et al. Comparative effects of ACE inhibitors and an angiotensin receptor blocker on atherosclerosis and vascular function. J Cardiovasc Pharmacol Ther. 2001;6:175-81.

107. Oosterga M, Voors AA, Pinto YM, Buikema H, Grandjean JG, Kingma JH, et al. Effects of quinapril on clinical outcome after coronary artery bypass grafting (The QUO VADIS Study). QUinapril on Vascular Ace and Determinants of Ischemia. Am J Cardiol. 2001;87:542-6.

108. Filion KB, Pilote L, Rahme E, Eisenberg MJ. Perioperative use of cardiac medical therapy among patients undergoing coronary artery bypass graft surgery: a systematic review. Am Heart J. 2007;154:407-14.

109. Wijeysundera DN, Beattie WS. Calcium channel blockers for reducing cardiac morbidity after noncardiac surgery: a metaanalysis. Anesth Analg. 2003;97:634-41.

110. Kertai MD, Westerhout CM, Varga KS, Acsady G, Gal J. Dihydropiridine calcium-channel blockers and perioperative mortality in aortic aneurysm surgery. $\mathrm{Br} \mathrm{J}$ Anaesth. 2008;101:458-65.

111. Shchukin Iu V, Vachev AN, Surkova EA, Germanov AV, Golovin EA, D'Iachkov VA. [The role of beta-adrenoblockers and If-inhibitor ivabradine in lowering of rate of development of cardiac complications after carotid endarterectomy]. Kardiologiia. 2008;48:56-9.

112. Oliver MF, Goldman L, Julian DG, Holme I. Effect of mivazerol on perioperative cardiac complications during non-cardiac surgery in patients with coronary heart disease: the European Mivazerol Trial (EMIT). Anesthesiology. 1999;91:951-61.

113. Wallace AW, Galindez D, Salahieh A, Layug EL, Lazo EA, Haratonik KA, et al. Effect of clonidine on cardiovascular morbidity and mortality after noncardiac surgery. Anesthesiology. 2004;101:284-93.
114. Wijeysundera DN, Naik JS, Beattie WS. Alpha-2 adrenergic agonists to prevent perioperative cardiovascular complications: a meta-analysis. Am J Med. 2003;114:742-52.

115. Vitez TS, Soper LE, Wong KC, Soper P. Chronic hypokalemia and intraoperative dysrhythmias. Anesthesiology. 1985;63:130-3.

116. Macdonald JE, Struthers AD. What is the optimal serum potassium level in cardiovascular patients? J Am Coll Cardiol. 2004;43:155-61.

117. Shah KB, Kleinman BS, Rao TL, Jacobs HK, Mestan K, Schaafsma M. Angina and other risk factors in patients with cardiac diseases undergoing noncardiac operations. Anesth Analg. 1990;70:240-7.

118. Domanski M, Norman J, Pitt B, Haigney M, Hanlon S, Peyster E. Diuretic use, progressive heart failure, and death in patients in the Studies Of Left Ventricular Dysfunction (SOLVD). J Am Coll Cardiol. 2003;42:705-8.

119. Lindblad B, Persson NH, Takolander R, Bergqvist D. Does low-dose acetylsalicylic acid prevent stroke after carotid surgery? A double-blind, placebocontrolled randomized trial. Stroke. 1993;24:1125-8.

120. Robless P, Mikhailidis DP, Stansby G. Systematic review of antiplatelet therapy for the prevention of myocardial infarction, stroke or vascular death in patients with peripheral vascular disease. Br J Surg. 2001;88:787-800.

121. Burger W, Chemnitius JM, Kneissl GD, Rucker G. Lowdose aspirin for secondary cardiovascular preventioncardiovascular risks after its perioperative withdrawal versus bleeding risks with its continuation-review and metaanalysis. J Intern Med. 2005;257:399-414.

122. Biondi-Zoccai GG, Lotrionte M, Agostoni P, Abbate A, Fusaro M, Burzotta F, et al. A systematic review and metaanalysis on the hazards of discontinuing or not adhering to aspirin among 50,279 patients at risk for coronary artery disease. Eur Heart J. 2006;27:2667-74.

123. Douketis JD, Johnson JA, Turpie AG. Low-molecular-weight heparin as bridging anticoagulation during interruption of warfarin: assessment of a standardized periprocedural anticoagulation regimen. Arch Intern Med. 2004;164:1319-26.

124. Vahanian A, Baumgartner H, Bax J, Butchart E, Dion R, Filippatos $\mathrm{G}$, et al. Guidelines on the management of valvular heart disease: the Task Force on the Management of Valvular Heart Disease of the European Society of Cardiology. Eur Heart J. 2007;28:230-68.

125. De Caterina R, Husted S, Wallentin L, Agnelli G, Bachmann $\mathrm{F}$, Baigent C, et al. Anticoagulants in heart disease: current status and perspectives. Eur Heart J. 2007;28:880-913.

126. Pengo V, Cucchini U, Denas G, Erba N, Guazzaloca G, La Rosa L, et al, for the Italian Federation of Centers for the Diagnosis of Thrombosis and Management of Antithrombotic T. Standardized low-molecular-weight heparin bridging regimen in outpatients on oral anticoagulants undergoing invasive procedure or surgery. an inception cohort management study. Circulation. 2009;119:2920-7.

127. Poldermans D, Boersma E, Bax JJ, Kliffen M, Van Urk $\mathrm{H}$, Van de Ven L, et al. Correlation of location of acute myocardial infarct after noncardiac vascular surgery with preoperative dobutamine echocardiographic findings. Am J Cardiol. 2001;88:1413-4.

128. Eagle KA, Rihal CS, Mickel MC, Holmes DR, Foster ED, Gersh BJ. Cardiac risk of noncardiac surgery: influence of coronary disease and type of surgery in 3368 operations. CASS Investigators and University of Michigan Heart Care Program. Coronary Artery Surgery Study. Circulation. 1997;96:1882-7.

129. Huber KC, Evans MA, Bresnahan JF, Gibbons RJ, Holmes DR Jr. Outcome of noncardiac operations in patients with severe coronary artery disease successfully treated preoperatively with coronary angioplasty. Mayo Clin Proc. 1992;67:15-21. 
130. Kaluza GL, Joseph J, Lee JR, Raizner ME, Raizner AE. Catastrophic outcomes of noncardiac surgery soon after coronary stenting. J Am Coll Cardiol. 2000;35:1288-94.

131. Howard-Alpe GM, De Bono J, Hudsmith L, Orr WP, Foex $\mathrm{P}$, Sear JW. Coronary artery stents and non-cardiac surgery. Br J Anaesth. 2007;98:560-74.

132. Nuttall GA, Brown MJ, Stombaugh JW, Michon PB, Hathaway MF, Lindeen KC, et al. Time and cardiac risk of surgery after bare-metal stent percutaneous coronary intervention. Anesthesiology. 2008;109:588-95.

133. Rabbitts JA, Nuttall GA, Brown MJ, Hanson AC, Oliver WC, Holmes DR, et al. Cardiac risk of noncardiac surgery after percutaneous coronary intervention with drug-eluting stents. Anesthesiology. 2008;109:596-604.

134. Douketis JD, Berger PB, Dunn AS, Jaffer AK, Spyropoulos $\mathrm{AC}$, Becker $\mathrm{RC}$, et al. The perioperative management of antithrombotic therapy: American College of Chest Physicians Evidence-Based Clinical Practice Guidelines (8th Edition). Chest. 2008;133 Suppl 6:S299-339.

135. McFalls EO, Ward HB, Moritz TE, Goldman S, Krupski WC, Littooy $\mathrm{F}$, et al. Coronary-artery revascularization before elective major vascular surgery. $\mathrm{N}$ Engl J Med. 2004;351:2795-804.

136. Poldermans D, Schouten O, Vidakovic R, Bax JJ, Thomson IR, Hoeks SE, et al. A clinical randomized trial to evaluate the safety of a noninvasive approach in high-risk patients undergoing major vascular surgery: the DECREASE-V Pilot Study. J Am Coll Cardiol. 2007;49:1763-9.

137. Serruys PW, Morice MC, Kappetein AP, Colombo A, Holmes DR, Mack MJ, et al. Percutaneous coronary intervention versus coronary-artery bypass grafting for severe coronary artery disease. N Engl J Med. 2009;360:961-72.

138. Kazmers A, Cerqueira MD, Zierler RE. Perioperative and late outcome in patients with left ventricular ejection fraction of $35 \%$ or less who require major vascular surgery. J Vasc Surg. 1988;8:307-15.

139. Hammill BG, Curtis LH, Bennett-Guerrero E, O'Connor CM, Jollis JG, Schulman KA, et al. Impact of heart failure on patients undergoing major noncardiac surgery. Anesthesiology. 2008;108:559-67.

140. Bhatia RS, Tu JV, Lee DS, Austin PC, Fang J, Haouzi A, et al. Outcome of heart failure with preserved ejection fraction in a population-based study. N Engl J Med. 2006;355:260-9.

141. Karagiannis SE, Feringa HH, Vidakovic R, Van Domburg $\mathrm{R}$, Schouten O, Bax JJ, et al. Value of myocardial viability estimation using dobutamine stress echocardiography in assessing risk preoperatively before noncardiac vascular surgery in patients with left ventricular ejection fraction $<35 \%$. Am J Cardiol. 2007;99:1555-9.

142. Feringa HH, Bax JJ, Schouten O, Poldermans D. Protecting the heart with cardiac medication in patients with left ventricular dysfunction undergoing major noncardiac vascular surgery. Semin Cardiothorac Vasc Anesth. 2006;10:25-31.

143. Mancia G, De Backer G, Dominiczak A, Cifkova R, Fagard R, Germano G, et al, the Task Force for the management of arterial hypertension of the European Society of Hypertension, the Task Force for the management of arterial hypertension of the European Society of C. 2007 Guidelines for the management of arterial hypertension: The Task Force for the Management of Arterial Hypertension of the European Society of Hypertension (ESH) and of the European Society of Cardiology (ESC). Eur Heart J. 2007;28:1462-536.

144. Weksler N, Klein M, Szendro G, Rozentsveig V, Schily $\mathrm{M}$, Brill S, et al. The dilemma of immediate preoperative hypertension: to treat and operate, or to postpone surgery? J Clin Anesth. 2003;15:179-83.

145. Iung B, Baron G, Butchart EG, Delahaye F, Gohlke-Barwolf $\mathrm{C}$, Levang OW, et al. A prospective survey of patients with valvular heart disease in Europe: the Euro Heart Survey on Valvular Heart Disease. Eur Heart J. 2003;24:1231-43.
146. Kertai MD, Bountioukos M, Boersma E, Bax JJ, Thomson IR, Sozzi F, et al. Aortic stenosis: an underestimated risk factor for perioperative complications in patients undergoing noncardiac surgery. Am J Med. 2004;116:8-13.

147. Vahanian A, Alfieri O, Al-Attar N, Antunes M, Bax J, Cormier B, et al. Transcatheter valve implantation for patients with aortic stenosis: a position statement from the European Association of Cardio-Thoracic Surgery (EACTS) and the European Society of Cardiology (ESC), in collaboration with the European Association of Percutaneous Cardiovascular Interventions (EAPCI). Eur Heart J. 2008;29:1463-70.

148. Habib G, Hoen B, Tornos P, Thuny F, Prendergast B, Vilacosta I, et al. Guidelines on the prevention, diagnosis, and treatment of infective endocarditis (new version 2009). Eur Heart J; doi:10.1093/eurheartj/ehp285.

149. Wilson W, Taubert KA, Gewitz M, Lockhart PB, Baddour LM, Levison M, et al. Prevention of infective endocarditis: guidelines from the American Heart Association: a guideline from the American Heart Association Rheumatic Fever, Endocarditis, and Kawasaki Disease Committee, Council on Cardiovascular Disease in the Young, and the Council on Clinical Cardiology, Council on Cardiovascular Surgery and Anesthesia, and the Quality of Care and Outcomes Research Interdisciplinary Working Group. Circulation. 2007;116:1736-54.

150. Forrest JB, Cahalan MK, Rehder K, Goldsmith CH, Levy WJ, Strunin L, et al. Multicenter study of general anesthesia. II. Results. Anesthesiology. 1990;72:262-8.

151. Forrest JB, Rehder K, Cahalan MK, Goldsmith $\mathrm{CH}$. Multicenter study of general anesthesia. III. Predictors of severe perioperative adverse outcomes. Anesthesiology. 1992;76:3-15

152. Katz RL, Bigger JT Jr. Cardiac arrhythmias during anesthesia and operation. Anesthesiology. 1970;33:193-213.

153. Bertrand CA, Steiner NV, Jameson AG, Lopez M. Disturbances of cardiac rhythm during anesthesia and surgery. JAMA. 1971;216:1615-7.

154. Zipes DP, Camm AJ, Borggrefe M, Buxton AE, Chaitman $\mathrm{B}$, Fromer M, et al. ACC/AHA/ESC 2006 guidelines for management of patients with ventricular arrhythmias and the prevention of sudden cardiac death: a report of the American College of Cardiology/American Heart Association Task Force and the European Society of Cardiology Committee for Practice Guidelines (Writing Committee to Develop Guidelines for Management of Patients with Ventricular Arrhythmias and the Prevention of Sudden Cardiac Death). J Am Coll Cardiol. 2006;48:e247-346.

155. AmarD. Perioperativeatrial tachyarrhythmias. Anesthesiology. 2002;97:1618-23.

156. Cox JL. A perspective of postoperative atrial fibrillation in cardiac operations. Ann Thorac Surg. 1993;56:405-9.

157. O'Kelly B, Browner WS, Massie B, Tubau J, Ngo L, Mangano DT. Ventricular arrhythmias in patients undergoing noncardiac surgery. The Study of Perioperative Ischemia Research Group. JAMA. 1992;268:217-21.

158. Polanczyk CA, Goldman L, Marcantonio ER, Orav EJ, Lee TH. Supraventricular arrhythmia in patients having noncardiac surgery: clinical correlates and effect on length of stay. Ann Intern Med. 1998;129:279-85.

159. Amar D, Zhang H, Miodownik S, Kadish AH. Competing autonomic mechanisms precede the onset of postoperative atrial fibrillation. J Am Coll Cardiol. 2003;42:1262-8.

160. Atlee JL. Perioperative cardiac dysrhythmias: diagnosis and management. Anesthesiology. 1997;86:1397-424.

161. Fuster V, Ryden LE, Cannom DS, Crijns HJ, Curtis AB, Ellenbogen KA, et al. ACC/AHA/ESC 2006 guidelines for the management of patients with atrial fibrillationexecutive summary: a report of the American College of Cardiology/American Heart Association Task Force on Practice Guidelines and the European Society of 
Cardiology Committee for Practice Guidelines (Writing Committee to Revise the 2001 Guidelines for the Management of Patients with Atrial Fibrillation). Eur Heart J. 2006;27:1979-2030.

162. Maisel WH, Rawn JD, Stevenson WG. Atrial fibrillation after cardiac surgery. Ann Intern Med. 2001;135:1061-73.

163. Balser JR. Perioperative arrhythmias: incidence, risk assessment, evaluation, and management. Card Electrophysiol Rev. 2002;6:96-9.

164. Balser JR, Martinez EA, Winters BD, Perdue PW, Clarke AW, Huang W, et al. Beta-adrenergic blockade accelerates conversion of postoperative supraventricular tachyarrhythmias. Anesthesiology. 1998;89:1052-9.

165. Bayliff CD, Massel DR, Inculet RI, Malthaner RA, Quinton SD, Powell FS, et al. Propranolol for the prevention of postoperative arrhythmias in general thoracic surgery. Ann Thorac Surg. 1999;67:182-6.

166. Jakobsen CJ, Bille S, Ahlburg P, Rybro L, Hjortholm K, Andresen EB. Perioperative metoprolol reduces the frequency of atrial fibrillation after thoracotomy for lung resection. $\mathbf{J}$ Cardiothorac Vasc Anesth. 1997;11:746-51.

167. Mahla E, Rotman B, Rehak P, Atlee JL, Gombotz H, Berger $\mathrm{J}$, et al. Perioperative ventricular dysrhythmias in patients with structural heart disease undergoing noncardiac surgery. Anesth Analg. 1998;86:16-21.

168. Vardas PE, Auricchio A, Blanc JJ, Daubert JC, Drexler H, Ector $\mathrm{H}$, et al. Guidelines for cardiac pacing and cardiac resynchronization therapy: The Task Force for Cardiac Pacing and Cardiac Resynchronization Therapy of the European Society of Cardiology. Developed in collaboration with the European Heart Rhythm Association. Eur Heart J. 2007;28:2256-95.

169. Eagle KA, Berger PB, Calkins H, Chaitman BR, Ewy GA, Fleischmann KE, et al. ACC/AHA guideline update for perioperative cardiovascular evaluation for noncardiac surgery-executive summary: a report of the American College of Cardiology/ American Heart Association Task Force on Practice Guidelines (Committee to Update the 1996 Guidelines on Perioperative Cardiovascular Evaluation for Noncardiac Surgery). J Am Coll Cardiol. 2002;39:542-53.

170. Gregoratos G, Cheitlin MD, Conill A, Epstein AE, Fellows C, Ferguson TB Jr, et al. ACC/AHA guidelines for implantation of cardiac pacemakers and antiarrhythmia devices: a report of the American College of Cardiology/American Heart Association Task Force on Practice Guidelines (Committee on Pacemaker Implantation). J Am Coll Cardiol. 1998;31:1175209.

171. Erdman S, Levinsky L, Servadio C, Stoupel E, Levy MJ. Safety precautions in the management of patients with pacemakers when electrocautery operations are performed. Surg Gynecol Obstet. 1988;167:311-4.

172. Potyk D, Raudaskoski P. Preoperative cardiac evaluation for elective noncardiac surgery. Arch Fam Med. 1998;7:164-73.

173. Simon AB. Perioperative management of the pacemaker patient. Anesthesiology. 1977;46:127-31.

174. Shapiro WA, Roizen MF, Singleton MA, Morady F, Bainton CR, Gaynor RL. Intraoperative pacemaker complications. Anesthesiology. 1985;63:319-22.

175. Madigan JD, Choudhri AF, Chen J, Spotnitz HM, Oz MC, Edwards N. Surgical management of the patient with an implanted cardiac device: implications of electromagnetic interference. Ann Surg. 1999;230:639-47.

176. Pinski SL, Trohman RG. Implantable cardioverterdefibrillators: implications for the nonelectrophysiologist. Ann Intern Med. 1995;122:770-7.

177. Cockcroft DW, Gault MH. Prediction of creatinine clearance from serum creatinine. Nephron. 1976;16:31-41.

178. Kertai MD, Boersma E, Bax JJ, Van den Meiracker AH, Van Urk H, Roelandt JR, et al. Comparison between serum creatinine and creatinine clearance for the prediction of postoperative mortality in patients undergoing major vascular surgery. Clin Nephrol. 2003;59:17-23.

179. Welten GM, Schouten O, Chonchol M, Hoeks SE, Feringa $\mathrm{HH}$, Bax JJ, et al. Temporary worsening of renal function after aortic surgery is associated with higher longterm mortality. Am J Kidney Dis. 2007;50:219-28.

180. Kheterpal S, Tremper KK, Englesbe MJ, O’Reilly M, Shanks AM, Fetterman DM, et al. Predictors of postoperative acute renal failure after noncardiac surgery in patients with previously normal renal function. Anesthesiology. 2007; 107:892-902.

181. McCullough PA, Soman SS. Contrast-induced nephropathy. Crit Care Clin. 2005;21:261-80.

182. Merten GJ, Burgess WP, Gray LV, Holleman JH, Roush TS, Kowalchuk GJ, et al. Prevention of contrast-induced nephropathy with sodium bicarbonate: a randomized controlled trial. JAMA. 2004;291:2328-34.

183. Maioli M, Toso A, Leoncini M, Gallopin M, Tedeschi D, Micheletti C, et al. Sodium bicarbonate versus saline for the prevention of contrast-induced nephropathy in patients with renal dysfunction undergoing coronary angiography or intervention. J Am Coll Cardiol. 2008;52:599-604.

184. Salem DN, Stein PD, Al-Ahmad A, Bussey HI, Horstkotte $\mathrm{D}$, Miller N, et al. Antithrombotic therapy in valvular heart disease-native and prosthetic: the Seventh ACCP Conference on Antithrombotic and Thrombolytic Therapy. Chest. 2004;126 Suppl 3:S457-82.

185. Murkin JM. Neurologic complications in noncardiac surgery. Semin Cardiothorac Vasc Anesth. 2006;10:125-7.

186. Newman S, Stygall J, Hirani S, Shaefi S, Maze M. Postoperative cognitive dysfunction after noncardiac surgery: a systematic review. Anesthesiology. 2007;106:572-90.

187. Selim M. Perioperative stroke. N Engl J Med. 2007;356:70613.

188. Armstrong MJ, Schneck MJ, Biller J. Discontinuation of perioperative antiplatelet and anticoagulant therapy in stroke patients. Neurol Clin. 2006;24:607-30.

189. Sin DDWL, Man SF. The relationship between reduced lung function and cardiovascular mortality. A population based study and a systview of the literature. Chest. 2005;127:1952-9.

190. Ramakrishna GSJ, Ravi BS, Chandrasekaran K, McGoon MD. Impact of pulmonary hypertension on the outcomes of non cardiac surgery: predictors of perioperative morbidity and mortality. J Am Coll Cardiol. 2005;45:1691-9.

191. Welten GM, Schouten O, Van Domburg RT, Feringa HH, Hoeks SE, Dunkelgrun M, et al. The influence of aging on the prognostic value of the revised cardiac risk index for postoperative cardiac complications in vascular surgery patients. Eur J Vasc Endovasc Surg. 2007;34:632-8.

192. Van Gestel YR, Hoeks SE, Sin DD, Simsek C, Welten GM, Schouten O, et al. Effect of statin therapy on mortality in patients with peripheral arterial disease and comparison of those with versus without associated chronic obstructive pulmonary disease. Am J Cardiol. 2008;102:192-6.

193. Galie N, Hoeper NM, Humbert M, Torbicki A, Vachiery J-C, Barbera JA, et al. Guidelines for the diagnosis and treatment of pulmonary hypertension. The Task Force for the Diagnosis and Treatment of Pulmonary Hypertension of the European Society of Cardiology (ESC) and the European Respiratory Society (ERS), endorsed by the International Society of Heart and Lung Transplantation (ISHLT). Eur Heart J. 2009; in press, doi:10.1093/eurheartj/ehp297.

194. Biagini A, L'Abbate A, Testa R, Carpeggiani C, Mazzei MG, Michelassi C, et al. Unreliability of conventional visual electrocardiographic monitoring for detection of transient ST segment changes in a coronary care unit. Eur Heart J. 1984;5:784-91.

195. Leung JM, O’Kelly B, Browner WS, Tubau J, Hollenberg M, Mangano DT. Prognostic importance of postbypass 
regional wall-motion abnormalities in patients undergoing coronary artery bypass graft surgery. SPI Research Group. Anesthesiology. 1989;71:16-25.

196. Leung JM, Voskanian A, Bellows WH, Pastor D. Automated electrocardiograph ST segment trending monitors: accuracy in detecting myocardial ischemia. Anesth Analg. 1998;87:4-10.

197. Kaplan JA, King SB 3rd. The precordial electrocardiographic lead (V5) in patients who have coronary-artery disease. Anesthesiology. 1976;45:570-4.

198. London MJ, Hollenberg M, Wong MG, Levenson L, Tubau $\mathrm{JF}$, Browner W, et al. Intraoperative myocardial ischemia: localization by continuous 12-lead electrocardiography. Anesthesiology. 1988;69:232-41.

199. Landesberg G, Mosseri M, Wolf Y, Vesselov Y, Weissman C. Perioperative myocardial ischemia and infarction: identification by continuous 12-lead electrocardiogram with online STsegment monitoring. Anesthesiology. 2002;96:264-70.

200. Kertai MD, Boersma E, Klein J, Van Urk H, Bax JJ, Poldermans D. Long-term prognostic value of asymptomatic cardiac troponin $\mathrm{T}$ elevations in patients after major vascular surgery. Eur J Vasc Endovasc Surg. 2004;28:59-66.

201. Landesberg G, Shatz V, Akopnik I, Wolf YG, Mayer M, Berlatzky Y, et al. Association of cardiac troponin, CK$\mathrm{MB}$, and postoperative myocardial ischemia with long-term survival after major vascular surgery. J Am Coll Cardiol. 2003;42:1547-54.

202. Martinez EA, Kim LJ, Faraday N, Rosenfeld B, Bass EB, Perler BA, et al. Sensitivity of routine intensive care unit surveillance for detecting myocardial ischemia. Crit Care Med. 2003;31:2302-8.

203. Drew BJ, Krucoff MW. Multilead ST-segment monitoring in patients with acute coronary syndromes: a consensus statement for healthcare professionals. ST-Segment Monitoring Practice Guideline International Working Group. Am J Crit Care. 1999;8:372-86.

204. Landesberg G, Luria MH, Cotev S, Eidelman LA, Anner H, Mosseri M, et al. Importance of long-duration postoperative ST-segment depression in cardiac morbidity after vascular surgery. Lancet. 1993;341:715-9.

205. Fleisher LA. Real-time intraoperative monitoring of myocardial ischemia in noncardiac surgery. Anesthesiology. 2000;92:1183-8.

206. Mangano DT, Browner WS, Hollenberg M, London MJ, Tubau JF, Tateo IM. Association of perioperative myocardial ischemia with cardiac morbidity and mortality in men undergoing noncardiac surgery. The Study of Perioperative Ischemia Research Group. N Engl J Med. 1990;323:1781-8.

207. Mangano DT, Goldman L. Preoperative assessment of patients with known or suspected coronary disease. N Engl J Med. 1995;333:1750-6.

208. London MJ, Tubau JF, Wong MG, Layug E, Hollenberg M, Krupski WC, et al. The 'natural history' of segmental wall motion abnormalities in patients undergoing noncardiac surgery. S.P.I. Research Group. Anesthesiology. 1990;73:64455.

209. Eisenberg MJ, London MJ, Leung JM, Browner WS, Hollenberg M, Tubau JF, et al. Monitoring for myocardial ischemia during noncardiac surgery. A technology assessment of transesophageal echocardiography and 12-lead electrocardiography. The Study of Perioperative Ischemia Research Group. JAMA. 1992;268:210-6.

210. Practice guidelines for perioperative transesophageal echocardiography. A report by the American Society of Anesthesiologists and the Society of Cardiovascular Anesthesiologists Task Force on Transesophageal Echocardiography. Anesthesiology. 1996;84:986-1006.

211. Polanczyk CA, Rohde LE, Goldman L, Cook EF, Thomas EJ, Marcantonio ER, et al. Right heart catheterization and cardiac complications in patients undergoing noncardiac surgery: an observational study. JAMA. 2001;286:309-14.
212. Sandham JD, Hull RD, Brant RF, Knox L, Pineo GF, Doig CJ, et al. A randomized, controlled trial of the use of pulmonary-artery catheters in high-risk surgical patients. N Engl J Med. 2003;348:5-14.

213. Feringa HH, Vidakovic R, Karagiannis SE, Dunkelgrun M, Elhendy A, Boersma E, et al. Impaired glucose regulation, elevated glycated haemoglobin and cardiac ischaemic events in vascular surgery patients. Diabet Med. 2008;25:314-9.

214. Noordzij PG, Boersma E, Schreiner F, Kertai MD, Feringa $\mathrm{HHH}$, Dunkelgrun $\mathrm{M}$, et al. Increased preoperative glucose levels are associated with perioperative mortality in patients undergoing noncardiac, nonvascular surgery. Eur $\mathbf{J}$ Endocrinol. 2007;156:137-42.

215. International Diabetes Federation. Diabetes atlas. 2006.

216. Umpierrez GE, Isaacs SD, Bazargan N, You X, Thaler LM, Kitabchi AE. Hyperglycemia: an independent marker of inhospital mortality in patients with undiagnosed diabetes. $\mathbf{J}$ Clin Endocrinol Metab. 2002;87:978-82.

217. Vanhorebeek I, Langouche L, Van den Berghe G. Tight blood glucose control with insulin in the ICU: facts and controversies. Chest. 2007;132:268-78.

218. Van den Berghe G, Wouters P, Weekers F, Verwaest C, Bruyninckx F, Schetz M, et al. Intensive insulin therapy in the critically ill patients. N Engl J Med. 2001;345:1359-67.

219. Van den Berghe G, Wilmer A, Hermans G, Meersseman W, Wouters PJ, Milants I, et al. Intensive insulin therapy in the medical ICU. N Engl J Med. 2006;354:449-61.

220. Gandhi GY, Nuttall GA, Abel MD, Mullany CJ, Schaff HV, O'Brien PC, et al. Intensive intraoperative insulin therapy versus conventional glucose management during cardiac surgery: a randomized trial. Ann Intern Med. 2007;146:233-43.

221. Ammori JB, Sigakis M, Englesbe MJ, O’Reilly M, Pelletier SJ. Effect of intraoperative hyperglycemia during liver transplantation. J Surg Res. 2007;140:227-33.

222. Ellger B, Debaveye Y, Vanhorebeek I, Langouche L, Giulietti A, Van Etten E, et al. Survival benefits of intensive insulin therapy in critical illness: impact of maintaining normoglycemia versus glycemia-independent actions of insulin. Diabetes. 2006;55:1096-105.

223. Finfer S, Chittock DR, Su SY, Blair D, Foster D, Dhingra $\mathrm{V}$, et al. Intensive versus conventional glucose control in critically ill patients. N Engl J Med. 2009;360:1283-97.

224. De Hert SG, Turani F, Mathur S, Stowe DF. Cardioprotection with volatile anesthetics: mechanisms and clinical implications. Anesth Analg. 2005;100:1584-93.

225. Slogoff S, Keats AS. Randomized trial of primary anesthetic agents on outcome of coronary artery bypass operations. Anesthesiology. 1989;70:179-88.

226. Rodgers A, Walker N, Schug S, McKee A, Kehlet H, Van Zundert A, et al. Reduction of postoperative mortality and morbidity with epidural or spinal anaesthesia: results from overview of randomised trials. BMJ. 2000;321:1493.

227. Wu CL, Rowlingson AJ, Herbert R, Richman JM, Andrews RA, Fleisher LA. Correlation of postoperative epidural analgesia on morbidity and mortality after colectomy in Medicare patients. J Clin Anesth. 2006;18:594-9.

228. Bode RH Jr, Lewis KP, Zarich SW, Pierce ET, Roberts M, Kowalchuk GJ, et al. Cardiac outcome after peripheral vascular surgery. Comparison of general and regional anesthesia. Anesthesiology. 1996;84:3-13.

229. Mauermann WJ, Shilling AM, Zuo Z. A comparison of neuraxial block versus general anesthesia for elective total hip replacement: a meta-analysis. Anesth Analg. 2006;103:1018-25.

230. Rigg JR, Jamrozik K, Myles PS, Silbert BS, Peyton PJ, Parsons RW, et al. Epidural anaesthesia and analgesia and outcome of major surgery: a randomised trial. Lancet. 2002;359:1276-82.

231. Birkmeyer JD, Stukel TA, Siewers AE, Goodney PP, Wennberg DE, Lucas FL. Surgeon volume and operative mortality in the United States. N Engl J Med. 2003;349:2117-27. 
232. Liu SS, Wu CL. The effect of analgesic technique on postoperative patientreported outcomes including analgesia: a systematic review. Anesth Analg. 2007;105:789-808.

233. White PF, Kehlet H. Postoperative pain management and patient outcome: time to return to work! Anesth Analg. 2007;104:487-9.

234. Polomano RC, Rathmell JP, Krenzischek DA, Dunwoody CJ. Emerging trends and new approaches to acute pain management. J Perianesth Nurs. 2008;23 Suppl 1:S43-53.

235. Dolin SJ, Cashman JN, Bland JM. Effectiveness of acute postoperative pain management: I. Evidence from published data. Br J Anaesth. 2002;89:409-23.
236. Jorgensen H, Wetterslev J, Moiniche S, Dahl JB. Epidural local anaesthetics versus opioid-based analgesic regimens on postoperative gastrointestinal paralysis, PONV and pain after abdominal surgery. Cochrane Database Syst Rev 2000;(4):CD001893.

237. Block BM, Liu SS, Rowlingson AJ, Cowan AR, Cowan JA $\mathrm{Jr}, \mathrm{Wu} \mathrm{CL}$. Efficacy of postoperative epidural analgesia: a meta-analysis. JAMA. 2003;290:2455-63.

238. Schug SA, Manopas A. Update on the role of non-opioids for postoperative pain treatment. Best Pract Res Clin Anaesthesiol. 2007;21:15-30. 